Cochrane Database of Systematic Reviews

\title{
Screening for genital chlamydia infection (Review)
}

Low N, Redmond S, Uusküla A, van Bergen J, Ward H, Andersen B, Götz H

Low N, Redmond S, Uusküla A, van Bergen J, Ward H, Andersen B, Götz H.

Screening for genital chlamydia infection.

Cochrane Database of Systematic Reviews 2016, Issue 9. Art. No.: CD010866.

DOI: 10.1002/14651858.CD010866.pub2.

www.cochranelibrary.com 
TABLE OF CONTENTS

HEADER 1

ABSTRACT

PLAIN LANGUAGE SUMMARY

SUMMARY OF FINDINGS

BACKGROUND

OBJECTIVES

METHODS

Figure 1.

RESULTS

Figure 2.

Figure 3.

Figure 4.

DISCUSSION

AUTHORS' CONCLUSIONS

ACKNOWLEDGEMENTS

REFERENCES

CHARACTERISTICS OF STUDIES

DATA AND ANALYSES

Analysis 1.1. Comparison 1 Offer of chlamydia screening vs usual care (inactive control), Outcome 1 Prevalence of chlamydia infection (positivity) measured in the whole study population at least 12 months after start of screening.

Analysis 1.2. Comparison 1 Offer of chlamydia screening vs usual care (inactive control), Outcome 2 Incidence of PID at 12 months (intention-to-treat).

Analysis 1.3. Comparison 1 Offer of chlamydia screening vs usual care (inactive control), Outcome 3 Incidence of PID at 12 months (per protocol analysis).

Analysis 1.4. Comparison 1 Offer of chlamydia screening vs usual care (inactive control), Outcome 4 Incidence of epididymitis in men at 12 months (intention to screen).

Analysis 1.5. Comparison 1 Offer of chlamydia screening vs usual care (inactive control), Outcome 5 Secondary outcomes for reproductive tract morbidity.

ADDITIONAL TABLES

APPENDICES

CONTRIBUTIONS OF AUTHORS

DECLARATIONS OF INTEREST

SOURCES OF SUPPORT

DIFFERENCES BETWEEN PROTOCOL AND REVIEW 
[Intervention Review]

\section{Screening for genital chlamydia infection}

Nicola Low ${ }^{1}$, Shelagh Redmond ${ }^{1}$, Anneli Uusküla ${ }^{2}$, Jan van Bergen ${ }^{3}$, Helen Ward ${ }^{4}$, Berit Andersen ${ }^{5}$, Hannelore Götz 6

1.nstitute of Social and Preventive Medicine (ISPM), University of Bern, Bern, Switzerland. 2Department of Public Health, University of Tartu, Tartu, Estonia. ${ }^{3}$ Department of General Practice and Family Medicine, University of Amsterdam, Amsterdam, Netherlands. ${ }^{4}$ Department of Infectious Disease Epidemiology, Imperial College London, London, UK. ${ }^{5}$ Department of Public Health Programmes, Randers, Denmark. ${ }^{6}$ Department of Infectious Disease Control, Rotterdam-Rijnmond Public Health Service, Rotterdam, Netherlands

Contact address: Nicola Low, Institute of Social and Preventive Medicine (ISPM), University of Bern, Finkenhubelweg 11, Bern, CH-3012, Switzerland. nicola.low@ispm.unibe.ch.

Editorial group: Cochrane STI Group.

Publication status and date: New, published in Issue 9, 2016.

Citation: Low N, Redmond S, Uusküla A, van Bergen J, Ward H, Andersen B, Götz H. Screening for genital chlamydia infection. Cochrane Database of Systematic Reviews 2016, Issue 9. Art. No.: CD010866. DOI: 10.1002/14651858.CD010866.pub2.

Copyright @ 2016 The Cochrane Collaboration. Published by John Wiley \& Sons, Ltd.

\section{A B S T R A C T}

\section{Background}

Genital infections caused by Chlamydia trachomatis are the most prevalent bacterial sexually transmitted infection worldwide. Screening of sexually active young adults to detect and treat asymptomatic infections might reduce chlamydia transmission and prevent reproductive tract morbidity, particularly pelvic inflammatory disease (PID) in women, which can cause tubal infertility and ectopic pregnancy.

\section{Objectives}

To assess the effects and safety of chlamydia screening versus standard care on chlamydia transmission and infection complications in pregnant and non-pregnant women and in men.

\section{Search methods}

We searched the Cochrane Sexually Transmitted Infections Group Specialised Register, the Cochrane Central Register of Controlled Trials (CENTRAL), MEDLINE, EMBASE, LILACS, CINAHL, DARE, PsycINFO and Web of Science electronic databases up to 14 February 2016, together with World Health Organization International Clinical Trials Registry (ICTRP) and ClinicalTrials.gov. We also handsearched conference proceedings, contacted trial authors and reviewed the reference lists of retrieved studies.

\section{Selection criteria}

Randomised controlled trials (RCTs) in adult women (non-pregnant and pregnant) and men comparing a chlamydia screening intervention with usual care and reporting on a primary outcome (C. trachomatis prevalence, PID in women, epididymitis in men or incidence of preterm delivery). We included non-randomised controlled clinical trials if there were no RCTs for a primary outcome.

\section{Data collection and analysis}

Two review authors independently assessed trials for inclusion, extracted data and assessed the risk of bias. We resolved disagreements by consensus or adjudication by a third reviewer. We described results in forest plots and conducted meta-analysis where appropriate using a fixed-effect model to estimate risk ratios (RR with 95\% confidence intervals, $\mathrm{Cl}$ ) in intervention vs control groups. We conducted a prespecified sensitivity analysis of the primary outcome, PID incidence, according to the risks of selection and detection bias.

\section{Main results}

We included six trials involving 359,078 adult women and men. One trial was at low risk of bias in all six specific domains assessed. Two trials examined the effect of multiple rounds of chlamydia screening on C. trachomatis transmission. A cluster-controlled trial in women and men 
in the general population in the Netherlands found no change in chlamydia test positivity after three yearly invitations (intervention $4.1 \%$ vs control 4.3\%, RR $0.96,95 \% \mathrm{Cl} 0.84$ to $1.09,1$ trial, 317,304 participants at first screening invitation, low quality evidence). Uptake of the intervention was low (maximum 16\%). A cluster-randomised trial in female sex workers in Peru found a reduction in chlamydia prevalence after four years (adjusted RR 0.72, 95\% Cl 0.54 to $0.98,1$ trial, 4465 participants, low quality evidence).

Four RCTs examined the effect of chlamydia screening on PID in women 12 months after a single screening offer. In analysis of four trials according to the intention-to-treat principle, the risk of PID was lower in women in intervention than control groups, with little evidence of between-trial heterogeneity (RR $0.68,95 \% \mathrm{Cl} 0.49$ to $0.94,127 \%, 4$ trials, 21,686 participants, moderate quality evidence). In a sensitivity analysis, the estimated effect of chlamydia screening in two RCTs at low risk of detection bias (RR $0.80,95 \% \mathrm{Cl} 0.55$ to 1.17 ) was compatible with no effect and was lower than in two RCTs at high or unclear risk of detection bias (RR $0.42,95 \% \mathrm{Cl} 0.22$ to 0.83 ).

The risk of epididymitis in men invited for screening, 12 months after a single screening offer, was $20 \%$ lower risk for epididymitis than in those not invited; the confidence interval was wide and compatible with no effect (RR $0.80,95 \% \mathrm{Cl} 0.45$ to $1.42,1$ trial, 14,980 participants, very low quality evidence).

We found no RCTs of the effects of chlamydia screening in pregnancy and no trials that measured the harms of chlamydia screening.

\section{Authors' conclusions}

Evidence about the effects of screening on $C$. trachomatis transmission is of low quality because of directness and risk of bias. There is moderate quality evidence that detection and treatment of chlamydia infection can reduce the risk of PID in women at individual level. There is an absence of RCT evidence about the effects of chlamydia screening in pregnancy.

Future RCTs of chlamydia screening interventions should determine the effects of chlamydia screening in pregnancy, of repeated rounds of screening on the incidence of chlamydia-associated PID and chlamydia reinfection in general and high risk populations.

\section{PLAIN LANGUAGE SUMMARY}

\section{Effects of screening for sexually transmitted chlamydia infection}

\section{Review question}

We reviewed the evidence about the effects ans safety of screening to detect and treat chlamydia infection in women and men.

\section{Background}

Chlamydia trachomatis is a common sexually transmitted infection. In several countries, about 3\%-5\% of sexually active adults aged 15 to 25 years have chlamydia at any given time. Untreated infections can lead to complications, including fertility problems in women and testicular inflammation in men. Screening to identify and treat people who are unknowingly infected might reduce the risk of complications and transmission to others.

\section{Study characteristics}

The evidence is up to date as of February 2016. We found six trials involving 359,078 adult women and men in Denmark, the Netherlands, Peru, the UK and the United States. Two trials examined the effect of chlamydia screening on levels of chlamydia infection. In the Netherlands, investigators invited women and men aged 15 to 29 every year for three years to have a chlamydia test. In Peru, mobile teams visited 20 cities to offer women sex workers tests for chlamydia over a period of four years.

\section{Key results}

With regard to the level of chlamydia infection, in the Netherlands there was no difference in women and men who had been invited to have yearly chlamydia screening tests compared with women and men who received only one invitation. Only $16 \%$ of those invited to be screened had a test in the first year and only $10 \%$ had a test in the third year. In Peru, female sex workers in cities with mobile teams had lower levels of chlamydia infection than those in cities without mobile teams.

Four trials provided comparable data on PID. The risk of PID was $32 \%$ lower in women who were invited to have a single chlamydia screening test than in women who were not invited. When we removed two trials with lower quality evidence, the protective effect of chlamydia screening decreased. I was found no effect on epididymitis in men.

\section{Quality of the evidence}

The effect of register-based chlamydia screening on C. trachomatis transmission in young adults in the general population is uncertain. We are moderately sure that chlamydia screening can reduce the risk of PID, but we are not sure by how much because of our concerns about quality in some trials. 
SUMMARY OF FINDINGS

Summary of findings for the main comparison.

Chlamydia screening compared with usual care for the prevention of $C$. trachomatis transmission and reproductive tract morbidity

Patient or population: healthy adults

Settings: general population, high schools or colleges

Intervention: chlamydia screening

Comparison: usual care

Outcomes
Chlamydia prevalence (general population)
Outcome was chlamydia test positivity after 3 yearly invi-
tations in intervention clusters vs 1 invitation in control
areas. Uptake was too low for chlamydia positivity to be
considered an unbiased estimate of prevalence.

\section{Chlamydia prevalence (high risk population)}

RD $-3.7 \%$

RR 0.72 ( 0.54 to

4156 (1 study)

$\oplus \oplus \odot \odot^{3}$

Outcome was prevalence of positive chlamydia tests in

repeated cross-sectional surveys of women tested at sex

venues after 4 years of intervention.

Incidence of pelvic inflammatory disease (PID) at 12

months (intention-to-treat)

Absolute effect

Relative effect

No of Participants

Quality of the evi-

Comments

$(95 \% \mathrm{Cl})$

$(95 \% \mathrm{CI})$

(GRADE)

RD $0.0 \%\left(-0-01, \quad\right.$ RR 0.96 (0.84 to $\quad 30,122$ ( 1 study) $\quad \oplus \oplus \ominus \Theta^{1,2}$

$+0.01 \%)$

1.09)

Low

RD $0.0 \%(0-0,0.0 \%)$

RR 0.68 ( 0.49 to

21,686 (4 studies)

$\oplus \oplus \oplus)^{4}$

0.94)

Moderate

Outcome was clinically diagnosed PID reported by the participant or extracted from medical records, pharmacy records or hospital discharge coding. Outcome very likely to be affected by risk of detection bias.

Incidence of epididymitis in men at 12 months (intention-to-treat)

RD $0.0 \%(0.0,0.0 \%) \quad$ RR $0.80(0.45$ to 1.42)
14,980 (1 study)

$\oplus \odot \odot \odot^{5,6}$

Very low

Outcome was epididymitis diagnosed in hospital and abstracted from hospital discharge coding. 
High quality: Further research is very unlikely to change our confidence in the estimate of effect.

Moderate quality: Further research is likely to have an important impact on our confidence in the estimate of effect and may change the estimate.

Low quality: Further research is very likely to have an important impact on our confidence in the estimate of effect and is likely to change the estimate.

Very low quality: We are very uncertain about the estimate.

CI: confidence interval; PID: pelvic inflammatory disease; RR: risk ratio.

1. Selection, attrition and other bias

2. One large non-randomized cluster-controlled trial.

3. Single large trial in female sex workers and uncertainty about generalisability to other screening interventions and populations.

4. Selection bias might have overestimated intervention effect.

5. Low uptake of the screening intervention with an imprecise effect estimate and uncertainty about estimated effect of screening interventions with higher sustained levels of uptake.

6. Performance bias 


\section{B A C K G R O U N D}

\section{Description of the condition}

Genital infections caused by Chlamydia trachomatis serovars D$\mathrm{K}$ are the most prevalent bacterial sexually transmitted infection worldwide, with an estimated 131 million people being infected in 2012 (Newman 2015). Chlamydia is the most common notifiable infection in the United States, with 1,441,789 infections reported in 2014 compared with 350,062 cases of gonorrhoea, the second most common notifiable condition (CDC 2015). Chlamydia is also the most commonly reported infection in Australia and Europe (DoHA 2016; ECDC 2015), and its prevalence is highest in young, sexually active adults. The prevalence of chlamydia has been estimated to be about $3 \%$ to $5 \%$ in nationally representative samples of sexually experienced women and men aged 25 years and under in highincome countries (Redmond 2015). Chlamydia prevalence in adults aged 15 to 44 years is about $2 \%$ to $3 \%$ in low- and lower-middleincome countries, $4 \%$ to $7 \%$ in upper-middle countries and $2 \%$ to $3 \%$ in high-income countries (Newman 2015).

C. trachomatis is a gram negative obligate intracellular bacterium, which infects columnar epithelium in the lower genital tract in women and men and can also infect the rectum, pharynx, conjunctiva and placenta (Rours 2011; Stamm 2008). Chlamydia infection causes complications, most commonly due to its spread from the lower to the upper genital tract. Upper genital tract infection occurs in both sexes, but is more common and has more severe consequences in women (Stamm 2008). In women, chlamydia ascends to the upper genital tract in approximately $10 \%$ of cases to cause symptomatic pelvic inflammatory disease (PID) (Herzog 2012; Oakeshott 2010). The resulting tubal damage can then cause ectopic pregnancy, tubal infertility and chronic pelvic pain (Paavonen 2008). Although about $45 \%$ of tubal infertility might be attributable to chlamydia infection (Price 2012), the probability of tubal infertility in women who have had chlamydia is estimated to be only 1\% to 4\% (Kavanagh 2013; Land 2010). Chlamydia infection in pregnancy is associated with preterm labour and can infect the neonate, causing ophthalmia neonatorum and atypical pneumonia (Kohlhoff 2008; Rours 2011). C. trachomatis can cause epididymo-orchitis in men, but its role in prostatitis and male infertility is not well established (Stamm 2008). Chlamydia can also cause reactive arthritis in men and is a cofactor for HIV infection, increasing both susceptibility and infectiousness (Fleming 1999; Stamm 2008).

Uncomplicated genital chlamydia infections are usually asymptomatic in both women and men (Stamm 2008), and untreated infections last more than a year on average (Althaus 2010). C. trachomatis can be treated with tetracyclines (usually doxycycline) or macrolide antibiotics (usually azithromycin) with short-term microbiological cure rates of $90 \%$ to $95 \%$ (Manhart 2013). Immunity after chlamydia infection is incomplete, and repeated chlamydia infection is common (Batteiger 2010a). In studies of women enrolled from primary care and sexual health clinics and followed up prospectively, about $25 \%$ of women treated for chlamydia had the infection detected again in the year after treatment (Scott LaMontagne 2007; Walker 2012). There are several reasons for repeated detection of chlamydia. In one prospective study amongst young women in the United States, Batteiger 2010b combined information about sexual behaviour and genotype from 183 women with more than one episode of chlamydia infection to estimate that about $66 \%$ of infections were probably acquired from a new partner, $17 \%$ were reinfections from untreated or inadequately treated sexual partners, $14 \%$ were probable antibiotic treatment failures, and $3 \%$ persisted without treatment. There is some evidence to suggest that immunity after natural clearance of chlamydia infection lasts longer than immunity after antibiotic treatment (Geisler 2013).

\section{Description of the intervention}

Screening of sexually active young adults is the only way to detect most chlamydia infections because of the lack of symptoms or clinical signs in most infected people. Screening is a process of identifying apparently healthy people who may be at increased risk of a disease or condition. They can then be offered information, further tests and appropriate treatment to reduce their risk and the impact of any complications arising from the disease (UKNSC 2013).

There are two goals of screening for genital chlamydia infection: first, to control the transmission of chlamydia and reduce the prevalence of infection in the population; and second, to reduce the risk of complications, especially reproductive tract complications in women (Meyers 2007; NCSP 2014). Screening is a programme, not a test (Raffle 2007). This means that screening includes the whole system of events needed to reach the endpoint of reducing the risk of disease or complications. For chlamydia infection, screening includes offering a test to diagnose $C$. trachomatis, treating people with a positive test, partner notification to identify and treat sexual partners and repeated screening to detect and treat newly acquired infection or reinfection.

The target group for chlamydia screening is usually defined by age and sex. For example, recommendations for chlamydia screening in the United States target women aged 25 years and under (USPSTF 2014); in Australia, women under 25 (RACGP 2012); and in the UK, women and men aged 25 years and under (NCSP 2014). Whilst behavioural and demographic factors can be used to identify groups at higher risk of chlamydia infection, risk factors differ between populations, and selective criteria can be difficult to apply in practice (Gotz 2005; Stergachis 1993).

Chlamydia screening can be offered systematically, using a population register to invite people in the target age group (van den Broek 2012). More commonly, screening is recommended as an opportunistic activity to be offered to eligible young adults attending healthcare services (USPSTF 2014; NCSP 2014; RACGP 2012). Some countries recommend repeated screening, given the frequency of repeated chlamydia and the fact that young adults may change sexual partners over time (Scott LaMontagne 2007). In England, the National Chlamydia Screening Programme recommends a screening test every year or after a change of sexual partner. Health professionals may also take advantage of visits for cervical cancer screening in young women to offer chlamydia screening in countries where the target age groups and screening frequency overlap. In the UK, however, cervical cancer screening is only recommended for women over 25 years (NCSP 2014).

\section{How the intervention might work}

The way that chlamydia screening might work depends on the goal of screening. To reduce chlamydia prevalence and incidence, the coverage of screening has to be high enough to identify and treat prevalent cases of chlamydia and to interrupt chains of chlamydia transmission in the population. Screening also has 
to be frequent enough to prevent repeated infections because of the limited immunity after treatment. Mathematical models show that chlamydia screening reduces prevalence over time; in several models, screening of $30 \%$ or more of the target population each year is necessary to markedly reduce chlamydia prevalence (Althaus 2012; Regan 2008).

There are two ways in which screening for chlamydia might work to prevent reproductive tract complications (Herzog 2013; Peterman 2009). First, direct prevention of PID occurs if screening detects and treats an endocervical chlamydia infection in an individual woman before the infection ascends into the genital tract to cause PID and subsequent tubal damage. The effectiveness of screening depends on the timing of progression from lower to upper genital tract infection. If PID occurs immediately or shortly after the initial lower genital tract infection, there is no opportunity for screening to work (Herzog 2012; Smith 2007). Randomised controlled trials (RCTs) have shown that the incidence of clinically diagnosed PID is lower in women actively invited for chlamydia screening compared to those receiving usual care (Andersen 2011; Ostergaard 2000; Oakeshott 2010; Scholes 2006). Women infected with chlamydia who are enrolled into trials have persisting prevalent infections with an unknown date of infection. The trial findings and supportive evidence from mathematical modelling studies suggest, therefore, that PID development can occur during the course of infection (Herzog 2012). Second, prevention of chlamydia transmission through screening and treatment has an indirect effect on the risk of PID because it reduces the risk of becoming infected with chlamydia in the first place.

Prevention of PID should lead to a reduction in the incidence of ectopic pregnancy and tubal infertility if tubal scarring is prevented. It is, however, very difficult to measure the impact of chlamydia screening on these outcomes because women in the age groups at highest risk of chlamydia infection are usually using contraception. In one RCT, the incidence of ectopic pregnancy and infertility after 11 years of follow-up were similar in women who had received a single invitation to be screened for chlamydia and women who received usual care (Andersen 2011).

There are also potential harms of chlamydia screening, for example an increased rate of repeated infection after treatment or the ending of a sexual partnership (Gottlieb 2011; O'Farrell 2013). First, a woman who has been treated for chlamydia becomes susceptible and is at risk of repeated infection and PID. Researchers have suggested that the risk of PID is higher with subsequent chlamydia infections (Hillis 1997), possibly because repeated exposure to $C$. trachomatis antigens can cause immune-mediated tubal damage (Brunham 2005). Second, being diagnosed with a sexually transmitted infection can have a negative emotional and psychological impact on the infected person (Gottlieb 2011; Mills 2006). In one study in the United States, sexual partnerships broke down for $33 \%$ of women with a positive chlamydia test result compared with $11 \%$ of those receiving a negative result (Gottlieb 2011). Third, the experience of screening can cause anxiety. In a study in the UK, however, chlamydia screening did not increase anxiety or depression and did not reduce self esteem (Campbell 2006).

\section{Why it is important to do this review}

Screening for chlamydia infection is widely recommended and practised (USPSTF 2014; Low 2012; NCSP 2014; RACGP 2012). Rates of chlamydia testing amongst young adults are high (4000 to 9000 per 100,000 population) in several high-income countries (Bender 2011). There is a strong rationale for early detection and treatment of chlamydia infection in asymptomatic young adults to reduce both transmission and complications (Low 2013), and these potential benefits should be weighed against the potential harms. There are few data about long-term trends in chlamydia prevalence in countries that recommend chlamydia screening. In the United States, repeated cross-sectional studies show that chlamydia prevalence fell between 1999 and 2008 in 14 to 39 year olds as a whole, but not in 15 to 25 year old women, who are the target population for screening (Datta 2012).

It is also important to review the effects of screening programmes from a health policy perspective, as they have implications beyond the application of a diagnostic test and are costly to administer (UKNSC 2013). Economic evaluations about the cost-effectiveness of chlamydia screening programmes are not consistent (ECDC 2014).

There is a systematic review of the effectiveness of chlamydia screening interventions in studies published up to 2007 (Low 2009). RCTs have found that a one-off screening invitation could reduce the incidence of PID one year later (Ostergaard 2000; Scholes 1996). Also, we know that there are new completed trials with PID and transmission as endpoints (Andersen 2011; Oakeshott 2010; van den Broek 2012), and there is at least one ongoing trial (Hocking 2012). It is therefore important to develop a Cochrane review about this issue.

\section{O B JECTIVES}

To assess the effects and safety of chlamydia screening versus standard care for chlamydia transmission and infection complications in pregnant and non-pregnant women and in men.

\section{METHODS}

\section{Criteria for considering studies for this review}

\section{Types of studies}

We included randomised and non-randomised controlled trials.

We included controlled trials with non-randomised allocation to intervention and control arms if there were no RCTs addressing a primary outcome of chlamydia screening.

We included trials with cluster allocation as long as investigators collected baseline and outcome data prospectively using the same criteria throughout the trial period.

We analysed results from randomised and non-randomised study designs separately.

We excluded cohort studies, case-control studies and interrupted time-series studies.

\section{Types of participants}

We included women (non-pregnant and pregnant) and men (heterosexual or men who have sex with men) aged over 13 years in any setting. The minimum age was arbitrary but allowed us to include only trials of sexually transmitted chlamydia infections. 


\section{Types of interventions}

- Intervention: screening for sexually transmitted genital chlamydia infection, defined as the offer of a test to apparently healthy people to identify those at increased risk of chlamydia infection. This definition was adapted from the UK National Screening Committee (UKNSC 2013). We included any test used to diagnose genital chlamydia infection.

- Comparison: inactive control (no offer of screening or standard care)

\section{Types of outcome measures}

Eligible trials included at least one of the pre-specified primary outcomes. The primary outcomes were measures of morbidity because one criterion for assessing the effectiveness of a screening programme is that 'there should be evidence from high quality Randomised Controlled Trials that the screening programme is effective in reducing mortality or morbidity' (http:// www.screening.nhs.uk/criteria).

\section{Primary outcomes}

We included one primary outcome for each goal of chlamydia screening.

- Outcome for C. trachomatis transmission: prevalence of chlamydia infection in women and men at least 12 months after the start of the screening intervention. Prevalence was estimated as the number of positive chlamydia tests divided by the number of people tested.

- Outcomes for reproductive tract morbidity: incidence of upper genital tract infection in women and men in the 12 months after the offer of screening. PID (women) or epididymitis (men) were clinical diagnoses made using clinical criteria defined in advance by the authors. Examples include criteria published by USPSTF 2014 or Hager 1983.

- Outcome for chlamydia infection in pregnancy: incidence of preterm delivery. Preterm delivery was defined as delivery at a gestational age of less than 37 weeks, with subgroups of gestational ages less than 32 weeks and less than 35 weeks (Rours 2011).

\section{Secondary outcomes}

- Outcomes measured in all participants

* Proportion of participants receiving the intervention, defined as the number tested for chlamydia divided by the number eligible and invited to take part. We did not consider uptake of chlamydia testing as a primary outcome because it is an intermediate outcome of a chlamydia screening intervention, and the relationship between uptake of screening and the primary outcomes has not been quantified.

* Harms of screening, including psychological distress, partner violence, relationship breakdown, using definitions described by the authors
- Outcomes measured in women who were not pregnant during the trial or in men

* Prevalence of chronic female pelvic pain, defined as patientreported pain in the lower abdomen or pelvis lasting at least six months (Paavonen 2008)

* Prevalence of female or male infertility, defined using a clinical definition of lack of pregnancy despite unprotected intercourse for 12 months or more (Paavonen 2008)

- Outcomes measured in women who were pregnant during the trial, or in their infants

* Incidence of $C$. trachomatis neonatal conjunctivitis, defined as C. trachomatis isolated from the conjunctiva by culture or detected by nucleic acid amplification test (Kohlhoff 2008)

* Incidence of C. trachomatis neonatal pneumonitis, defined as signs of lower respiratory tract infection presenting between 4 and 12 weeks with $C$. trachomatis isolated from the nasopharynx by culture or detected by nucleic acid amplification test (Kohlhoff 2008)

\section{Search methods for identification of studies}

We aimed to identify trials meeting the inclusion criteria irrespective of their language, publication date or publication status (published, unpublished, in press and in progress). We used both electronic searching in bibliographic databases and handsearching, as described in the Cochrane Handbook for Systematic Reviews of Interventions (Higgins 2011a).

We downloaded and managed the results of all searches using Endnote bibliographic software. We deleted duplicate records of the same study.

\section{Electronic searches}

The Cochrane Sexually Transmitted Infections (STI) Review Group Specialised Register includes RCTs and controlled clinical trials, from 1944 to 2015, located through electronic searching in the Cochrane Central Register of Controlled Trials (CENTRAL), MEDLINE and EMBASE, and handsearching in journals not indexed in those databases (according to the journals' master list of the STI Cochrane Review Group): Anatolian Journal of Obstetrics \& Gynecology, Current Medical Literature Gynecology \& Obstetrics, Current Obstetrics and Gynecology Reports, ISRN Obstetrics and Gynecology, Journal of South Asian Federation of Obstetrics \& Gynecology, Obstetrics and Gynecology International, Obstetrics Gynaecology and Reproductive Medicine, and Sexual Science: the newsletter of the Society for the Scientific Study of Sexuality and Sexualities.

The Trials Search Coordinator (TSC) of the STI Cochrane Review Group implemented a comprehensive search strategy to capture as many relevant trials as possible in electronic databases. We used a combination of controlled vocabulary (MeSH, Emtree, DeCS, including exploded terms) and free-text terms (considering spelling variants, plurals, synonyms, acronyms and abbreviations) for 'genital chlamydia infection' and 'screening', with field labels, truncation, and proximity and Boolean operators. We present the electronic search strategies in Appendix 1.

We searched the following electronic databases.

- The Cochrane Sexually Transmitted Infections (STI) Review Group Specialised Register. 
- CENTRAL, Ovid platform.

- MEDLINE, Ovid platform (1991 to February 2016).

- MEDLINE In-Process \& Other Non-Indexed Citations, Ovid platform (January 1946 to February 2016).

- MEDLINE Daily Update, Ovid platform (January 1946 to February 2016).

- EMBASE (1947 to February 2016).

- LILACS, iAHx interface (1982 to February 2016).

- CINAHL (inception to February 2016).

- Database of Abstracts of Reviews of Effects (DARE) (inception to February 2016).

- PsycINFO (inception to February 2016).

We searched MEDLINE using the Cochrane highly sensitive search strategy for identifying RCTs: sensitivity and precision maximizing version (2008 revision), Ovid format (Higgins 2011a). We combined the LILACS search strategy with the RCT filter of the iAHx interface.

\section{Searching other resources}

1. Trial registers

a. WHO International Clinical Trials Registry Platform (ICTRP) portal (http://apps.who.int/trialsearch/) (inception to February 2016)

b. ClinicalTrials.gov (http://clinicaltrials.gov/) (inception to February 2016)

2. Web of Science (inception to February 2016)

3. Grey literature in System for Information on Grey Literature in Europe 'OpenGrey' (http://www.opengrey.eu/) (inception to February 2016)

4. Handsearch of conference proceeding abstracts

a. The International Society for Sexually Transmitted Diseases Research - ISSTDR (http://www.isstdr.org/): 2007, 2009 and 2011

b. The British Association for Sexual Health and HIV - BASHH (http://www.bashh.org/): 2004, 2006, 2007 and 2009

c. International Congress on Infectious Diseases - ICID (http:// www.isid.org/): 2010 and 2012

d. The International Union against Sexually Transmitted Infections - IUSTI (http://www.iusti.org/): 2011 and 2012 e. International Society for Infectious Diseases - ISID (http:// www.isid.org/): 2011

f. International Meeting on Emerging Diseases and Surveillance - IMED (http://www.isid.org/): 2007, 2009 and 2011

g. Interscience Conference on Antimicrobial Agents and Chemotherapy - ICAAC (http://www.icaac.org/): 2011 and 2012

h. The International Federation of Gynecology and Obstetrics FIGO (http://www.figo2012.org/home/): 2012

5. Handsearching previous systematic reviews and other relevant publications on the same topic

6. Handsearching reference lists of all relevant RCTs identified by other methods

\section{Data collection and analysis}

\section{Selection of studies}

Two review authors (NL, SR) independently reviewed titles and abstracts of articles identified through the search strategy, using a pilot-tested form to document potential eligibility. We obtained the full-text records that both review authors agreed were potentially eligible as well as articles about which the authors still disagreed after discussion; we also retrieved records with no abstract if there was insufficient information available from the title or publication type to make a decision.

We used the same criteria for the abstracts of articles identified through searching other resources as for studies identified through electronic database searches.

NL and SR examined full-text records using a pilot-tested form to assess eligibility, and we included studies identified by both authors as fulfilling our inclusion criteria. Where there were discrepancies, the authors discussed the article and reached a consensus decision.

We used a flow chart to document the numbers of articles assessed, included and excluded at each stage, with a summary of reasons for exclusion (Figure 1). The flow chart shows the total number of studies included in the review and the total number of articles pertaining to these studies. We briefly record the characteristics of excluded studies in case readers might expect them to have been included. 
Figure 1. \#Study flow diagram.

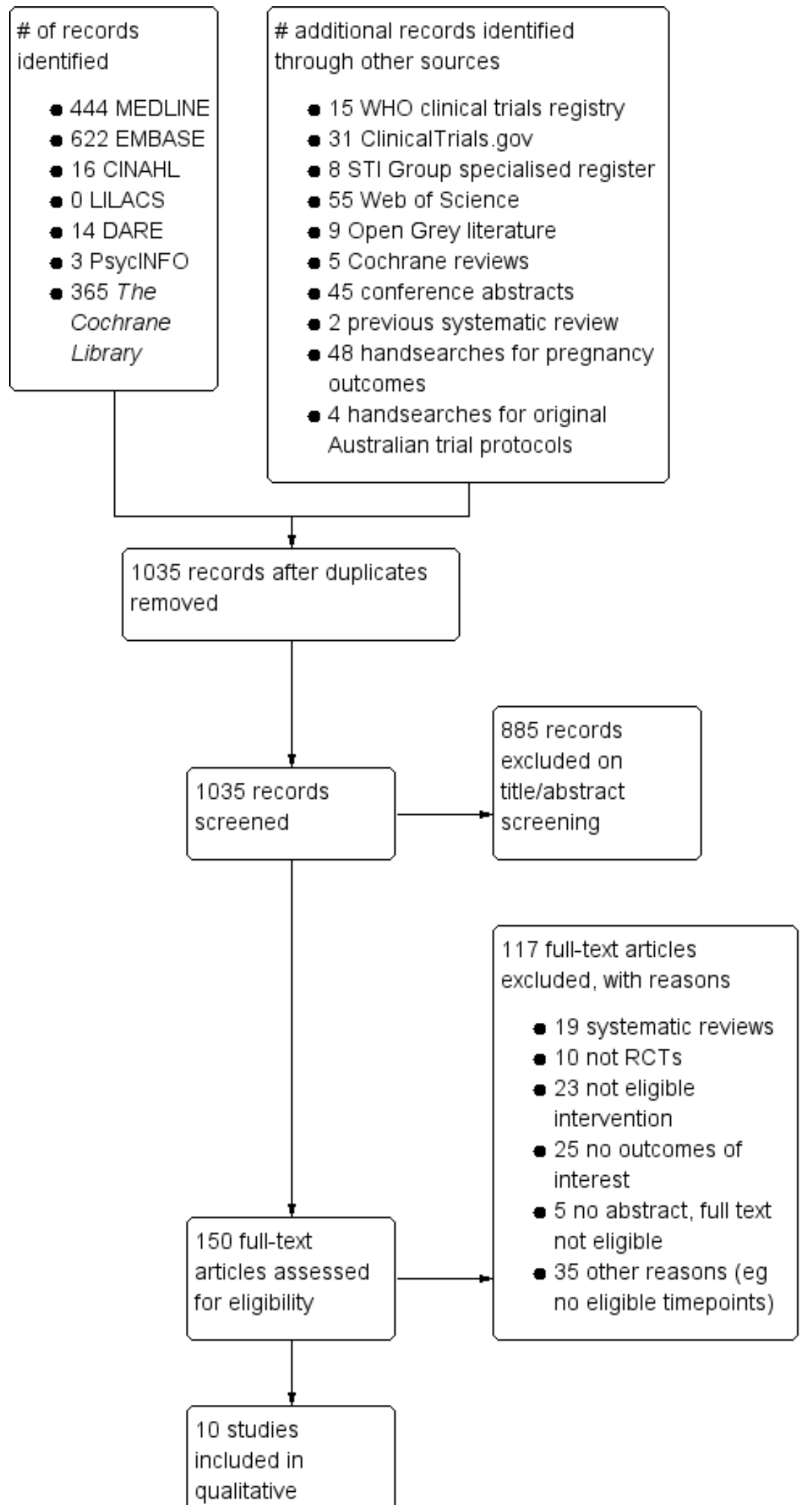


Figure 1. (Continued)

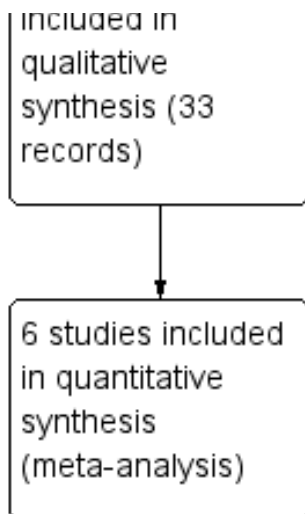

\section{Data extraction and management}

We used piloted, standardised forms to extract data about:

- study location and setting;

- trial design and power calculation;

- ethical approval;

- inclusion and exclusion criteria;

- baseline characteristics of trial participants, including sex, age, sexual orientation, pregnancy status for women, diagnostic test used to detect $C$. trachomatis;

- types of intervention: opportunistic or systematic invitation for screening, number of screening rounds, screening interval;

- types of comparison group: usual care, alternative screening method;

- types of outcome: primary, secondary;

- reporting of methodological characteristics (see next section, Assessment of risk of bias in included studies for details).

We extracted numerical data on:

- number of people assessed for eligibility;

- numbers randomised to intervention and comparison groups;

- numbers receiving screening in intervention and comparison groups (at each screening round if multiple rounds);

- numbers included in analyses in intervention and comparison groups;

- numbers with outcomes in intervention and comparison groups;

SR extracted data about study characteristics, and NL checked these details for accuracy. They resolved discrepancies by discussion.

Pairs of appropriately qualified review authors (BA and JvB, HG and $\mathrm{NL}, \mathrm{AU}$ and $\mathrm{HW}$ ) extracted numerical data independently from each included study into Epidata using a structured form (Epidata). If a reviewer had been an investigator of an included study, they did not extract data from that study. If there were multiple publications relating to the same study, we allowed the extraction of data items from different publications. If there were discrepancies between publications about a data item, we used the data presented in the main trial publication (the publication that includes the results for the primary outcome) or the first chronological publication reporting that data item.

We compared the two files using the validation function available in Epidata, resolving discrepancies in data extraction or data entry by consensus. If there was no agreement, a third independent author adjudicated to make a final decision. We entered the agreed data into Review Manager 5.3 (RevMan) software (RevMan).

If there were insufficient details given to allow the extraction of numerical data, we included the study and described the results narratively.

\section{Assessment of risk of bias in included studies}

We assessed the methods that trial authors reported using in the design and execution of all included trials. The assessment determined whether there was a risk of bias that would overor underestimate the effect of the intervention on one or more outcomes (Higgins 2011a). This assessment relied on reports of methods described by trial authors in publications and, where available, trial protocols. For any trial, the findings of the assessment could only say whether there was a risk of biased results, not whether the results themselves were or were not biased.

For both randomised and non-randomised trials, we assessed the risk of five specific sources of bias: selection bias, performance bias, detection bias, attrition bias and reporting bias, and we also recorded any other biases related to a particular trial.

For RCTs we used the Cochrane 'Risk of bias' tool and criteria in Higgins 2011a (Table 8.5.d) to assess the relevant domains of the reported methods and results (Reeves 2011).

Selection bias was only the domain for which there are important differences in assessing the risk of bias in randomised and nonrandomised controlled trials. For non-randomised controlled trials, we used the UK National Insitute of Health and Care Excellence (NICE) 'methodology checklist' for cohort studies to assess the risk of selection bias (NICE 2012). The NICE methodology checklist format follows that of the Cochrane tool, with criteria to assess bias in each domain and a choice of low, high or unclear risk of bias. We used the Cochrane 'Risk of bias' tool to assess non-randomised controlled trials for risk of performance, detection, attrition and reporting biases. 
Assessors recorded whether there was a low, high or unclear risk of bias in each domain of each included trial and gave a justification for their decision. Two independent assessors assessed each trial, including at least one expert in trial methodology (NL) and one expert in chlamydia screening (HG). They resolved discrepancies by discussion.

The domains and their source are summarised here.

\section{(1a) Random sequence generation (possible selection bias, Cochrane 'Risk of bias' tool)}

Selection bias could occur if investigators are able to predict allocation to intervention or control groups and selectively enrol participants or clusters of participants. The method used to generate the allocation sequence should be unpredictable and should balance prognostic factors, on average, across intervention and comparison groups. We assessed the method as being at:

- low risk of bias (adequate description of a truly random process, e.g. random number tables, computer-generated random numbers);

- high risk of bias (explicit description of an allocation process that is not truly random, e.g. odd or even dates of birth of individuals, clusters of participants selected for implementation of the intervention with subsequent enrolment of comparison groups); or

- unclear risk of bias (description that does not include enough information to decide whether sequence generation was truly random or not).

\section{(1b) Allocation concealment (possible selection bias, Cochrane 'Risk of bias' tool)}

Selection bias can occur if investigators selectively enrol participants or clusters of participants and allocate them to a particular group according to whether their characteristics are associated with the outcome. If the sequence has been randomly generated, selective enrolment can occur if the next assignment is known before allocation. Allocation concealment up to the point of assignment prevents selective assignment to a particular intervention group. We assessed the methods of allocation concealment as having:

- Low risk of bias (adequate description of a process that prevented foreknowledge of allocation up to the point at which assignment was recorded, e.g. telephone or central randomisation);

- high risk of bias (description of a process that meant that those assigning participants or clusters of participants knew or could predict the allocation in advance); or

- unclear risk of bias (insufficient details to be able to decide whether the allocation was concealed or not).

\section{(1c) Systematic differences between comparison groups (possible selection bias, NICE 'methodology checklist')}

In a non-randomised trial, selection bias can occur because of the lack of a random allocation sequence and concealment. If the person assigning individuals or clusters to a particular group knows about the distribution of factors associated with the outcome, they might introduce selection bias. We assessed studies as having:
- low risk of bias (the reason for participant allocation to treatment groups is not expected to affect the outcomes of the study, there were attempts made within the design or analysis to balance the comparison groups for potential confounders, and the groups were comparable at baseline for all known major confounders and prognostic factors);

- high risk of bias (any of the above conditions are not fulfilled); or

- unclear risk of bias (insufficient details to be able to decide whether there was a risk of systematic differences between comparison groups).

\section{(2) Blinding of participants and personnel (possible performance bias)}

Screening is an intervention that involves systematic differences in the delivery of a health service. Personnel who offer chlamydia screening tests might offer other sexual health information, advice or interventions, such as condoms, that could affect participants' risk of chlamydia infection or another outcome. Such information and interventions could also be considered a part of the screening programme, however. Trial participants or clusters of participants in an inactive 'usual care' control group might also be considered blinded if they do not know that they are part of a trial. For each included trial, we described the intervention. We considered studies as being at low risk of bias if participants were blinded or if the lack of blinding was unlikely to affect results for a particular outcome.

\section{(3) Blinding of outcome assessment (possible detection bias)}

For chlamydia screening interventions, adequate descriptions of blinding of those assessing the outcomes are important. We distinguished between outcomes that were objectively assessed (e.g. chlamydia test results obtained from automated diagnostic systems) and those that were subjective (e.g. clinical diagnosis of pelvic inflammatory disease).

The incidence of clinically diagnosed pelvic inflammatory disease is a primary outcome of chlamydia screening interventions. The main symptom is lower abdominal pain, which is common and non-specific. Knowledge of group assignment could influence the interpretation of symptoms by both trial participants and personnel delivering the intervention in unpredictable ways. For example, healthcare providers who know whether a woman has been screened for chlamydia might be more likely to assign a diagnosis of pelvic inflammatory disease to a woman who presents with abdominal pain because of increased awareness of the complications of chlamydia infection. On the other hand, they might be reassured if the test was negative or if treatment had been given and then interpret abdominal pain with or without accompanying signs as resulting from another cause. Women who have accepted or declined screening might also modify their assessment of symptoms or their health-seeking behaviour. For subjective outcomes, we assessed methods as having:

- low risk of bias (adequate description of assessment that reduced the risk of bias, e.g. uniform assessment of all trial participants by an independent assessor blinded to allocation, or assessment of diagnoses by an independent assessment panel blinded to allocation);

- high risk of bias (assessment of outcomes by personnel who knew the group assignment); or 
- unclear risk of bias (insufficient information to determine whether outcome assessment was blinded or not).

\section{(4) Incomplete outcome data (possible attrition bias due to the amount, nature and handling of incomplete outcome data)}

For each outcome or class of outcomes, we described the completeness of data and exclusions from analysis in each included trial. We stated whether analyses were conducted and reported according to intention-to-treat or not. Where reported, we stated numbers included in the analysis as a proportion of the totals randomised to intervention and comparison groups, reasons for attrition or exclusion, and whether missing data were balanced across groups or were related to outcomes. Where trials or trial authors provided sufficient information, we re-included missing data in our analyses. We used a cutoff of $20 \%$ to assign trials with missing outcome data as being at low or high risk of bias. In addition, we assessed methods as being at:

- low risk of bias (e.g. no missing outcome data; missing outcome data balanced across groups);

- high risk of bias (e.g. numbers or reasons for missing data imbalanced across groups; 'per protocol' analysis done with substantial departure of intervention received from that assigned at randomisation); or

- unclear risk of bias (insufficient information about missing data or exclusions from analysis).

\section{(5) Selective outcome reporting (possible reporting bias)}

Where available, we assessed the trial protocol and trial registration documents as well as articles or publications resulting from a trial. We described the documents available for each included study and assessed the methods as having:

- low risk of bias (adequate description that reports all prespecified outcomes and all expected outcomes of interest to the review);

- high risk of bias (explicit evidence that trials did not report all pre-specified outcomes or did not pre-specify one or more reported primary outcomes, that they reported outcomes of interest incompletely so that they cannot be used in the review, or that there are no results for a key outcome that would have been expected to have been reported); or

- unclear risk of bias (insufficient information to decide whether selective reporting bias is likely or not).

\section{(6) Other biases}

For each included trial we described other potential sources of bias. We assessed these sources after data extraction and did not prespecify them in the protocol.

We assessed trials that received any funding from pharmaceutical or diagnostic manufacturers as being at unclear risk of bias.

'Contamination' of the intervention could occur if chlamydia testing in the control group increased to approach the levels achieved in the intervention group. This would reduce the size of the effect in cluster-randomised trials. Contamination could also occur in a cluster-controlled trial if sexual mixing between individuals in intervention and control groups occurred. We assessed trials as being at:
- low risk of bias (adequate description that contamination did not occur or was not relevant to the trial design);

- high risk of bias (explicit evidence that contamination occurred, with documentation of chlamydia testing rates in control group during the intervention period); or

- unclear risk of bias (contamination was possible but there was insufficient information to assess).

\section{Measures of treatment effect}

We compared the treatment effect or harmful effect for each outcome in the intervention versus the control group, expressing the association as a risk ratio (RR) with $95 \%$ confidence intervals (Cl). An advantage of the RR is that it can be interpreted easily for both high and low event rates. We also calculated the risk difference $(\mathrm{RD}, 95 \% \mathrm{Cl})$, the actual difference in the event rate between intervention and control groups.

For the primary outcome of chlamydia prevalence, we reported the overall effect estimate at the level of the cluster, and stated whether the analysis took into account the correlation between individuals within a cluster.

\section{Unit of analysis issues}

Cluster-randomised trials of chlamydia screening interventions might measure the effect of the intervention in a geographic area or a school community. In trials of chlamydia screening, the intervention affects not only individuals who are screened and treated (direct effect), but their sexual partners and members of the same sexual network (indirect effect). The indirect effect of screening can reduce the level of repeated exposure to infection of individuals within a cluster.

If meta-analysis was appropriate and both individually and clusterrandomised trials reported the same outcome, we adjusted the size of the trial to an 'effective sample size' (Campbell 2005; Higgins 2011a; Ukoumunne 1999). We then combined the effect sizes in meta-analyses. The effective sample size took into account the design effect of the cluster, based on the average cluster size and intraclass correlation coefficient (ICC). The design effect was $(1+$ (average cluster size -1 ) * ICC). We calculated an effective sample size, dividing both number of events and number of participants by the design effect (Higgins 2011a).

This issue applied to the outcome PID in (Ostergaard 2000), which had 17 clusters (schools) and an average cluster size of 100 . The trial publication did not report the ICC so we used an external source that reported a median ICC of 0.028 for 12 -month follow-up data from cluster-randomised trials of adolescent HIV/STI/pregnancy prevention interventions (Glassman 2015). The design effects were 3.77 for the intention-to-treat and 2.5 for per protocol data.

If we identified studies with multiple treatment groups we reported all intervention groups in the 'Characteristics of included studies' section and included only those that met the inclusion criteria. We combined relevant groups to create a single pair-wise comparison; all relevant intervention groups were combined into a single intervention group. 


\section{Dealing with missing data}

We reported the percentage of observations with missing data in each included trial. We used sensitivity analyses to explore the effect of including or excluding trials with $>20 \%$ missing data.

For each outcome we attempted to analyse data according to the intention-to-treat principle, with all participants included in the group to which they were randomised and exclusion only of participants with missing outcome data.

\section{Assessment of heterogeneity}

We reported statistical heterogeneity in results between studies using $\mathrm{I}^{2}$, Tau ${ }^{2}$ and $\mathrm{Chi}^{2}$ statistics obtained from analyses in RevMan. We used the $1^{2}$ statistic to quantify the percentage of variability between the results that is due to heterogeneity rather than sampling error (Higgins 2002). We took into account the fact that 12 values are affected by the number of studies, the magnitude and direction of effects in individual trials, and the strength of evidence of heterogeneity. In general, we considered $\mathrm{I}^{2}$ values below $40 \%$ as showing little evidence of statistical heterogeneity.

\section{Assessment of reporting biases}

We looked for evidence of publication and other reporting biases using funnel plots that plot the effect size against precision. If there were more than 10 studies in a meta-analysis we used statistical tests of funnel plot asymmetry for continuous or binary endpoints (Egger 1997; Harbord 2005).

\section{Data synthesis}

We described the results of trials where there were too few studies for meta-analysis or where we considered that meta-analysis was not clinically meaningful. We used forest plots to display results of trials examining the same outcome.

Where appropriate, we combined data using meta-analyses conducted in RevMan. If there were trials that examined the same intervention and measured the same underlying effect in similar populations, we used a fixed-effect model. If there was clinical heterogeneity or evidence of substantial statistical heterogeneity, we used a random-effects model to estimate the average treatment effect across trials. We presented results as the summary RR $(95 \% \mathrm{Cl})$ with $\mathrm{I}^{2}$ and $\mathrm{Tau}^{2}$ estimates. For meta-analyses with at least three studies combined using a random-effects model, we also calculated a prediction interval to examine the range of effect estimates that might be expected in different settings or populations (Riley 2011). We did not combine results from randomised and non-randomised trials in the same meta-analysis but compared these in a sensitivity analysis.

\section{Subgroup analysis and investigation of heterogeneity}

If there was evidence of substantial heterogeneity ( $I^{2}$ greater than $40 \%$ ) for the primary outcome measures and if there were enough trials, we used subgroup analyses to explore it. We explored the following subgroups.

- Sex of the participant.

- Level of sexual behaviour risk of the study population (high risk, low risk).

- Uptake of the intervention (greater or less than 50\%).
- Intensity of the intervention (single offer, multiple screening rounds).

For fixed-effect models based on inverse variance meta-analysis, we used tests of interaction to examine differences between groups. For random-effects models and fixed-effect models using methods other than inverse variance, we inspected confidence intervals for the subgroup estimates.

\section{Sensitivity analysis}

We planned to conduct the following sensitivity analyses to investigate the influence of methodological aspects of the review that might influence the results.

1. The treatment effect for pelvic inflammatory disease incidence in RCTs assessed as being at low versus high risk of detection bias (i.e. blinded versus non-blinded assessment).

2. The treatment effect for each primary outcome in RCTs assessed at being at low versus high risk of selection bias.

3. The treatment effect for chlamydia prevalence in RCTs versus non-randomised studies.

4. The treatment effect for each primary outcome in intention-totreat versus per protocol study populations.

In view of the small number of included studies, we only did sensitivity analyses for PID as an outcome.

\section{Summary of findings table}

We produced a 'Summary of findings' table to present the assessment of the overall level of evidence for each primary outcome (Higgins 2011b). We used the GRADE approach, as incorporated in RevMan. We summarised the quality of evidence as high, moderate, low or very low. We downgraded the overall level from 'high quality' by one level for serious (and by two levels for very serious) methodological limitations (risk of bias), inconsistency of results, indirectness of evidence, imprecision or publication bias.

\section{RE S U L T S}

\section{Description of studies}

\section{Results of the search}

Our search strategy identified 981 unique records as of 14 February 2016 (Figure 1). Of these, we examined the full text manuscript for 150 records. We found 10 potentially eligible trials (33 records). Of these, four were ongoing trials with no results about the primary outcomes (Characteristics of ongoing studies) (Hocking 2010; Kaldor 2010; Lehtinen 2015; NCT01195220).

\section{Included studies}

We included six trials that studied 359,078 adult women and men (Characteristics of included studies). Scholes 1996 took place in the United States, Andersen 2011 and Ostergaard 2000 in Denmark, Oakeshott 2010 in the UK, van den Broek 2012 in the Netherlands and Garcia 2012 in Peru.

\section{Participants}

Two trials included both women and men. Andersen 2011 enrolled 30,439 women and men aged 21 to 23 years, selected at random from the county health service register in Aarhus, Denmark. van 
den Broek 2012 took place in three locations in the Netherlands; investigators invited all women and men aged 16 to 29 years in Amsterdam and Rotterdam, while in South Limburg, participants were women and men aged 16 to 29 years who completed a webbased questionnaire and had a score indicating a high risk of chlamydia infection (total 317,304). Ostergaard 2000 enrolled both women and men, but for this review, primary outcome data were only from 1700 women aged around 18 years in high schools in Aarhus. Three trials included only women (Garcia 2012; Oakeshott 2010; Scholes 2007, total 9635).

Four trials enrolled participants from the general population, rather than from groups known to be at high risk of chlamydia infection (Andersen 2011; Oakeshott 2010; Ostergaard 2000; van den Broek 2012). Andersen 2011 and van den Broek 2012 invited people from municipal population registers so the eligible participants in these trials could be considered representative of the general population. Ostergaard 2000 invited students in their final year at school. The trial included all schools in one Danish county, so the eligible participants would be representative of the general population. Oakeshott 2010 invited older students at further education colleges in London and only enrolled those agreeing to be tested for chlamydia.

Two trials enrolled participants at increased risk of chlamydia. Scholes 1996 randomised 36,547 women aged 18 to 34 years in a health maintenance organisation in the United States, assessed questionnaire responses from 20,836 and enrolled 2607 who had a score indicating a high risk of chlamydia infection and agreed to take part. Garcia 2012 implemented an intervention for female sex workers (median age 22 years, interquartile range 20 to 26 years) in 20 cities in Peru and assessed 4465 in repeated cross-sectional surveys.

\section{Trial design}

In two RCTs, individuals were first randomised to intervention and control groups and then invited to undergo screening (Andersen 2011; Scholes 1996). In Andersen 2011, individuals in the intervention group were selected at random from the population register and then invited by post to undergo screening. In the trial by Scholes 1996, women in the intervention group fulfilling criteria for being at high risk of chlamydia were invited to a study clinic. In both control groups, individuals could receive usual care but did not receive any further information about the trial.

In one RCT, Oakeshott 2010 invited women to take part and randomised those who agreed to be tested for chlamydia individually to intervention or control groups.

The other three trials used a cluster design (Garcia 2012; Ostergaard 2000; van den Broek 2012). In the RCTs by Garcia 2012 and Ostergaard 2000, the clusters were allocated to intervention or control groups, and investigators compared outcomes at the same time points in both groups. In Ostergaard 2000 the statistical analysis did not account for clustering.

van den Broek 2012 used a stepped wedge design in a controlled clinical trial. Clusters were postal areas, which were allocated to intervention (two groups of postal areas) and control areas (one group of postal areas) according to population size, level of community risk of STI (low, medium or high) and demographic characteristics (proportions of 16 to 29 year olds, African Caribbean minority ethnic groups and low income earners). The screening intervention was rolled out sequentially in a randomly determined order so that each person in the cluster received an invitation for screening at least once. People in the intervention group clusters received three invitations at roughly 10-month intervals. The control group clusters received only one screening invitation. We included this trial because there were no RCTs in the general population that reported prevalence of chlamydia as a primary outcome. For the outcome of PID, we estimated the design effect for participants in 164 clusters involved in the first two screening rounds.

\section{Screening interventions}

Four trials used a register-based approach to identify and invite potentially eligible participants (Andersen 2011; Ostergaard 2000; Scholes 1996; van den Broek 2012). In Ostergaard 2000, the register included the final classes of high schools, and students in the intervention group received an invitation to be screened by means of a home-collected specimen. Two trials identified participants from municipal population registers and sent a postal invitation that offered a screening test by means of a home-collected specimen (Andersen 2011; van den Broek 2012). Andersen 2011 tested two methods for offering the home-collected specimen. We combined the results for both methods into a single intervention. All four trials used nucleic acid amplification tests to detect $C$. trachomatis.

In the trial by Scholes 1996, women in the intervention group were invited to a study clinic to have endocervical swabs taken by a physician. C. trachomatis was detected by enzyme-linked immunoassay.

Two trials used a venue-based approach. In the trial by Oakeshott 2010, women were approached in colleges. All women gave consent to be screened before enrolment. They provided a self collected vaginal swab specimen. Those in the intervention group received their results and were treated if the chlamydia test result was positive. Women in the control group had their specimens stored and received the result one year later. They were therefore unscreened for one year and underwent deferred screening. Garcia 2012 used mobile teams who visited sex work venues of 8 -week periods in each city. They invited female sex workers opportunistically and offered testing for chlamydia and other STIs. C. trachomatis was detected by nucleic acid amplification test.

All trials made arrangements to follow up and treat participants with positive screening test results. Two trials offered screening on more than one occasion (Garcia 2012; van den Broek 2012).

\section{Primary outcomes}

\section{Outcome for C. trachomatis transmission}

Three trials measured the proportion of positive chlamydia test results amongst all screened participants in women (in the case of Garcia 2012) or in women and men (in Ostergaard 2000 and van den Broek 2012) at least 12 months after the start of the screening intervention. Garcia 2012 measured the prevalence of positive test results among samples of female sex workers at sex work venues in each city in 2002 and 2003 (baseline) and at followup in 2005 and 2006, after implementing the intervention. van den Broek 2012 measured the prevalence of positive chlamydia test results following each round of postal invitations. They compared 
the results in postal areas that had received two or three yearly invitations versus those that had received only one invitation (control group). Ostergaard 2000 measured chlamydia prevalence amongst women who agreed to be followed up 12 months after the intervention, but there was no measure of prevalence in the control group at baseline (Table 1).

\section{Outcomes for reproductive tract morbidity}

Five trials measured the incidence of PID in women in the 12 months after the offer of screening (Andersen 2011; Oakeshott 2010; Ostergaard 2000; Scholes 1996; van den Broek 2012). For the cluster-randomised trial by Ostergaard 2000, we applied a design effect of 3.77 (based on an ICC of 0.028) to calculate an effective sample size so that we could combine the results with those of the individually randomised trials (Glassman 2015).

One trial measured the incidence of epididymitis in men in the 12 months after the offer of screening (Andersen 2011).

\section{Outcome for chlamydia infection in pregnancy}

We did not find any RCTs that measured the incidence of preterm delivery or secondary outcomes related to chlamydia screening in pregnancy.

\section{Secondary outcomes}

\section{Outcomes measured in all participants}

- Proportion of participants receiving the intervention (screening uptake) (Andersen 2011; van den Broek 2012)

- Harms of screening (not reported in any trial)

Outcomes measured in women who were not pregnant during the trial or in men

- Prevalence of chronic female pelvic pain (not reported in any trial)
- Prevalence of female infertility and incidence of ectopic pregnancy (Andersen 2011)

- Male infertility (not reported in any trial)

We did not find any trials reporting neonatal outcomes of chlamydia screening interventions.

\section{Excluded studies}

We assessed and excluded 41 full-text records. Of these, 31 were RCTs that involved screening for chlamydia but did not report a pre-specified primary outcome (ISRCTN38526137; Bailey 2013; ISRCTN16261241; Bowden 2008; Brown 2010; Chandeying 1998; Cook 2007; De Barbeyrac 2013; Downing 2013; Gotz 2013; Graseck 2010; Guy 2013; ACTRN12608000499381; Jones 2007; Kersaudy-Rahib 2013; Klovstad 2013; Lawton 2010; McKee 2011; Meyer 1991; Niza 2014; NCT01654991; Scholes 2006; Scholes 2007; NCT00829517; Senok 2005; Shafer 2002; Smith 2014; Tebb 2005; Tebb 2009; Walker 2010; Xu 2011). We excluded two trials that reported chlamydia prevalence as an outcome. One was a non-randomised controlled trial with retrospective inclusion of a control group (Cohen 1999). One trial did not measure chlamydia prevalence in all eligible participants in the control group (Hodgins 2002). We assessed and excluded eight studies in pregnant women (Andrews 2006; Banhidy 2011; Kekki 2001; Kiss 2004; Martin 1997; McGregor 1990; McGregor 1995; Stevens-Simon 2002). None involved chlamydia screening as the intervention.

\section{Risk of bias in included studies}

Of the six included trials, we considered one to be at low risk of bias in the six specified domains (Garcia 2012). The other trials had an unclear or high risk of bias in at least one domain (Figure 2; Figure 3). 
Figure 2. Risk of bias summary: review authors' judgements about each risk of bias item for each included study.

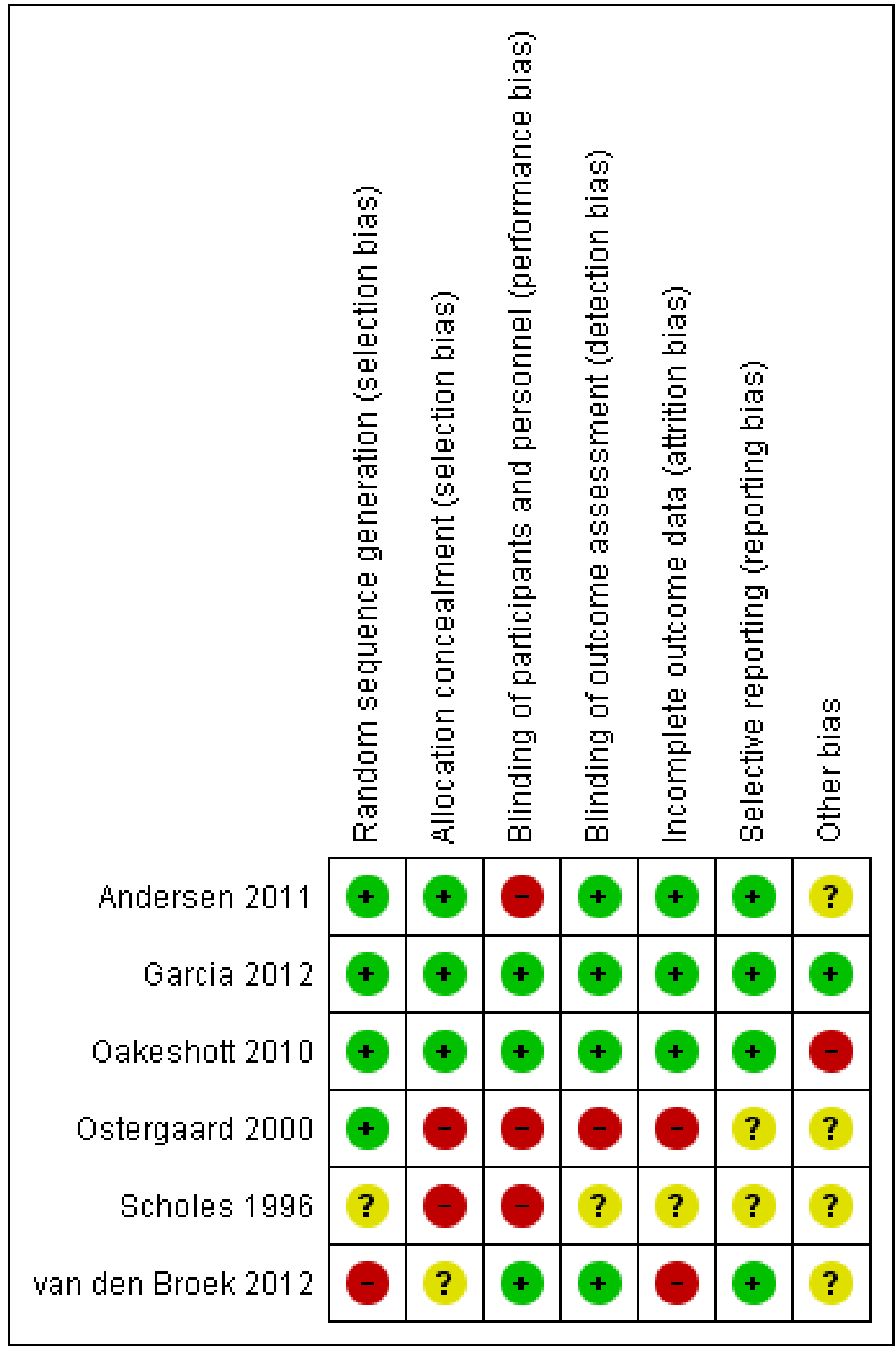


Figure 3. Risk of bias graph: review authors' judgements about each risk of bias item presented as percentages across all included studies.

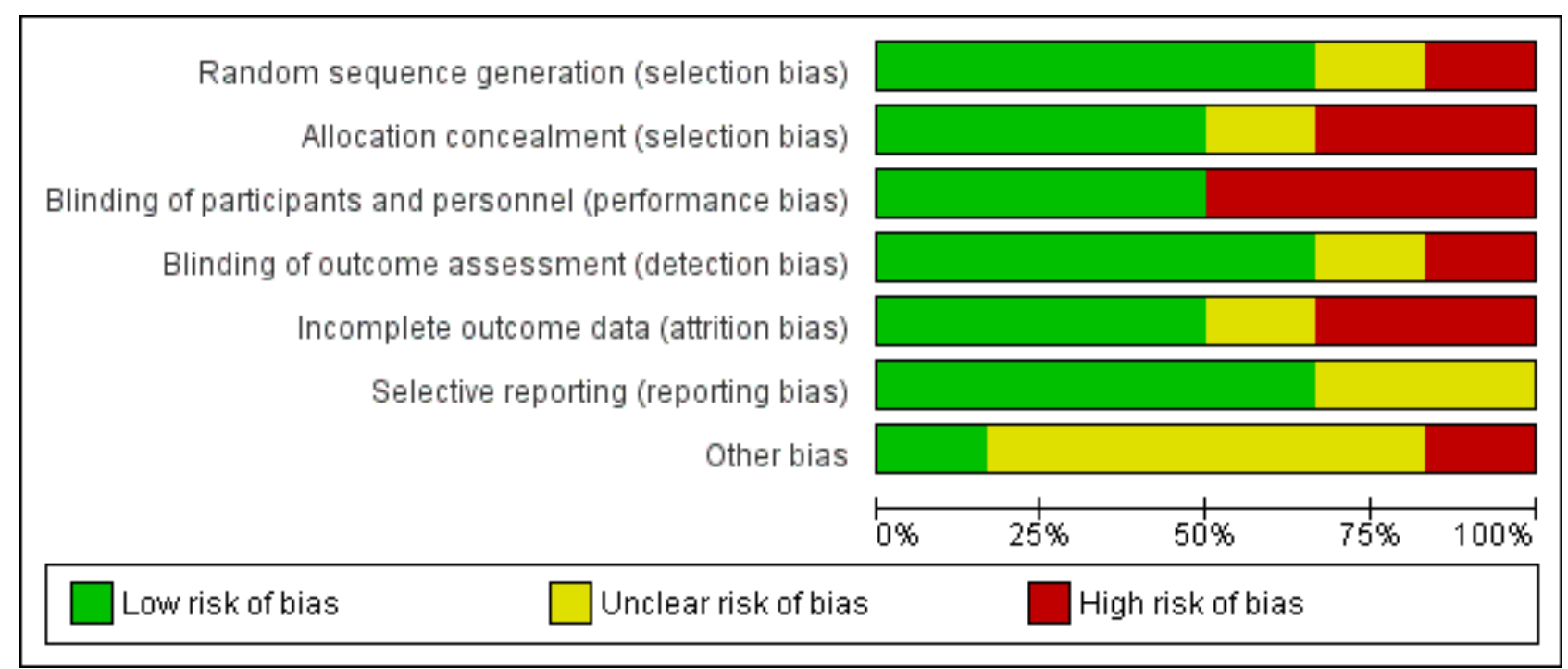

\section{Allocation}

Of the five RCTs, four were at low risk of selection bias in the generation of the randomisation sequence. Two used computergenerated lists (Andersen 2011; Garcia 2012), one used random number tables (Oakeshott 2010), and one allocated schools by drawing lots from a hat (Ostergaard 2000). In one RCT the risk of bias was unclear because the methods only stated that "women were randomly assigned" (Scholes 1996).

In van den Broek 2012, allocation to intervention and control groups did not follow a randomly generated sequence, so we judged it to be at high risk of bias in this domain.

We judged two trials to be at low risk of bias for allocation concealment, as they explicitly stated that neither participants nor staff could predict the allocation (Garcia 2012; Oakeshott 2010). Andersen 2011 did not explicitly describe allocation concealment, but we judged it to be at low risk of bias, as individuals in the intervention group were selected at random from a population register and invited to be screened without knowing that there was a control group.

Unconcealed allocation resulted in a high risk of selection bias in two trials in which randomisation occurred before seeking consent (Ostergaard 2000; Scholes 1996). In both trials the ratio of intervention to control group participants was distorted. In Ostergaard 2000, students randomised to the intervention arm were more likely to agree to take part $(48 \%, 1254 / 2603)$ than those randomised to the control arm (38\%, 1097/2884). In Scholes 1996 , women randomised to the intervention group were actively encouraged to complete the risk assessment questionnaire. The planned ratio of intervention to control was $1: 2$, while the actual ratio of enrolled women was 1:1.6 (1009 intervention, 1598 control).

The risk of bias in allocation concealment was unclear in van den Broek 2012. The intervention was allocated and implemented in two stages. Allocation was not random, but the investigators who assigned 191 postal areas to intervention and control groups were blinded to their identity. The invitations were sent out in a random order.

\section{Blinding}

The two trials reporting the primary outcome of chlamydia prevalence did not explicitly mention that laboratory staff were blinded, but we considered the risk of detection bias to be low because the $C$. trachomatis test result reporting was automated (Garcia 2012; van den Broek 2012).

The risk of performance bias was high in RCTs that sent invitations or instructions for sample collection only to participants in the intervention group (Andersen 2011; Ostergaard 2000; Scholes 1996). Advice about healthcare-seeking behaviour for symptoms related to upper genital tract infection might result in differences in management compared with participants in the control groups.

Detection bias was possible for the primary outcome PID, which is a subjective diagnosis based on clinical findings. Assigning a diagnosis of PID can be influenced if the assessor knows whether a person has received screening and treatment for chlamydia or not. We considered Oakeshott 2010 to be at low risk of detection bias because a panel of independent experts used pre-specified criteria to assign the outcome PID. We also deemed Andersen 2011 to be at low risk of detection bias because outcomes were extracted from hospital discharge and prescription registers. In the trial by Scholes 1996 the risk of detection bias was unclear; people abstracting information from medical records were unaware of group allocation, but investigators did not explicitly describe the blinding of those assigning outcome diagnoses. In Ostergaard 2000 the risk of detection bias was high because outcome assessors were not reported to have been blinded. In the trial by van den Broek 2012 the risk of detection bias was high because investigators only collected data from women who responded to the screening invitation, and the response rate within this group to questions about self reported PID was very low. 


\section{Incomplete outcome data}

In trials reporting the primary outcome of chlamydia prevalence, attrition was high in van den Broek 2012. Garcia 2012 did not measure attrition from participation in the intervention, but participation in surveys to assess the outcome was high.

In trials that reported the primary outcome of PID, the risk of attrition bias was low in Andersen 2011, Oakeshott 2010 and Scholes 1996 and high in Ostergaard 2000 and van den Broek 2012.

\section{Selective reporting}

There was a risk of reporting bias in three RCTs that did not have a protocol (Andersen 2011; Ostergaard 2000; Scholes 1996). The reported results matched the methods, so we assessed the risk of bias as unclear. We judged the remaining three trials to be at low risk of reporting bias.

\section{Other potential sources of bias}

There was a risk of contamination of the intervention in three trials (Andersen 2011; Oakeshott 2010; van den Broek 2012). We considered the risk to be high in Oakeshott 2010 and unclear in the other two trials. Three trials reported receiving funding from diagnostic or pharmaceutical companies (Oakeshott 2010; Ostergaard 2000; Scholes 1996). We assessed the risk that this had resulted in biased results to be unclear in all three trials.

\section{Effects of interventions}

See: Summary of findings for the main comparison

\section{Primary outcomes}

\section{C. trachomatis transmission}

The three included trials that evaluated $C$. trachomatis transmission used different populations, screening interventions, study designs and follow-up periods (Garcia 2012; Ostergaard 2000; van den Broek 2012). The effect measure differed in each trial. We could not generate a common effect measure because all were cluster trials and none reported an ICC. We describe the results of each trial separately and report results in Table 1.

In the general adult population, van den Broek 2012 found no statistical evidence of a difference in overall chlamydia test positivity in intervention compared with control clusters after the first (baseline, $4.3 \%$ vs $4.3 \%$ ), second ( 12 months, $4.0 \%$ vs $4.3 \%$ ) and third ( 24 months, $4.1 \%$ vs $4.3 \%$ ) invitations (numbers invited differed between screening rounds, see Table 2 for details). Analysis 1.1 shows the results as the risk ratio (RR) comparing second and third rounds with the first round. The results for women and men separately were similar. The results from analyses at the individual level, with clustering taken into account, were the same. We graded the quality of the evidence to be low, as data from nonrandomised trials begin at low quality. We would have downgraded this evidence further because there were no other trials and because of uncertainty about the effect of this intervention at higher sustained levels of uptake. However, the trial was very large, at low risk of other biases and it is unclear whether, in practice, the lack of randomisation resulted in biased allocation.

Garcia 2012 found a lower risk of chlamydia infection in female sex workers in intervention compared with control cities in 2006 (RR $0.72,95 \% \mathrm{Cl} 0.54$ to $0.98,4465$ women). Amongst female sex workers tested in 2002 (baseline), prevalence was 13.8\% in intervention vs $15.5 \%$ in control cities, and in 2006 (at 48 months), it was $9.9 \%$ in intervention vs $14.5 \%$ in control cities. We adjusted the analysis for differences in prevalence between intervention and control groups in 2002, but not for the pairing of intervention and control cities. We downgraded the quality of the evidence for this outcome to low because directeness and only one trial assessed screening in this population.

\section{Reproductive tract morbidity in women}

In five trials that reported the incidence of clinically diagnosed PID, follow-up data at 12 months were available for $100 \%$ of participants either invited to be screened or in the control group in the RCT by Andersen 2011, 94\% in Oakeshott 2010, 76\% in Scholes 1996, and $55 \%$ in Ostergaard 2000. In the cluster-controlled trial by van den Broek 2012, information was not available from all women invited; from those who responded to the screening invitation, information was available for $3.6 \%$ in the control group and $11.2 \%$ in the intervention group after the first 12-month intervention period. We applied a design effect of 1.608 (average cluster size 100) to data extracted from the trial by Ostergaard 2000.

Intention-to-treat analysis (Analysis 1.2, Figure 4): We calculated the risk ratio of clinically diagnosed PID in women invited to be screened compared with women who were not invited or who had deferred screening (Andersen 2011; Oakeshott 2010; Ostergaard 2000; Scholes 1996). This analysis assumed that women who were not followed up at 12 months did not develop PID. The risk of PID was lower in women in intervention than control groups, with little evidence of between-trial heterogeneity (RR $0.68,95 \% \mathrm{Cl} 0.49$ to $0.94,127 \%, 4$ trials, 21,686 participants). We found one trial that provided results in women who had a positive chlamydia test result at baseline (Oakeshott 2010). PID incidence was much lower in women who received immediate treatment $(1 / 64)$ than those who received deferred treatment $(7 / 74, \mathrm{RR} 0.17,95 \% \mathrm{Cl} 0.03$ to 1.01$)$. In women in the same RCTs with complete data at follow-up, the risk of PID in the intervention group was $32 \%$ lower than in the control group (RR $0.68,95 \% \mathrm{Cl} 0.49$ to $0.93, \mathrm{I}^{2} \mathrm{0} \%$ ). 
Figure 4. Forest plot of comparison: 1 Offer of chlamydia screening vs usual care (inactive control), outcome: 1.2 Incidence of PID at 12 months (intention-to-treat).

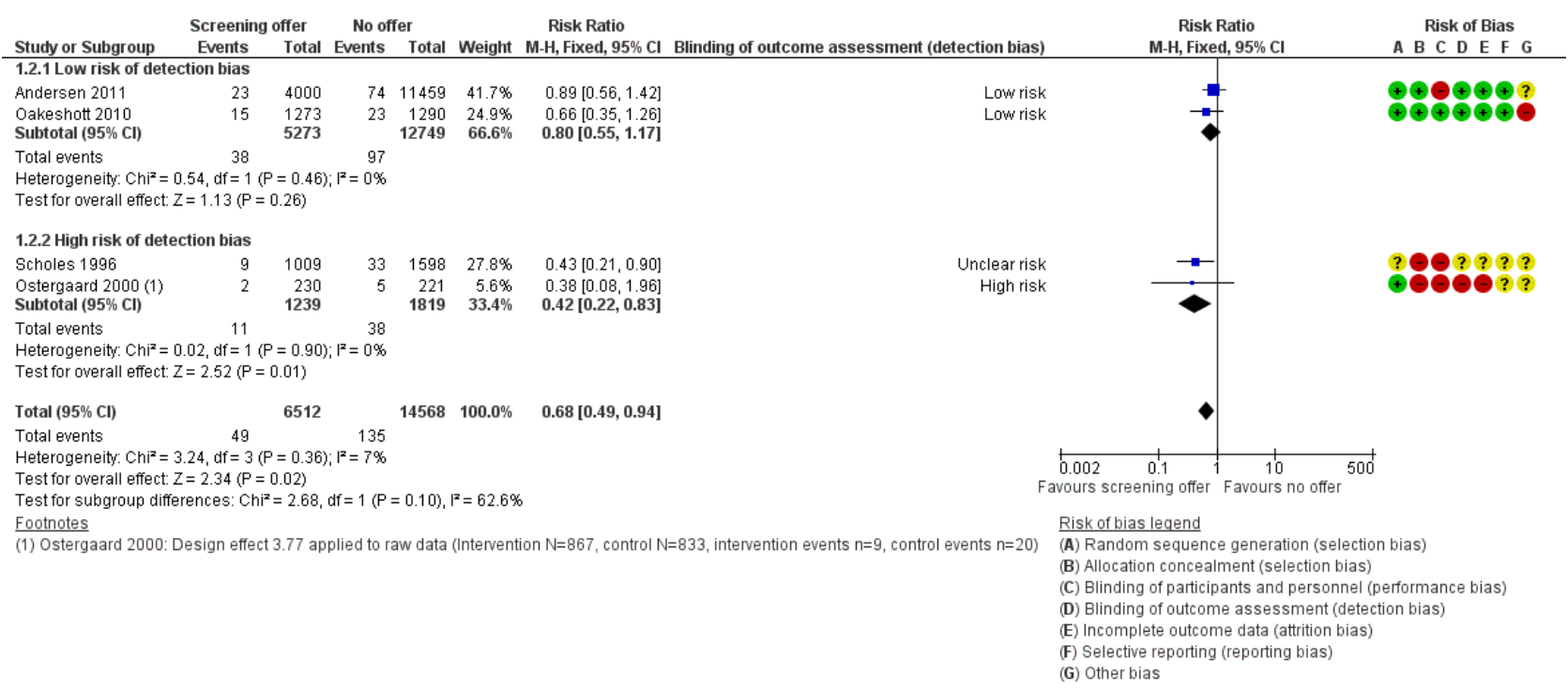

Data from the non-randomised cluster-controlled trial by van den Broek 2012 were not combined with RCT data. The authors reported results according to screening round; in women who provided information, the incidence in the previous 12 months was $1.8 \%$ $(19 / 1072)$ at the first invitation, $2.1 \%(47 / 2261)$ at the second invitation and $1.9 \%(44 / 2340)$ at the third invitation. Using data from the first two screening rounds, we calculated a design effect of 1.119 (average cluster size 20.3).

For our sensitivity analyses, we analysed the results separately for, on the one hand, Andersen 2011 and Oakeshott 2010, two RCTs at low risk of selection bias and bias for detecting PID, and, on the other, Ostergaard 2000 and Scholes 1996, two trials at high or unclear risk of bias. Within these groups there was no evidence of between trial heterogeneity ( $120 \%)$. The estimated effect of chlamydia screening was less strong in RCTs at low risk of detection bias than in RCTs at high or unclear risk of detection bias (Analysis $1.2, \mathrm{P}=0.10$; Analysis 1.3, ). In the intention-to-treat analysis, the risk of PID in women invited for screening was $20 \%$ lower than for those whose were not in RCTs at low risk of detection bias (RR 0.80, 95\% Cl 0.55 to $1.17,2$ trials, 18,022 participants) and 53\% lower in RCTs at high or unclear risk of detection bias (RR $0.47,95 \% \mathrm{Cl} 0.26$ to 0.84 ) (2 trials, 3664 participants).

We downgraded the quality of the evidence to moderate because of statistical evidence that detection bias might have overestimated the intervention effect.

\section{Reproductive tract morbidity in men}

The trial by Andersen 2011 was the only one to provide information about epididymitis in men. Men invited for screening had a $20 \%$ lower risk for epididymitis than those not invited (RR $0.80,95 \% \mathrm{Cl}$ 0.45 to $1.42,1$ trial, 14,980 participants). The effect size is similar to that observed for PID for women in the same trial, but the number of events in men was smaller so the confidence interval is wider and includes the possibility of no effect. We downgraded the quality of the evidence to very low because risk of bias and there was only one trial with low uptake of the screening intervention.

\section{Chlamydia infection in pregnancy}

We did not find any trials of chlamydia screening in pregnant women.

\section{Secondary outcomes in all participants \\ Uptake of chlamydia screening}

The included trials did not calculate uptake of the chlamydia screening intervention uniformly, owing to differences in trial design. Table 2 shows the data reported in each trial.

\section{Harms of screening}

None of the included trials reported any harms of screening.

\section{Secondary outcomes in non-pregnant women}

\section{Female infertility}

The trial by Andersen 2011 was the only one to provide information about infertility in women, assessed up to nine years after a single round of the screening intervention. The risk of infertility was 15\% higher in women invited to be screened compared with those not invited; the number of events was small so the confidence interval is wide and compatible with no effect (RR $1.15,95 \% \mathrm{Cl} 0.94$ to 1.40 , 1 trial, 15,459 participants, very low quality evidence).

\section{Ectopic pregnancy}

The trial by Andersen 2011 was the only one to provide information about ectopic pregnancy, assessed up to nine years after a single round of the screening intervention. There was no evidence of a difference in the risk of ectopic pregnancy in women invited to be screened compared with those not invited (RR $1.03,95 \% \mathrm{Cl} 0.67$ to 1.60, 1 trial, 15,459 participants, very low quality evidence).

\section{Subgroup and sensitivity analyses}

There were too few included trials for subgroup analyses or sensitivity analyses other than the one reported above for reproductive tract morbidity in women. 


\section{DISCUSSION}

\section{Summary of main results}

We found six trials that investigated the effect of chlamydia screening interventions on either $C$. trachomatis transmission (one $\mathrm{RCT}$, one cluster-controlled trial) or reproductive tract morbidity (three RCTs, one cluster-RCT). We found no trials assessing the effects of chlamydia screening in pregnancy on obstetric or neonatal outcomes. One trial in the Netherlands found no effect of register-based yearly invitations in the general population, but uptake of the intervention was low. One trial in Peru found that mobile teams offering periodic testing and treatment for sexually transmitted infections in female sex workers reduced the prevalence of chlamydia infection. Four RCTs found a reduction in the incidence of clinically diagnosed PID in women (RR 0.67, $95 \% \mathrm{Cl} 0.49$ to 0.92$) 12$ months after a single offer of chlamydia screening. The quality of this evidence was downgraded from high to moderate because of statistical evidence that the effect of the intervention was less strong in trials with a low risk of detection bias compared with trials at high or unclear risk. One trial found no statistical evidence of an effect of chlamydia screening on epididymitis, female infertility or ectopic pregnancy.

\section{Overall completeness and applicability of evidence}

We aimed to assess evidence about the effects of chlamydia screening interventions on transmission of $C$. trachomatis infection, reproductive tract morbidity and pregnancy and neonatal outcomes. We found a small number of trials assessing outcomes in non-pregnant women and men and no trials of chlamydia screening in pregnancy (Andersen 2011; Garcia 2012; Oakeshott 2010; Ostergaard 2000; Scholes 1996; van den Broek 2012).

Trials of the effect of screening on $C$. trachomatis transmission aimed to measure effects on chlamydia prevalence but not on chlamydia incidence. van den Broek 2012 focused on the general population, Ostergaard 2000 on school students and Garcia 2012 on female sex workers, all attempting to measure prevalence as an outcome. Garcia 2012 and van den Broek 2012 implemented the intervention over more than one screening round, which acknowledges screening as an ongoing process. Multiple screening rounds need to be done for infections like chlamydia because people who have been treated become susceptible to further infections from untreated partners or from new infected partners.

van den Broek 2012 found that the uptake of register-based postal invitations for screening in the Netherlands was very low and there was no reduction in the proportion of positive tests after three rounds of screening. This trial was done in a pragmatic way and these results are applicable to all settings. In contrast, Ostergaard 2000 found that a subset of female school students with very high screening uptake at baseline had a lower prevalence of chlamydia after 12 months than women who had not been screened. The generalisability of this finding is unknown because attrition was high, and there was no long-term follow-up of the sustainability of the intervention. Between these extremes, the precise relationship between screening uptake and change in chlamydia prevalence remains unknown. Mathematical modelling studies show that uptake is the strongest determinant of the impact of screening on chlamydia prevalence over time (Althaus 2010; Regan 2008).
Trials of the effects of chlamydia screening interventions on PID mostly assessed the effects of a single round of screening (Andersen 2011; Oakeshott 2010; Ostergaard 2000; Scholes 1996). It is not known whether the effect size stays the same over time. van den Broek 2012 found no change in self reported PID over three rounds of invitations for chlamydia screening. Uptake of screening was low and information about PID was only available for a small minority of eligible participants, so this trial could not address the question.

Evidence about the effects of chlamydia screening on epididymitis and on female infertility and ectopic pregnancy is incomplete. Only one trial examined these outcomes following a single offer of a screening test and found no strong statistical evidence of an effect on any of them (Andersen 2011). Uptake and intensity of the intervention in this trial might have been too low to have a measurable impact on rare and long-term outcomes.

RCT evidence about the effects of chlamydia screening in pregnancy is lacking.

\section{Quality of the evidence}

The quality of evidence about the effects of chlamydia screening interventions is influenced by the small number of trials and the risk of bias. For any trial, we could only assess whether there was a risk of biased results, and not whether the results themselves were or were not biased.

The paucity of trials assessing chlamydia prevalence or incidence as an outcome means that we are very uncertain about the effects of chlamydia screening for preventing transmission of $C$. trachomatis in high risk individuals and the general population (Garcia 2012; van den Broek 2012). In the general population, the large trial by van den Broek 2012 provides a precise estimate for that particular intervention. Additional trials that evaluate different interventions with higher and sustained coverage might well find different results. The trial by Garcia 2012 in high risk populations was at low risk of bias, but the findings might not be applicable to other settings and interventions.

For the effect of chlamydia screening on reducing the risk of PID, the summary risk ratio might overestimate the effect because of the risks of selection and detection bias in some trials. Whilst the findings of the four RCTs were statistically compatible (127\%), the effect sizes in individual trials varied from modest in Andersen 2011 and Oakeshott 2010 to large in Ostergaard 2000 and Scholes 1996. We pre-specified sensitivity analyses according to the risks of selection and detection bias. Two trials were at high or unclear risk of both of these biases, and these trials showed the largest effects (Ostergaard 2000; Scholes 1996).

\section{Potential biases in the review process}

The search strategy was broad and unlikely to have missed RCTs. We followed the protocol reasonably closely and did not undertake any non-specified subgroup analyses.

\section{Agreements and disagreements with other studies or reviews}

This review updates systematic reviews of literature published up to October 2007 and August 2012 (ECDC 2014; Low 2009). The current review identified new studies about the effects of chlamydia screening on both $C$. trachomatis transmission and 
reproductive tract morbidity (PID, infertility and ectopic pregnancy in women, epididymitis in men). Narrative reviews have also addressed this research question (Gottlieb 2010; Gottlieb 2013). The main conclusions of these reviews agree with each other.

The modelling study by Herzog 2013 examined the direct effect of identifying and treating asymptomatic infections on the risk of clinically diagnosed PID. It is assumed in this study that a fall in the incidence of PID is the direct result of antimicrobial treatment of a prevalent chlamydia infection. A fall in PID incidence in clinical trials of women who might have been infected with chlamydia many months before enrolment suggests that symptoms can develop throughout the course of a lower genital tract chlamydia infection. This finding contradicts the assumption that PID resulting from ascending chlamydial infection occurs at the beginning of the infectious duration.

Chlamydia screening can also have an indirect effect on the risk of PID (Herzog 2013). If screening and treatment are sustained at high enough levels, the prevalence of chlamydia infection should fall, and exposure to the risk of chlamydia should also decrease. Gottlieb 2013 and colleagues suggest that PID incidence at the population level can fall, even if chlamydia prevalence stays the same. A screening intervention could detect and treat chlamydia infections and shorten the average duration of infection. Women who have received treatment are susceptible to infection again. The rate of incidence of $C$. trachomatis infections following treatment might then increase so the net effect would be to maintain prevalence. It is not clear what levels of chlamydia screening would result in this apparently paradoxical effect. In the trial by van den Broek 2012, at the low levels of chlamydia screening uptake achieved, neither chlamydia positivity in the tested population nor self reported PID decreased.

The outcome measured in the included trials was PID from all causes. Only the trial by Oakeshott 2010 collected information about PID in women with and without $C$. trachomatis at baseline. In this subset of women, investigators assumed that PID diagnosed during the trial was caused by untreated chlamydia infection. The risk of chlamydia-associated PID in screened compared with unscreened women was $83 \%$ lower (RR $0.17,95 \% \mathrm{Cl} 0.03$ to 1.01 ). $C$. trachomatis is only one cause of PID, however. The reduction in PID at the population level if chlamydia screening overall population might therefore be modest if the population attributable fraction is small.

Ongoing studies should provide more evidence about the effects of opportunistic chlamydia screening interventions on chlamydia prevalence in young adults in the general population (Hocking 2010; Lehtinen 2015).

\section{AUTHORS' CONCLUSIONS}

\section{Implications for practice}

Detection and treatment of chlamydia infection can reduce the risk of PID in an individual woman. The size of the effect is uncertain because of methodological biases in some trials that could exaggerate the effect of the intervention. It is not known whether chlamydia screening to prevent PID has an impact on rates of infertility and ectopic pregnancy.

The effect of register-based chlamydia screening for $C$. trachomatis transmission in young adults in the general population is uncertain. The results of ongoing trials of opportunistic chlamydia screening are pending.

There is an absence of RCT evidence about the effects of chlamydia screening in pregnancy and of the harms of chlamydia screening.

\section{Implications for research}

RCTs of chlamydia screening in pregnancy and men are necessary for determining both benefits and harms. RCTs of chlamydia screening interventions in high risk populations such as sex workers are necessary to replicate the findings of Garcia 2012.

Diagnostic tests to improve the accuracy of diagnosing PID would help to improve outcome ascertainment in RCTs. RCTs of chlamydia screening interventions to prevent PID should determine the effects of repeated rounds of screening on the incidence of chlamydia-associated PID and chlamydia reinfection.

RCT evidence about the effects of chlamydia screening on infertility and ectopic pregnancy would be valuable. There are substantial methodological challenges involved in using these conditions as trial outcomes. Non-invasive diagnostic tests for fallopian tube damage or blockage might provide surrogate markers for tubal factor infertility.

Mathematical modelling and evidence synthesis studies should be conducted to determine whether chlamydia screening interventions that reduce PID incidence are compatible with stable chlamydia prevalence at the population level.

\section{ACK N OWLEDGEMENTS}

The authors would like to thank Marita van der Laar, Otilia Sfetcu and Andrew Amato of the the European Centre for Disease Prevention and Control for funding this review and for their support in developing the review questions and comments on an earlier version of the review (ECDC 2014). 


\section{R E F E R E N C E S}

\section{References to studies included in this review}

Andersen 2011 \{published data only\}

Andersen B, Olesen F, Moller JK, Ostergaard L. Populationbased strategies for outreach screening of urogenital Chlamydia trachomatis infections: A randomized, controlled trial. Journal of Infectious Diseases 2002;185(2):252-8.

* Andersen B, Van Valkengoed I, Sokolowski I, Moller JK, Ostergaard L, Olesen F. Impact of intensified testing for urogenital Chlamydia trachomatis infections: A randomised study with 9-year follow-up. Sexually Transmitted Infections 2011;87(2):156-61.

NCT00827970. Randomized population-based study on Chlamydia trachomatis screening. http://clinicaltrials.gov/ show/NCT00827970 (accessed 9 June 2016).

\section{Garcia 2012 \{published data only\}}

Campos PE, Buffardi AL, Carcamo CP, Garcia PJ, Buendia C, Chiappe $\mathrm{M}$, et al. Reaching the unreachable: providing STI control services to female sex workers via mobile team outreach. PLOS ONE 2013;8(11):e81041.

* García PJ, Holmes KK, Cárcamo CP, Garnett GP, Hughes JP, Campos PE, et al. Prevention of sexually transmitted infections in urban communities (Peru PREVEN): a multicomponent community-randomised controlled trial. Lancet 2012;379(9821):1120-8.

Peru PREVEN Study. Urban community randomized trial for STD prevention: trial summary and protocol summary of revisions. http://www.proyectopreven.org/portal/index.php/about-theproject/preven-main-protocol (accessed 9 June 2016).

\section{Oakeshott 2010 \{published data only\}}

NCT00115388. Community-based trial of screening for Chlamydia trachomatis to prevent pelvic inflammatory disease. http://ClinicalTrials.gov/show/NCT00115388 (accessed 9 June 2016).

* Oakeshott P, Kerry S, Aghaizu A, Atherton H, Hay S, TaylorRobinson $\mathrm{D}$, et al. Randomised controlled trial of screening for Chlamydia trachomatis to prevent pelvic inflammatory disease: the POPI (prevention of pelvic infection) trial. BMJ 2010;340:c1642.

Oakeshott P, Kerry S, Atherton H, Aghaizu A, Hay S, TaylorRobinson D, Simms I, Williams E, Hay P. Community-based trial of screening for Chlamydia trachomatis to prevent pelvic inflammatory disease: the POPI (Prevention Of Pelvic Infection) trial. [Abstract P4.77]. ISSTDR/BASHH meeting. 200928 June-1 July; London, UK.

Oakeshott P, Kerry S, Atherton H, Aghaizu A, Hay S, TaylorRobinson $D$, et al. Community-based trial of screening for Chlamydia trachomatis to prevent pelvic inflammatory disease: The POPI (prevention of pelvic infection) trial. Trials 2008;9:15.

\section{Ostergaard 2000 \{published data only\}}

* Ostergaard L, Andersen B, Moller JK, Olesen F. Home sampling versus conventional swab sampling for screening of Chlamydia trachomatis in women: a cluster-randomized 1-year follow-up study. Clinical Infectious Diseases 2000;31(4):951-7.

Ostergaard L, Andersen B, Olesen F, Moller JK. Efficacy of home sampling for screening of Chlamydia trachomatis: randomised study. BMJ 1998;317(7150):26-7.

\section{Scholes 1996 \{published data only\}}

Scholes D, Stergachis A, Heidrich FE, Andrilla H, Holmes KK, Stamm WE. Prevention of pelvic inflammatory disease by screening for cervical chlamydial infection. New England Journal of Medicine 1996;334(21):1362-6.

\section{van den Broek 2012 \{published data only\}}

Op de Coul EL, Weenen TC, van Bergen JEAM, Brouwers EEHG, de Feijter EM, Fennema JSA, Gotz HM, Hoebe CJPA, Koekenbier RH, van Ravensteijn SM, van den Broek IVF. Process evaluation of the chlamydia screening implementation Netherlands: results from the first operational phase. [Abstract P4.68]. ISSTDR/BASHH meeting. 200928 June-1 July; London, UK.

van Bergen JEAM, Fennema JSA, van den Broek IVF, Brouwers EEHG, de Feijter EM, Hoebe CJPA, Koekenbier RH, Op de Coul ELM, van Ravensteijn SM, Gotz HM. Development and implementation of a systematic selective internet-based chlamydia screening program, the Netherlands 2008-2010: rationale and design. [Abstract P4.42]. ISSTDR/BASHH meeting. 200928 June-1 July; London, UK.

van den Broek IVF, Hoebe CJPA, van Bergen JEAM, Brouwers EEHG, De Feijter EM, Fennema JSA, et al. Evaluation design of a systematic, selective, internet-based, chlamydia screening implementation in the Netherlands,2008-2010: implications of first results for the analysis. BMC Infectious Diseases 2010;10:89.

van den Broek IVF, Hoebe CJPA, van Bergen JEAM, Brouwers EEHG, de Feijter EM, Fennema JSA, Gotz HM, Koekenbier RH, van Ravensteijn SM, Op de Coul EL. First phase of the stepwise chlamydia screening implementation in the Netherlands: participation rates and implications for measures of effect. [Abstract P4.67]. ISSTDR/BASHH meeting. 200928 June-1 July; London, UK.

* van den Broek IVF, van Bergen JEAM, Brouwers EEHG, Fennema JSA, Gotz HM, Hoebe CJPA, et al. Effectiveness of yearly, register based screening for chlamydia in the Netherlands: controlled trial with randomised stepped wedge implementation. BMJ 2012;345:7869.

van den Broek IVF, van Bergen JEAM, Fennema HSA, Gotz HM, Hoebe CJPA, Over E, et al. Main results and impact analysis of annual chlamydia screening in a large register-based programme in the Netherlands. Sexually Transmitted Infections. 2011; Vol. 87:A45. 
van den Broek IVF, van Bergen JEAM, Fennema JSA, Gotz HM, Hoebe CJPA, van der Sande MAB, et al. Systematic annual chlamydia screening: results of the effectiveness after 3-year trial implementation [Jaarlijkse systematische chlamydiascreening: resultaten van de effectiviteit na 3 jaar proefimplementatie]. Nederlands Tijdschrift voor Geneeskunde 2012;156:A5503.

\section{References to studies excluded from this review}

ACTRN12608000499381 \{published data only\}

ACTRN12608000499381. Chlamydia prevalence and testing program targetting women aged 16 to 24 years in general practice. http://www.anzctr.org.au/ ACTRN12608000499381.aspx (accessed 9 June 2016).

\section{Andrews 2006 \{published data only\}}

Andrews WW, Klebanoff MA, Thom EA, Hauth JC, Carey JC, Meis PJ, et al. Midpregnancy genitourinary tract infection with Chlamydia trachomatis: association with subsequent preterm delivery in women with bacterial vaginosis and Trichomonas vaginalis. American Journal of Obstetric Gynecology 2006;194(2):493-500.

Bailey 2013 \{published data only\}

*Bailey J, McCarthy O, Carswell K, et al. The Sexunzipped website for sexual wellbeing for young people: early results of a pilot online RCT. Journal of Sexual Medicine 2011;8(Suppl 3):126.

Bailey JV, Pavlou M, Copas A, McCarthy O, Carswell K, Rait G, et al. The Sexunzipped trial: optimizing the design of online randomized controlled trials. Journal of Medical Internet Research 2013;15(12):e278.

\section{Banhidy 2011 \{published data only\}}

Banhidy F, Duda SI, Czeizel AE. Preconceptional screening of sexually transmitted infections/diseases. Central European Journal of Medicine 2011;6(1):49-57.

\section{Bowden 2008 \{published data only\}}

Bowden FJ, Currie MJ, Toyne H, McGuiness C, Lim LL, Butler JR, et al. Screening for Chlamydia trachomatis at the time of routine Pap smear in general practice: a cluster randomised controlled trial. Medical Journal of Australia 2008;188(2):76-80.

\section{Brown 2010 \{published data only\}}

Brown L, Patel S, Ives NJ, McDermott C, Ross JD. Is non-invasive testing for sexually transmitted infections an efficient and acceptable alternative for patients? A randomised controlled trial. Sexually Transmitted Infections 2010;86(7):525-31.

\section{Cabeza 2015 \{published data only\}}

Cabeza J. Chlamydia trachomatis screening and treatment in pregnant women in Lima, Peru [Abstract P5.015]. Sexually Transmitted Infections. 2013; Vol. 89, issue Suppl 1:A339.

* Cabeza J, Garcia PJ, Segura E, García P, Escudero F, La Rosa S, et al. Feasibility of Chlamydia trachomatis screening and treatment in pregnant women in Lima, Peru: a prospective study in two large urban hospitals. Sexually Transmitted Infections 2015;91(1):7-10.
Chandeying 1998 \{published data only\}

Chandeying V, Skov S, Kemapunmanus M, Law M, Geater A, Rowe P. Evaluation of two clinical protocols for the management of women with vaginal discharge in southern Thailand. Sexually Transmitted Infections 1998;74(3):194-201.

Cohen 1999 \{published data only\}

Cohen DA, Nsuami M, Martin DH, Farley TA. Repeated school-based screening for sexually transmitted diseases: a feasible strategy for reaching adolescents. Pediatrics 1999;104(6):1281-5.

\section{Cook 2007 \{published data only\}}

* Cook RL, Ostergaard L, Hillier SL, Murray PJ, Chang CCH, Comer DM, et al. Home screening for sexually transmitted diseases in high-risk young women: randomised controlled trial. Sexually Transmitted Infections 2007;83(4):286-91.

NCT00177437. Home screening for chlamydia surveillance. http://clinicaltrials.gov/show/NCT00177437 (accessed 9 June 2016).

\section{De Barbeyrac 2013 \{published data only\}}

De Barbeyrac B, Rahib D, De Diego S, Le Roy C, Bébéar C, Lydie N. Internet testing for Chlamydia trachomatis in France in 2012 [P3.025]. Sexually Transmitted Infections 2013;89(Suppl 1):A155-A156.

\section{Downing 2013 \{published data only\}}

Downing SG, Cashman C, McNamee H, Penney D, Russell DB, Hellard ME. Increasing chlamydia test of re-infection rates using SMS reminders and incentives. Sexually Transmitted Infections 2013;89(1):16-9.

\section{Gotz 2013 \{published data only\}}

Gotz HM, Wolfers MEG, Luijendijk A, Van den Broek IVF. Retesting for genital Chlamydia trachomatis among visitors of a sexually transmitted infections clinic: randomized intervention trial of home- versus clinic-based recall. BMC Infectious Diseases 2013;13(1):16.

\section{Graseck 2010 \{published data only\}}

*Graseck A, Secura G, Allsworth J, Madden T, Peipert J. Randomized trial of home vs. clinic-based screening for sexually transmitted infections in long-acting reversible Contraceptive users. Contraception 2010;82(2):187.

Graseck AS, Secura GM, Allsworth JE, Madden T, Peipert JF. Home compared with clinic-based screening for sexually transmitted infections: a randomized controlled trial. Obstetrics and Gynecology 2010;116(6):1311-8.

NCT01184157. Randomized trial of home versus clinic-based screening for sexually transmitted infections in long-acting reversible contraceptive users. http://clinicaltrials.gov/show/ NCT01184157. clintrials, (accessed 9 June 2016).

\section{Guy 2013 \{published data only\}}

ACTRN12613000808741. A randomised trial to evaluate whether point-of-care testing for chlamydia and gonorrhoea in remote Aboriginal communities can reduce repeat positivity at three months after treatment, among people with 
chlamydia or gonorrhoea infection. http://www.anzctr.org.au/ ACTRN12613000808741.aspx (accessed 9 June 2016).

Guy RJ. Point-of-care tests for Chlamydia and Gonorrhoea infections in remote Aboriginal communities: the Test, Treat and Go- The 'TTANGO' Trial. [Paper Ref 1065]. IUSTI Meeting. 2012 15-17 October; Melbourne, Australia.

Guy RJ, Natoli L, Ward J, Causer L, Hengel B, Whiley D, et al. A randomised trial of point-of-care tests for chlamydia and gonorrhoea infections in remote Aboriginal communities: Test, Treat ANd GO- the "TTANGO" trial protocol. BMC Infectious Diseases 2013;13(1):19.

Natoli L. The First Cluster Randomised Trial of a Molecular Chlamydia and Gonorrhoea Point-Of-Care Assay. Abstract P5.036. Sexually Transmitted Infections. 2013; Vol. 89, issue Suppl 1:A345.

\section{Hodgins 2002 \{published data only\}}

Hodgins S, Peeling RW, Dery S, Bernier F, LaBrecque A, Proulx JF, et al. The value of mass screening for chlamydia control in high prevalence communities. Sexually Transmitted Infections 2002;78 Suppl 1:i64-8.

\section{ISRCTN16261241 \{published data only\}}

ISRCTN16261241. Screening for Chlamydia trachomatis (CT) with routine Pap smears in general practice: a randomized controlled trial. http://www.isrctn.com/ISRCTN16261241 (accessed 9 June 2016).

\section{ISRCTN38526137 \{published data only\}}

ISRCTN38526137. A randomised controlled study of mouth swab testing versus same-day blood tests for human immunodeficiency virus (HIV) infection in young people attending a young person's community drug service. http:// isrctn.org/ISRCTN38526137 (accessed 9 June 2016).

\section{Jones 2007 \{published data only\}}

Jones HE, Altini L, De Kock A, Young T, Van De Wijgert JHHM. Home-based versus clinic-based self-sampling and testing for sexually transmitted infections in Gugulethu, South Africa: randomised controlled trial. Sexually Transmitted Infections 2007;83(7):552-7.

\section{Kekki 2001 \{published data only\}}

Kekki M, Kurki T, Pelkonen J, Kurkinen-Raty M, Cacciatore B, Paavonen J. Vaginal clindamycin in preventing preterm birth and peripartal infections in asymptomatic women with bacterial vaginosis: a randomized, controlled trial. Obstetric Gynecology 2001;97(5 Pt 1):643-8.

\section{Kersaudy-Rahib 2013 \{published data only\}}

Kersaudy-Rahib D, De Barbeyrac B, de Diego S, le Roy C, Bebear C, Lydie N. Home screening compared with clinic-based screening for Chlamydiae trachomatis in France: a randomised controlled trial. Lancet 2013;382:S53.

\section{Kiss 2004 \{published data only\}}

Kiss H, Petricevic L, Husslein P. Prospective randomised controlled trial of an infection screening programme to reduce the rate of preterm delivery. BMJ 2004;329(7462):371.

\section{Klovstad 2013 \{published data only\}}

* Klovstad H, Natas O, Tverdal A, Aavitsland P. Systematic screening with information and home sampling for genital Chlamydia trachomatis infections in young men and women in Norway: A randomized controlled trial.. BMC Infectious Diseases 2013;13(1):30-39.

NCT00283127. Home sampling versus conventional sampling for screening of urogenital Chlamydia trachomatis in young men and women - a randomized controlled trial. http:// clinicaltrials.gov/show/NCT00283127 (accessed 9 June 2016).

Lawton 2010 \{published data only\}

Lawton BA, Rose SB, Elley CR, Bromhead C, MacDonald EJ, Baker MG. Increasing the uptake of opportunistic chlamydia screening: a pilot study in general practice. Journal of Primary Health Care 2010;2(3):199-207.

\section{Martin 1997 \{published data only\}}

Martin DH, Eschenbach DA, Cotch MF, Nugent RP, Rao AV, Klebanoff MA, et al. Double-blind placebo-controlled treatment trial of Chlamydia trachomatis endocervical infections in pregnant women. Infectious Diseases in Obstetrics and Gynecology 1997;5(1):10-7.

\section{McGregor 1990 \{published data only\}}

McGregor JA, French JI, Richter R, Vuchetich M, Bachus V, Seo K, et al. Cervicovaginal microflora and pregnancy outcome: results of a double-blind, placebo-controlled trial of erythromycin treatment. American Journal of Obstetrics \& Gynecology 1990;163(5 Pt 1):1580-91.

\section{McGregor 1995 \{published data only\}}

French JI, McGregor JA, Parker R. Readily treatable reproductive tract infections and preterm birth among black women. American Journal of Obstetrics \& Gynecology 2006;194(6):1717-26.

* McGregor JA, French JI, Parker R, Draper D, Patterson E, Jones W, et al. Prevention of premature birth by screening and treatment for common genital tract infections: results of a prospective controlled evaluation. American Journal of Obstetrics \& Gynecology 1995;173(1):157-67.

\section{McKee 2011 \{published data only\}}

McKee DM, Rubin S, Alderman E, Fletcher J, Campos G. A pilot intervention to improve sexually transmitted infection testing for urban adolescents. Journal of Adolescent Health 2011;48(2):S65.

\section{Meyer 1991 \{published data only\}}

Meyer L, Job-Spira N, Bouyer J, Bouvet E, Spira A. Prevention of sexually transmitted diseases: a randomised community trial. Journal of Epidemiology and Community Health 1991;45(2):152-8.

\section{NCT00829517 \{published data only\}}

NCT00829517. Computer-assisted provision of reproductive health care. http://clinicaltrials.gov/show/NCT00829517 (accessed 9 June 2016). 


\section{NCT01654991 \{published data only\}}

NCT01654991. A randomized trial of home versus clinicbased STD testing among men. http://clinicaltrials.gov/show/ NCT01654991 (accessed 9 June 2016).

\section{Niza 2014 \{published data only\}}

Niza C, Rudisill C, Dolan P. Vouchers versus lotteries: what works best in promoting chlamydia screening? A cluster randomized controlled trial. Applied Economic Perspectives and Policy 2014;36(1):109-24

\section{Scholes 2006 \{published data only\}}

Scholes D, Grothaus L, McClure J, Reid R, Fishman P, Sisk $C$, et al. A randomized trial of strategies to increase chlamydia screening in young women. Preventive Medicine 2006;43(4):343-50

\section{Scholes 2007 \{published data only\}}

Scholes D, Heidrich FE, Yarbro P, Lindenbaum JE, Marrazzo JM. Population-based outreach for chlamydia screening in men: results from a randomized trial. Sexually Transmitted Diseases 2007;34(11):837-9.

\section{Senok 2005 \{published data only\}}

Senok A, Wilson P, Reid M, Scoular A, Craig N, McConnachie A, et al. Can we evaluate population screening strategies in UK general practice? A pilot randomised controlled trial comparing postal and opportunistic screening for genital chlamydial infection. Journal of Epidemiology and Community Health. 2005;59(3):198-204

\section{Shafer 2002 \{published data only\}}

* Shafer MA, Tebb KP, Pantell RH, Wibbelsman CJ, Neuhaus JM, Tipton AC, et al. Effect of a clinical practice improvement intervention on chlamydial screening among adolescent girls. JAMA: the journal of the American Medical Association 2002;288(22):2846-52.

Tebb K, A Shafer M. A clinical practice intervention to increase chlamydial screening: sustaining the gain and translating into practice 4 years later. Sexually Transmitted Infections 2011;87(Suppl 1):A321-A322.

\section{Smith 2014 \{published data only\}}

ACTRN12611000968976. Randomised controlled trial (RCT) of self-collection samples to increase chlamydia re-testing following a chlamydia diagnosis amongst clients attending two urban sexual health clinics. http://www.anzctr.org.au/ ACTRN12611000968976.aspx (accessed 9 June 2016).

Smith KS, Hocking J, Wand H. Home-based sample collection increases chlamydia retesting and detects additional repeat positive tests: a randomised controlled trial in three risk groups. [Abstract 022.7]. Sexually Transmitted Infections 2013;89(Suppl 1):A1-A428.

* Smith KS, Hocking JS, Chen M, Fairley CK, McNulty A, Read P, et al. Rationale and design of REACT: a randomised controlled trial assessing the effectiveness of home-collection to increase chlamydia retesting and detect repeat positive tests. $B M C$ Infectious Diseases 2014;14:223.

\section{Stevens-Simon 2002 \{published data only\}}

Stevens-Simon C, Rudnick M, Beach RK, Weinberg A. Screening positive urine pregnancy tests for sexually transmitted diseases expedites the treatment of infected adolescent gravidas. Journal of Maternal-Fetal and Neonatal Medicine 2002;11(6):391-5.

Tebb 2005 \{published data only\}

Tebb KP, Pantell RH, Wibbelsman CJ, Neuhaus JM, Tipton AC, Pecson SC, et al. Screening sexually active adolescents for Chlamydia trachomatis: what about the boys?. American Journal of Public Health 2005;95(10):1806-10.

Tebb 2009 \{published data only\}

Tebb KP, Wibbelsman C, Neuhaus JM, Shafer MA. Screening for asymptomatic chlamydia infections among sexually active adolescent girls during pediatric urgent care. Archives of Pediatrics and Adolescent Medicine 2009;163(6):559-64.

\section{Walker 2010 \{published data only\}}

ACTRN12605000411640. A computer alert to increase chlamydia testing of high risk women in general practice: a cluster randomised controlled trial. http://www.anzctr.org.au/ ACTRN12605000411640.aspx (accessed 9June 2016).

* Walker J, Fairley CK, Walker SM, Gurrin LC, Gunn JM, Pirotta MV, et al. Computer reminders for chlamydia screening in general practice: a randomized controlled trial. Sexually Transmitted Diseases 2010;37(7):445-50.

Walker J, Walker S, Fairley CK, Gunn J, Pirotta M, Gurrin L, et al. Computer reminders for chlamydia screening in general practice: a randomised controlled trial. Sexual Health 2009;6(4):363.

Walker, J. Computer reminders for chlamydia screening in general practice: a randomised controlled trial. [Abstract OS2.1.05]. ISSTDR/BASHH Meeting. 200928 June-1 July; London, UK.

\section{Xu 2011 \{published data only\}}

Xu F, Stoner B, Taylor S, Mena L, Tian L, Papp J, et al. Rescreening for chlamydial infection using home-based, self-obtained vaginal swabs: a randomised controlled trial in family planning clinic clients. Sexually Transmitted Infections 2011;87(Suppl 1):A75-A76.

\section{References to ongoing studies}

Hocking 2010 \{published data only\}

ACTRN12610000297022. Australian Chlamydia Control Effectiveness Pilot: a trial to determine whether annual chlamydia testing in general practice can lead to a reduction in chlamydia prevalence.. http://www.anzctr.org.au/ ACTRN12610000297022.aspx (accessed 9 June 2016).

Hocking J. The Australian Chlamydia Control Effectiveness Pilot (ACCEPt): early results from a randomised trial of annual chlamydia screening in general practice. [Abstract P5.017]. Sexually Transmitted Infections. 2013; Vol. 89, issue Suppl 1:A339-A340. 
Hocking J, Poznanski S, Vaisey A, Walker J, Wood A, Lewis D, et al. A multifaceted intervention to increase chlamydia testing in Australian general practice. Sexually Transmitted Infections 2011;87(Suppl 1):A199.

* Hocking J, Spark S, Guy R, Temple-Smith M, Fairley C, Kaldor J, et al. The Australian Chlamydia Control Effectiveness Pilot (ACCEPT): first results from a randomised trial of annual chlamydia screening in general practice. Sexually Transmitted Infections 2012;88(Suppl 1):A3-4.

Hocking J, Temple-Smith M, Poznanski S, Guy R, Low N, Donovan B, et al. Australian chlamydia control effectiveness pilot: preliminary results from a trial of chlamydia testing in general practice. Sexually Transmitted Infections 2011;87(Suppl 1):A202.

Hocking JS, Temple-Smith M, Low N, Donovan B, Gunn J, Law M, et al. Accept (Australian chlamydia control effectiveness pilot): design of the pilot evaluation. Sexual Health 2009;6(4):367-8

Yeung A. Is this ACCEPtable? High chlamydia prevalence among young men in Australia- results from the Australian Chlamydia Control Effectiveness Pilot(ACCEPt) [Paper Ref 202]. IUSTI Meeting. 2012 15-17 October; Melbourne, Australia.

\section{Kaldor 2010 \{published data only\}}

* ACTRN12610000358044. Sexually transmitted infections (STI) in remote communities: ImproVed \& Enhanced primary health care. http://www.anzctr.org.au/ACTRN12610000358044.aspx (accessed 9 June 2016).

Garton L. High levels of re-testing after chlamydia and gonorrhoea infection in remote Aboriginal communities 2009-2011: findings from the STRIVE trial [Paper Ref 608]. IUSTI Meeting. 2012 15-17 October; Melbourne, Australia.

Silver B. Chlamydia trachomatis, Neisseria gonorrhoea and Trichomonas vaginalis incidence in remote Australain Aboriginal communities: findings from the STRIVE trial. [Paper Ref 596]. IUSTI Meeting. 2012 15-17 October; Melbourne, Australia.

Ward J. Addressing endemic rates of STI in remote Aboriginal communities in Australia using quality improvement as a key strategy: the STRIVE Study. [Abstract P6.007]. Sexually Transmitted Infections. 2013; Vol. 89, issue Suppl 1:A371-A372.

\section{Lehtinen 2015 \{published data only\}}

Lehtinen M, Rana M, Korhonen S, Öhman H, Eriksson T, Apter D, et al. Characteristics of a randomized Chlamydia screening trial. Proceedings of the Thirteenth International Symposium on Human Chlamydial Infections. 2014 22-27 june; Asilomar, CA:409-412.

* Lehtinen, M, Apter, D, Baussano, I, et al. Characteristics of a cluster-randomized phase IV human papillomavirus vaccination effectiveness trial. Vaccine 2015;33(10):1284-90.

NCT01195220 \{published data only\}

NCT01195220. Project AWARE: using the emergency department (ED) to prevent sexually transmitted infections (STIS) in youth.
http://clinicaltrials.gov/show/NCT01195220 (accessed 9 June 2016).

\section{Additional references}

\section{Althaus 2010}

Althaus CL, Heijne JCM, Roellin A, Low N. Transmission dynamics of Chlamydia trachomatis affect the impact of screening programmes. Epidemics 2010;2(3):123-31.

\section{Althaus 2012}

Althaus CL, Turner KM, Schmid BV, Heijne JC, Kretzschmar M, Low N. Transmission of Chlamydia trachomatis through sexual partnerships: a comparison between three individualbased models and empirical data. Journal of the Royal Society Interface 2012;9:136-46.

\section{Batteiger 2010a}

Batteiger BE, Xu F, Johnson RE, Rekart ML. Protective immunity to Chlamydia trachomatis genital infection: evidence from human studies. Journal of Infectious Diseases 2010;201(Suppl 2):178-89.

\section{Batteiger 2010b}

Batteiger BE, Tu W, Ofner S, Van Der Pol B, Stothard DR, Orr DP, et al. Repeated Chlamydia trachomatis genital infections in adolescent women. Journal of Infectious Diseases 2010;201(1):42-51.

\section{Bender 2011}

Bender N, Herrmann B, Andersen B, Hocking JS, Van Bergen J, Morgan J, et al. Chlamydia infection, pelvic inflammatory disease, ectopic pregnancy and infertility: cross-national study. Sexually Transmitted Infections 2011;87(7):601-8.

\section{Brunham 2005}

Brunham RC, Rey-Ladino J. Immunology of Chlamydia infection: implications for a Chlamydia trachomatis vaccine. Nature Reviews Immunology 2005;5(2):149-61.

\section{Campbell 2005}

Campbell MK, Fayers PM, Grimshaw JM. Determinants of the intracluster correlation coefficient in cluster randomized trials: the case of implementation research. Clinical Trials 2005;2(2):99-107.

\section{Campbell 2006}

Campbell R, Mills N, Sanford E, Graham A, Low N, Peters TJ. Does population screening for Chlamydia trachomatis raise anxiety among those tested? Findings from a population based chlamydia screening study. BMC Public Health 2006;6:106. [DOI: 10.1186/1471-2458-6-106]

\section{CDC 2015}

Centers for Disease Control and Prevention. Sexually Transmitted Disease Surveillance 2014. Atlanta: U.S. Department of Health and Human Services, 2015. 


\section{Datta 2012}

Datta SD, Torrone E, Kruszon-Moran D, Berman S, Johnson R, Satterwhite $\mathrm{CL}$, et al. Chlamydia trachomatis trends in the United States among persons 14 to 39 years of age, 1999-2008. Sexually Transmitted Diseases 2012;39(2):92-6.

\section{DoHA 2016}

Australian Government Department of Health and Ageing. National Notifiable Diseases Surveillance System. http:// www9.health.gov.au/cda/Source/CDA-index.cfm (accessed 9 June 2016).

\section{ECDC 2014}

European Centre for Disease Prevention and Control. Chlamydia Control in Europe: Literature Review. Technical report. Stockholm: ECDC, 2014.

\section{ECDC 2015}

European Centre for Disease Prevention and Control. Annual epidemiological report. Sexually transmitted infections, including HIV and blood-borne viruses 2014. www.ecdc.europa.eu (accessed 9 June 2016).

\section{Egger 1997}

Egger M, Davey Smith G, Schneider M, Minder C. Bias in meta-analysis detected by a simple, graphical test. BMJ 1997;315(7109):629-34.

\section{Epidata [Computer program]}

Lauritsen JM. EpiData Data Entry, Data Management and basic Statistical Analysis System.. Version Version 3.1. Odense, Denmark: EpiData Association, 2005.

\section{Fleming 1999}

Fleming DT, Wasserheit JN. From epidemiological synergy to public health policy and practice: the contribution of other sexually transmitted diseases to sexual transmission of HIV infection. Sexually Transmitted Infections 1999;75(1):3-17.

\section{Geisler 2013}

Geisler WM, Lensing SY, Press CG, Hook EW 3rd. Spontaneous resolution of genital Chlamydia trachomatis infection in women and protection from reinfection. Journal of Infectious Diseases 2013;207(12):1850-6. [PUBMED: 23470847]

\section{Glassman 2015}

Glassman JR, Potter SC, Baumler ER, Coyle KK. Estimates of intraclass correlation coefficients from longitudinal grouprandomized trials of adolescent HIV/STI/pregnancy prevention programs. Health Education \& Behavior 2015;42(4):545-53.

\section{Gottlieb 2010}

Gottlieb SL, Berman SM, Low N. Screening and treatment to prevent sequelae in women with Chlamydia trachomatis genital infection: how much do we know?. Journal of Infectious Diseases 2010;201(Suppl 2):S156-S167.

\section{Gottlieb 2011}

Gottlieb SL, Stoner BP, Zaidi AA, Buckel C, Tran M, Leichliter JS, et al. A prospective study of the psychosocial impact of a positive Chlamydia trachomatis laboratory test. Sexually Transmitted Diseases 2011;38(11):1004-11.

\section{Gottlieb 2013}

Gottlieb SL, Xu F, Brunham RC. Screening and treating Chlamydia trachomatis genital infection to prevent pelvic inflammatory disease: interpretation of findings from randomized controlled trials. Sexually Transmitted Diseases 2013;40(2):97-102.

\section{Gotz 2005}

Gotz HM, Van Bergen JE, Veldhuijzen IK, Broer J, Hoebe CJ, Richardus JH. A prediction rule for selective screening of Chlamydia trachomatis infection. Sexually Transmitted Infections 2005;81(1):24-30.

\section{Hager 1983}

Hager D, Eschenbach D. Criteria for diagnosis and grading of salpingitis. Obstetrics and Gynecology 1983;61(1):113-4.

\section{Harbord 2005}

Harbord RM, Egger M, Sterne JAC. A modified test for smallstudy effects in meta-analyses of controlled trials with binary endpoints. Statistics in Medicine 2006;25(20):3443-57. [DOI: 10.1002/sim.2380]

\section{Herzog 2012}

Herzog SA, Althaus CL, Heijne JC, Oakeshott P, Kerry S, Hay P, et al. Timing of progression of Chlamydia trachomatis infection to pelvic inflammatory disease: a mathematical modelling study. BMC Infectious Diseases 2012;12(1):187.

\section{Herzog 2013}

Herzog SA, Heijne JCM, Scott P, Althaus CL, Low N. Direct and indirect effects of screening for Chlamydia trachomatis on the prevention of pelvic inflammatory disease: a mathematical modelling study. Epidemiology 2013;24(6):854-62.

\section{Higgins 2002}

Higgins JP, Thompson SG. Quantifying heterogeneity in a metaanalysis. Statistics in Medicine 2002;21(11):1539-58.

\section{Higgins 2011a}

Higgins JPT, Green S (editors). Cochrane Handbook for Systematic Reviews of Interventions. Version 5.1.0 [updated March 2011]. The Cochrane Collaboration, 2011. Available from www.cochrane-handbook.org. Chichester, UK: John Wiley \& Sons.

\section{Higgins 2011b}

Higgins JPT, Altman DG, Sterne JAC (editors). Chapter 8: Assessing risk of bias in included studies. In: Higgins JPT, Green S (editors). Cochrane Handbook for Systematic Reviews of Interventions. Version 5.1.0 [updated March 2011]. The Cochrane Collaboration, 2011. Available from www.cochranehandbook.org. Chichester, UK: John Wiley \& Sons.

\section{Hillis 1997}

Hillis SD, Owens LM, Marchbanks PA, Amsterdam LF, MacKenzie WR. Recurrent chlamydial infections increase the risks of hospitalization for ectopic pregnancy and pelvic 
inflammatory disease. American Journal of Obestetrics \& Gynecology 1997;176(1 Pt 1):103-7.

\section{Hocking 2012}

Hocking JS, Spark S, Guy R, Temple-Smith M, Fairley CK, Kaldor J, et al. The Australian chlamydia control effectiveness pilot (ACCEPt): first results from a randomised controlled trial of annual chlamydia screening in general practice. Oral presentation 08. Abstracts of the 4th joint BASHH-ASTDA meeting; 2012 June 27-29; Brighton (UK). Sexually Transmitted Infections 2012;88(Suppl 1):A3-A4.

\section{Kavanagh 2013}

Kavanagh K, Wallace LA, Robertson C, Wilson P, Scoular A. Estimation of the risk of tubal factor infertility associated with genital chlamydial infection in women: a statistical modelling study. International Journal of Epidemiology 2013;42(2):493-503.

\section{Kohlhoff 2008}

Kohlhoff SA, Hammerschlag MR. Chapter 83. Gonococcal and chlamydial infections in infants and children. In: Holmes KK, Sparling PF, Stamm WE, Piot P, Wasserheit JN, Corey L, et al. editor(s). Sexually Transmitted Diseases. Vol. 4, New York: McGraw-Hill, 2008:1613-27.

\section{Land 2010}

Land JA, Van Bergen JE, Morre SA, Postma MJ. Epidemiology of Chlamydia trachomatis infection in women and the costeffectiveness of screening. Human Reproduction Update 2010;16(2):189-204.

\section{Low 2009}

Low N, Bender N, Nartey L, Shang A, Stephenson JM. Effectiveness of chlamydia screening: systematic review. International Journal of Epidemiology 2009;38(2):435-48.

\section{Low 2012}

Low N, Cassell JA, Spencer B, Bender N, Martin Hilber A, van Bergen J, et al. Chlamydia control activities in Europe: cross-sectional survey. European Journal of Public Health 2012;22(4):556-61. [DOI: 10.1093/eurpub/ckr046]

\section{Low 2013}

Low N, Geisler WM, Stephenson JM, Hook EW 3rd, Aral SO, Fenton KA, et al. Chlamydia control: a comparative review from the USA and UK. The New Public Health and STD/HIV Prevention. New York: Springer, 2013. [DOI: 10.1007/978-1-4614-4526-5_20]

\section{Manhart 2013}

Manhart LE, Gillespie CW, Lowens MS, Khosropour CM, Colombara DV, Golden MR, et al. Standard treatment regimens for nongonococcal urethritis have similar but declining cure rates: a randomized controlled trial. Clinical Infectious Diseases 2013;56(7):934-42.

\section{Meyers 2007}

Meyers DS, Halvorson H, Luckhaupt S. Screening for chlamydial infection: an evidence update for the U.S. Preventive Services Task Force. Annals of Internal Medicine 2007;147(2):134-41.

\section{Mills 2006}

Mills N, Daker-White G, Graham A, Campbell R. Population screening for Chlamydia trachomatis infection in the UK: a qualitative study of the experiences of those screened. Family Practice 2006;23(5):550-7.

\section{NCSP 2014}

Public Health England. National chlamydia screening programme standards (seventh edition). Available from https://www.gov.uk/government/uploads/system/uploads/ attachment_data/file/477343/NCSP_Standards_7th_edition_ FINAL.pdf. London, (accesed 9 June 2016).

\section{Newman 2015}

Newman L, Rowley J, Vander Hoorn S, Wijesooriya NS, Unemo M, Low N, et al. Global estimates of the prevalence and incidence of four curable sexually transmitted infections in 2012 based on systematic review and global reporting. PLOS ONE 2015;10(12):e0143304. [doi:10.1371/journal.pone.0143304]

\section{NICE 2012}

UK National Institute of Health and Care Excellence. Appendix D: Methodology checklist: cohort studies. In: Process and Methods Guides. The Guidelines Manual - Appendices B-1. National Institute of Health and Care Excellence, 2012: 21-4. Available from http://publications.nice.org.uk/pmg6.

\section{O'Farrell 2013}

O'Farrell N, Weiss HA. Effect of chlamydia diagnosis on heterosexual relationships. International Journal of STD \& AIDS 2013;24(9):722-6.

\section{Paavonen 2008}

Paavonen J, Westrom L, Eschenbach D. Holmes KK, Sparling PF, Stamm WE, et al. Chapter 56: Pelvic inflammatory disease. Sexually Transmitted Diseases. 4th Edition. New York: McGraw Hill Medical, 2008:1017-50.

\section{Peterman 2009}

Peterman TA, Gottlieb SL, Berman SM. Chlamydia trachomatis screening: what are we trying to do? [Commentary]. International Journal of Epidemiology 2009;38(2):449-51.

\section{Price 2012}

Price MJ, Ades AE, Welton NJ, Macleod J, Turner K, Simms I, et al. How much tubal factor infertility is caused by Chlamydia? Estimates based on serological evidence corrected for sensitivity and specificity. Sexually Transmitted Diseases 2012;39(8):608-13.

\section{RACGP 2012}

Royal Australian College of General Practitioners. Guidelines for Preventive Activities in General Practice 8th Edition. The Royal Australian College of General Practitioners (RACGP). Available from http://www.racgp.org.au/your-practice/guidelines/ redbook/. Melbourne, (accessed 9 June 2016).

\section{Raffle 2007}

Raffle A, Gray M. Screening: Evidence and practice. Screening: Evidence and Practice. Oxford: Oxford University Press, 2007. 


\section{Redmond 2015}

Redmond SM, Alexander-Kisslig K, Woodhall SC, Van den Broek IVF, Van Bergen J, Ward H, et al. Genital chlamydia prevalence in Europe and non-European high-income countries: systematic review and meta-analysis. PLOS One 2015;10(1):e0115753.

\section{Reeves 2011}

Reeves BC, Deeks JJ, Higgins JPT, Wells GA. Chapter 13: Including non-randomized studies. In: Higgins JPT, Green $S$ (editors), Cochrane Handbook for Systematic Reviews of Interventions Version 5.1.0 [updated March 2011]. The Cochrane Collaboration, 2011. Available from www.cochranehandbook.org. Chichester: John Wiley \& Sons Ltd.

\section{Regan 2008}

Regan DG, Wilson DP, Hocking JS. Coverage is the key for effective screening of Chlamydia trachomatis in Australia. Journal of Infectious Diseases 2008;198(3):349-58.

\section{RevMan [Computer program]}

The Nordic Cochrane Centre, The Cochrane Collaboration. Review Manager (RevMan). Version 5.3. Copenhagen: The Nordic Cochrane Centre, The Cochrane Collaboration, 2014.

\section{Riley 2011}

Riley RD, Higgins JP, Deeks JJ. Interpretation of random effects meta-analyses. BMJ 2011;342:d549.

\section{Rours 2011}

Rours GI, De Krijger RR, Ott A, Willemse HF, De Groot R, Zimmermann LJ, et al. Chlamydia trachomatis and placental inflammation in early preterm delivery. European Journal of Epidemiology 2011;26(5):421-8.

\section{Scott LaMontagne 2007}

Scott LaMontagne D, Baster K, Emmett L, Nichols T, Randall S, McLean L, et al. Incidence and reinfection rates of genital chlamydial infection among women aged 16 - 24 years attending general practice, family planning and genitourinary medicine clinics in England: a prospective cohort study by the Chlamydia Recall Study Advisory Group. Sexually Transmitted Infections 2007;83(4):292-303.

\section{Smith 2007}

Smith KJ, Cook RL, Roberts MS. Time from sexually transmitted infection acquisition to pelvic inflammatory disease development: influence on the cost-effectiveness of different screening intervals. Value in Health 2007;10(5):358-66.

\section{Stamm 2008}

Stamm WE, Holmes KK, Sparling PF, Stamm WE, Piot P, Wasserheit JN, et al. Chlamydia trachomatis infections of the adult. Sexually Transmitted Diseases. 4th Edition. New York: McGraw Hill Medical, 2008:575-93.

\section{Stergachis 1993}

Stergachis A, Scholes D, Heidrich FE, Sherer DM, Holmes KK, Stamm WE. Selective screening for Chlamydia trachomatis infection in a primary care population of women. American Journal of Epidemiology 1993;138(3):143-53.

\section{UKNSC 2013}

UK National Screening Committee. UK Screening Portal. Screening Information. What is a screening?. https:// www.gov.uk/guidance/nhs-population-screening-explained (accessed 9 June 2016).

\section{Ukoumunne 1999}

Ukoumunne OC, Gulliford MC, Chinn S, Sterne JAC, Burney PG. Methods for evaluating area-wide and organisation-based interventions in health and health care: a systematic review. Health Technology Assessment 1999;3(5):iii-92.

\section{USPSTF 2014}

U.S. Preventive Services Task Force. Final Recommendation Statement. Gonorrhea and Chlamydia: Screening, September 2014. Available from http:// www.uspreventiveservicestaskforce.org/Page/Document/ RecommendationStatementFinal/chlamydia-and-gonorrheascreening 2014; Vol. (accessed 9 June 2016).

\section{Walker 2012}

Walker J, Tabrizi SN, Fairley CK, Chen MY, Bradshaw CS, Twin J, et al. Chlamydia trachomatis incidence and re-infection among young women: behavioural and microbiological characteristics. PloS One 2012;7(5):e37778.

* Indicates the major publication for the study

\section{CHARACTERISTICS OF STUDIES}

Characteristics of included studies [ordered by study ID]

Andersen 2011

Methods Study design:

Setting: population-based screening programme in Aarhus county, Denmark

Study duration: 1 year from screening test offer for PID and epididymitis; 9 years from screening offer for ectopic pregnancy and infertility 
Andersen 2011 (Continued)

\section{Inclusion criteria}

- Women and men born in 1974,1975 , or 1976

- Living in the county of Aarhus on 13 October 1997 (aged 21-24 years at initiation of the study).

\section{Exclusion criteria:}

- non-Danish citizens (missing personal identification number (CPR number))

Interventions

Enrolment: through population registry

Intervention group:invitation for CT testing, $\mathrm{N}=9000$ (4000 women, 5000 men)

All participants in the intervention group received an invitation by direct mail to be tested for $C$. trachomatis by taking a sample at home and mailing it directly to the diagnostic laboratory. The intervention group was further subdivided into 2 randomly assigned groups (group 1 and group 2), each containing 2000 women and 2500 men. The difference between intervention groups 1 and 2 was that group 1 participants received the test package together with the invitation, whereas group 2 participants had to return a franked, preaddressed reply card to the study centre to receive the test package. (For the purpose of current analysis, we merged the data for the 2 types of approach strategies.)

Co-interventions: Infected individuals received instructions to contact a general practitioner (GP) for medical treatment and partner notification. People in the intervention groups also had the opportunity of receiving usual care, which consisted of swab samples obtained at a physician's office. All C. trachomatis positive individuals also received a second offer to be tested for the infection by the use of a mail-in home-obtained sample 24 weeks after the initial test.

\section{Control group: usual care, $\mathrm{N}=\mathbf{2 1 , 4 3 9}$ (11,459 women, 9980 men)}

No contact during the study period. Individuals in the intervention groups as well as those in the control group had the opportunity of usual care consisting of an endocervical and/or urethral swab sample taken by a physician in office. Free testing is available in Denmark. At 3 months $9.4 \%$ of women in the control group and $9.0 \%$ of women in the intervention group had been tested as part of usual care. For men, the corresponding figures were $1.4 \%$ and $1.5 \%$ for the 2 groups, respectively.

Co-interventions: There are no recommendations with regard to repeated testing in any age group, but, as a general rule, samples are taken because of symptoms or intrauterine procedures such as induced abortion or insertion of an intrauterine device (Andersen 2002).

\section{Primary outcomes}

- Incidence of upper genital tract infection in women in the 12 months after the offer of screening (intervention group vs control group)

- Incidence of upper genital tract infection in women in the 12 months after the offer of screening (intervention group only; non-participants vs participants)

- Incidence of epididymitis in men in the 12 months after the offer of screening (intervention group vs control group)

- Incidence of epididymitis in men in the 12 months after the offer of screening (intervention group only; non-participants vs participants)

\section{Secondary outcomes}

- Proportion of participants receiving the intervention at 3 months (uptake of screening)

Investigators followed the entire study population (comprising individuals who accepted the test offer, those who did not and the control group) using central governmental registers during the first year after the test offer to assess the rates of PID (women) or epididymitis (men) diagnosed according to the Danish versions of the International Classification of Disease Codes (ICD-10).

Notes 
support from the Danish Medical Research Council (grant no 22-02-0540), the NOVO Foundation and the Research Foundation in Aarhus County.

\section{Risk of bias}

\begin{tabular}{lll}
\hline Bias & Authors' judgement & Support for judgement \\
\hline $\begin{array}{l}\text { Random sequence genera- } \\
\text { tion (selection bias) }\end{array}$ & Low risk & Comment: computer-based randomisation \\
\hline $\begin{array}{l}\text { Allocation concealment } \\
\text { (selection bias) }\end{array}$ & Low risk & $\begin{array}{l}\text { Comment: Individuals selected for screening invitation did not know there was } \\
\text { a control group, so unlikely to have affected decision to take part or not; con- } \\
\text { trol group did not know they were in a trial. }\end{array}$
\end{tabular}

\begin{tabular}{|c|c|c|}
\hline $\begin{array}{l}\text { Blinding of participants } \\
\text { and personnel (perfor- } \\
\text { mance bias) } \\
\text { All outcomes }\end{array}$ & High risk & $\begin{array}{l}\text { Comment: Blinding was not used. Participants in intervention group might re- } \\
\text { ceive different advice about risks of upper genital tract infection and about } \\
\text { what to do if they have symptoms. Control group did not receive any informa- } \\
\text { tion. }\end{array}$ \\
\hline
\end{tabular}

Blinding of outcome as- Low risk
sessment (detection bias) All outcomes

Comments: Data on blinding of outcome assessment was not provided. The review authors judge that the outcome is not likely to be influenced by lack of blinding.

The same applies for both primary outcomes: PID and epididymitis.

\begin{tabular}{|c|c|c|}
\hline $\begin{array}{l}\text { Incomplete outcome data } \\
\text { (attrition bias) } \\
\text { All outcomes }\end{array}$ & Low risk & Comment: The same applies for both primary outcomes: PID and epididymitis \\
\hline $\begin{array}{l}\text { Selective reporting (re- } \\
\text { porting bias) }\end{array}$ & Low risk & $\begin{array}{l}\text { Comment: The study protocol is not available, but it is clear that the published } \\
\text { reports include all expected outcomes, including those that were pre-specified } \\
\text { (convincing text of this nature may be uncommon) }\end{array}$ \\
\hline Other bias & Unclear risk & $\begin{array}{l}\text { Contamination is a risk, if women in the control group continued to be tested } \\
\text { at the same rate as during the study period, the percentage tested by the time } \\
\text { the outcome PID was measured might have been higher. This could reduce the } \\
\text { size of any difference between intervention and control groups. Not enough in- } \\
\text { formation to know what proportion of control group was tested during the fol- } \\
\text { low-up period. }\end{array}$ \\
\hline
\end{tabular}

Garcia 2012

Methods Study design: cluster-randomised trial of a multicomponent intervention for the prevention of sexually transmitted disease in female sex workers and the general population

Setting: urban communities in Peru

Study duration: 4 years

Participants Female sex workers (FSW). 24 cities assessed for eligibility. 20 cities cluster-randomised in 10 pairs, 4483 FSW (range 75-209 per city enrolled, 4465 provided samples, 4413 completed survey)

\section{Inclusion criteria:}

- Cities with $>50,000$ inhabitants

\section{Exclusion criteria:}


Garcia 2012 (Continued)

- Lima (too big), cities taking part in other STI intervention trials

Interventions

Enrolment: All eligible cities randomised. Sex venues "includ[ing] brothels, bars, nightclubs, streetbased venues and truck stops" were mapped and visited by mobile teams (in all 24 cities assessed for eligibility). Baseline survey participants were non-randomly sampled, consecutive FSW from all venues in a city or until $200 \mathrm{FSW}$ per city sampled (p. 1121). In intervention cities only, mobile teams approached FSWs in sex venues in spaces varying from private bedrooms to small side rooms at bars. The baseline survey took place from November 2002 to April 2003, outcome surveys and sampling took place from September to December in both 2005 and 2006.

Intervention group (median population 190,102, range 54,148-272,231)

Quote: "We created mobile teams and laboratory support systems in intervention cities to deliver clinical and preventive services to FSWs from July, 2003, to December, 2006. Each mobile team was made up of a nurse or midwife and an FSW peer educator. Mobile teams' activities included two visits to each sex venue in each of 20 cycles of 8 weeks to provide periodic presumptive treatment with metronidazole for trichomoniasis and bacterial vaginosis to FSWs who were not pregnant or breastfeeding, and willing to forego alcohol consumption for $72 \mathrm{~h}$. Self obtained vaginal swabs were collected for local T vaginalis culture and for nucleic acid amplification in Lima for $\mathrm{N}$ gonorrhoea and $\mathrm{C}$ trachomatis. The teams returned 1 week later, providing test results and treatment for specific infections identified (ciprofloxacin for gonorrhoea, azithromycin for chlamydia, and metronidazole for positive $T$ vaginalis cultures not treated a week earlier). FSWs were encouraged to visit local government clinics for periodic syphilis and HIV testing, and for interim STI symptoms. Laboratory technicians joined mobile teams from February, 2005, to December, 2006, and did rapid syphilis testing."

Co-interventions: "Mobile teams also provided motivational interviewing to promote condom use by sex workers, and gave up to 15 condoms to each FSW in each 8 week cycle in the first 1.5 years, then increased to 50 condoms per cycle. For the general population, the local non-governmental organisation APROPO implemented social marketing of a low-cost condom, the OK condom, through pharmacies in intervention cities only, from October, 2003, to October, 2004, then more widely."

Control group: usual care:10 cities (median population 135,187, range 50,183-291,408)

Usual care: "status quo services", no other description reported

Outcomes Primary outcomes

- Prevalence of chlamydia infection (chlamydia test positivity) measured at baseline, 3 years and 4 years

- Composite STI prevalence ( Chlamydia, gonorrhoea, trichomonas, syphilis, HIV) measured in at baseline, 3 years and 4 years

\section{Secondary outcomes}

- none

Each sex venue visited during 20 cycles lasting 8 weeks each. Continuous mapping to record closed down and new venues. For evaluation surveys, FSW surveyed by quota sampling individuals at randomly selected venues and times.

Notes

Institutional review boards at the University of Washington, Universidad Peruana Cayetano Heredia, and US Naval Medical Research Center Detachment approved the protocol, consent forms, and instruments. Eligible FSWs older than 14 years and survey participants provided verbal consent. Trial registration: ISRCTN43722548. This research was supported by the Wellcome Trust-Burroughs Wellcome Fund Infectious Disease Initiative 059131/Z/99/Z, 078835/Z/05/Z, and 078835/Z/05/B; National Institutes of Health NIAID STD Cooperative Research Center Al31448, Center for AIDS Research AI27757, and CIPRA U19 AI053218; and USAID-Peru.

\section{Risk of bias}

Authors' judgement Support for judgement 
Garcia 2012 (Continued)
Random sequence genera- Low risk
Comment: computer-generated randomisation sequence (see below) tion (selection bias)

\begin{tabular}{ll}
\hline $\begin{array}{l}\text { Allocation concealment } \\
\text { (selection bias) }\end{array}$ & Quote: "Within each pair, one city was randomly assigned to an intervention \\
& with an S-PLUS (version 3·1) program written by JPH; the other city was as- \\
& signed to standard care." (p. 1121), Comment: No chance to know allocation in \\
& advance or to change once allocated
\end{tabular}

\begin{tabular}{|c|c|c|}
\hline $\begin{array}{l}\text { Blinding of participants } \\
\text { and personnel (perfor- } \\
\text { mance bias) }\end{array}$ & Low risk & $\begin{array}{l}\text { Quote: "US and UK investigators (except JPH) were masked to identities of in- } \\
\text { tervention cities until completion of all surveys and laboratory testing." "Field- } \\
\text { workers and the Peruvian study team could not be masked." (p. 1121) }\end{array}$ \\
\hline
\end{tabular}

\begin{tabular}{|c|c|c|}
\hline $\begin{array}{l}\text { Blinding of outcome as- } \\
\text { sessment (detection bias) } \\
\text { All outcomes }\end{array}$ & Low risk & $\begin{array}{l}\text { Quote: "Laboratory personnel and the data analyst (KKT) were masked to as- } \\
\text { signments until final analysis." (p. 1121) }\end{array}$ \\
\hline $\begin{array}{l}\text { Incomplete outcome data } \\
\text { (attrition bias) } \\
\text { All outcomes }\end{array}$ & Low risk & Comment: very high participation in cross-sectional surveys \\
\hline $\begin{array}{l}\text { Selective reporting (re- } \\
\text { porting bias) }\end{array}$ & Low risk & Comment: primary outcome same as in protocol and in the trial registration \\
\hline Other bias & Low risk & - \\
\hline
\end{tabular}

\section{Oakeshott 2010}

Methods

Study design: Individually randomised controlled trial comparing immediate with deferred screening

Setting: common rooms, lecture theatres, and student bars at universities and further education colleges in London..

Study period: 1 year from acceptance of offer of chlamdia testing

Sexually active female students 16-27 years ( $N=2563)$
Inclusion criteria:
- Aged 27 or less
- Sexually active females
Exclusion criteria:
- Never had sexual intercourse
- Had been tested for chlamydial infection in the past 3 months
- Pregnant

Interventions

Enrolment: Investigators personally recruited women in bars, common rooms and lecture theatres at 20 London universities and further education colleges, randomising them between September 2004 and October 2006.

\section{Intervention group: screening:1273 women randomised (but 14 excluded = 1259 included)}

Vaginal swab samples were obtained (at nearest lavatory) and analysed for $C$. trachomatis. In case of infection the woman was contacted and urged to contact a physician for treatment and partner notification. 
Oakeshott 2010 (Continued)

\section{Control group:deferred screening:1290 randomised (but 20 excluded = 1270 included)}

Samples were obtained (at nearest lavatory) but stored for 12 months. Women were obliged to seek a health care provider if they considered themselves at risk or if they had symptoms (= standard care).

\section{Outcomes}

\section{Primary outcomes}

- Incidence of pelvic inflammatory disease in women evaluated in the 12 months after recruitment; assessed by a doctor as probable, with a clinical diagnosis of PID which was treated (modified Hager's criteria - pelvic pain, cervical motion tenderness, uterine or adnexal tenderness)

- Incidence of pelvic inflammatory disease in women evaluated in the 12 months after recruitment; assessed by a doctor as possible, with clinical features of PID (abdominal pelvic pain with features of PID, which may have responded to antimicrobial therapy, but no record of cervical excitation or uterine or adnexal tenderness; or longstanding abdominal pain consistent with endometriosis, but some features of PID - for example, uterine tenderness, and unable to confirm if antimicrobial therapy had a benefit)

\section{Secondary outcomes: none reported}

Outcomes measured via questionnaires, answered by participants by e-mail, postal questionnaires or telephone calls. Non-responders were followed up by contacting a GP.

\section{Notes}

The study was approved by Wandsworth research ethics committee (reference 03.0012). Trial registration number: NCT00115388. This study was supported by the BUPA Foundation (grant No 684/GB14B). TMA sample collecting kits were provided by Gen-Probe (San Diego, CA).

\begin{tabular}{|c|c|c|}
\hline \multicolumn{3}{|l|}{ Risk of bias } \\
\hline Bias & Authors' judgement & Support for judgement \\
\hline $\begin{array}{l}\text { Random sequence genera- } \\
\text { tion (selection bias) }\end{array}$ & Low risk & Comment: random number tables were used (p. 2). \\
\hline $\begin{array}{l}\text { Allocation concealment } \\
\text { (selection bias) }\end{array}$ & Low risk & $\begin{array}{l}\text { Comment: Sealed sample packs, which contained the completed, unopened } \\
\text { questionnaires and consent forms were allocated (blinded procedure) (p. 2). }\end{array}$ \\
\hline $\begin{array}{l}\text { Blinding of participants } \\
\text { and personnel (perfor- } \\
\text { mance bias) } \\
\text { All outcomes }\end{array}$ & Low risk & $\begin{array}{l}\text { Comment: Participants were blind to group allocation except for those in the } \\
\text { interventions group with baseline samples that tested positive for chlamydia } \\
\text { and who were referred for treatment and } 38 \text { women with indeterminate test } \\
\text { results who were asked to post a repeat sample (masking p. 2). Samples were } \\
\text { obtained before allocation and therefore the recruiting personnel could not } \\
\text { be aware of allocation. Not clear what happened with indeterminate results in } \\
\text { control group if tested after } 12 \text { months. }\end{array}$ \\
\hline $\begin{array}{l}\text { Blinding of outcome as- } \\
\text { sessment (detection bias) } \\
\text { All outcomes }\end{array}$ & Low risk & $\begin{array}{l}\text { Comment: A panel of } 3 \text { genitourinary medicine physicians assessed patient } \\
\text { questionnaires and medical records using standardised criteria; they were } \\
\text { blinded to trial group (p. 2). }\end{array}$ \\
\hline $\begin{array}{l}\text { Incomplete outcome data } \\
\text { (attrition bias) } \\
\text { All outcomes }\end{array}$ & Low risk & $\begin{array}{l}\text { Comment: In the intervention group, } 68 \text { were lost to follow-up; in the control } \\
\text { group } 84 \text { were lost to follow-up. These numbers are very low and unlikely to in- } \\
\text { fluence the results. }\end{array}$ \\
\hline \multirow[t]{2}{*}{$\begin{array}{l}\text { Selective reporting (re- } \\
\text { porting bias) }\end{array}$} & Low risk & $\begin{array}{l}\text { Comment: The single primary aim from the protocol is reported in the publica- } \\
\text { tion. }\end{array}$ \\
\hline & & $\begin{array}{l}2 \text { primary aims from the introduction section are reported in the results. The } \\
\text { protocol is available. }\end{array}$ \\
\hline
\end{tabular}


Oakeshott 2010 (Continued)

Other bias High risk
Contamination of intervention: possibility of independent testing in the year of the study, which would reduce differences between the intervention and control group (about $22 \%$ in each group were tested);

Received funding of diagnostic tests from manufacturer.

\section{Ostergaard 2000}

Methods Study design: cluster-randomised controlled trial

Setting: 17 high schools in Aarhus county, Denmark

Study duration: 1 year after the offer of screening

\section{Participants}

High school female students in Aarhus region aged $15-19+$ years $(N=5487$ randomised, $N=1700$ provided follow-up data)

\section{Inclusion criteria:}

- All 17 high schools in Aarhus county

- Female students who were sexually experienced

Exclusion criteria: not mentioned
Enrolment: The report does not include a description about how schools were approached or how home sampling kits/instructions for control arm were given. Possibly, investigators may have used the baseline questionnaire to identify sexually experienced students ("eligible responders"), telling these to return specimen. Enrolment took place between January and April 1997.

\section{Intervention group: home sampling:2603 women in 8 schools}

Quote: "[H]ome sampling kits given to the students at the end of gatherings at which information about the $C$. trachomatis diseases and the study was given. The home sampling kit consisted of a vaginal pipette (containing $5 \mathrm{~mL}$ sterile sodium chloride) for obtaining vaginal flush samples (women) and a urine sample (men), a questionnaire, written instructions on how to obtain the sample, and a self-addressed, stamped envelope. Students were instructed to administer the vaginal pipette for sampling on receipt. The samples obtained at home were mailed by the students directly to the Department of Clinical Microbiology, where they were analyzed. The students also provided the address where the test results were to be sent. Students with positive test results were requested in writing to visit a doctor for treatment and partner tracing and to take a letter to the doctor." (p. 952).

\section{Control group:usual care:2884 women in 9 schools}

Quote: "The control group received the same information and questionnaire as the home sampling group, but they were not supplied with the home sampling kit. Instead, they were offered a free testing at the local clinic for sexually transmitted diseases (STDs) or at the office of any other physician, including that of their general practitioner."

\section{Primary outcomes}

- Prevalence of chlamydia infections after 1 year of follow-up

- Incidence of pelvic inflammatory disease in women (self reported) measured in the 12 months after the offer of testing

\section{Secondary outcomes}

- Incidence of pelvic inflammatory disease requiring hospitalisation in women measured in the 12 months after the offer of testing 
A questionnaire was sent to participants asking for "information about treatment for PID and admittance to a hospital for PID during the year of follow-up. In an attempt to verify that treatment for PID had been given, every student who reported treatment for PID was sought among all records of antimicrobial prescriptions at the central Danish register for prescriptions (Lægemiddelstyrelsen)."

\section{Notes}

The study was funded by the Danish National Board of Health (grant No 210 i 1997), Løvens Kemiske Fabriks Research Foundation, Nycomed DAK, Pfizer, and Chairman Jacob Madsen and Hustru Olga Madsen's foundation.

\section{Risk of bias}

\begin{tabular}{lll}
\hline Bias & Authors' judgement & Support for judgement \\
\hline $\begin{array}{l}\text { Random sequence genera- } \\
\text { tion (selection bias) }\end{array}$ & Low risk & $\begin{array}{l}\text { Quote: "All } 17 \text { high schools in the county of Aarhus, Denmark, were cluster-ran- } \\
\text { domised 1:1 by simple redeeming (drawing lots from a hat) into an inter- } \\
\text { vention (home sampling) group consisting of } 8 \text { high schools composed } 2603 \\
\text { women and } 1733 \text { men, and a control group consisting of } 9 \text { high schools com- } \\
\text { posed 2884 women and } 1689 \text { men." }\end{array}$
\end{tabular}

Allocation concealment High risk
(selection bias)

Comment: not described, but randomisation was done before asking for con(selection bias) sent. More students in the intervention arm (48\%, 1254/2603) than the control $\operatorname{arm}(38 \%, 1097 / 2884)$ agreed to take part. At a subsequent stage, women were asked to consent to be followed up for the outcome PID. A lower proportion of the sexually experienced women in the intervention arm (93\%, 867/928) than the control arm $(100 \%, 833 / 833)$ agreed to follow up.

\begin{tabular}{|c|c|c|}
\hline $\begin{array}{l}\text { Blinding of participants } \\
\text { and personnel (perfor- } \\
\text { mance bias) } \\
\text { All outcomes }\end{array}$ & High risk & Comment: no blinding \\
\hline $\begin{array}{l}\text { Blinding of outcome as- } \\
\text { sessment (detection bias) } \\
\text { All outcomes }\end{array}$ & High risk & $\begin{array}{l}\text { Comment: Participants self assessed PID. Possibility of detection bias. Investi- } \\
\text { gators checked prescription records, and there was no statement about blind- } \\
\text { ing. }\end{array}$ \\
\hline $\begin{array}{l}\text { Incomplete outcome data } \\
\text { (attrition bias) } \\
\text { All outcomes }\end{array}$ & High risk & $\begin{array}{l}\text { Comment: Almost 50\% in both groups lost to follow-up (intervention, } 51 \% \text {, } \\
43 / 867 \text {; control 58\%, 487/833). }\end{array}$ \\
\hline $\begin{array}{l}\text { Selective reporting (re- } \\
\text { porting bias) }\end{array}$ & Unclear risk & $\begin{array}{l}\text { Comment: testing in follow-up period not reported, which might influence pri- } \\
\text { mary outcome and determine PID outcome. No protocol was available, so the } \\
\text { risk of reporting bias is unclear. }\end{array}$ \\
\hline Other bias & Unclear risk & Received funding from pharmaceutical company \\
\hline
\end{tabular}

Scholes 1996

Methods Study design: Randomisation before assessment of eligibility or obtaining consent for participation

Setting: staff-model health maintenance organization (HMO) located in western Washington State, USA

Study duration: 1 year afer offer of screening to intervention group

Participants

Enrolment: Women aged 18-34 years enrolled in a health maintenance organization (HMO) on 1 October 1990 ( $N=36,547$ received an initial questionnaire on eligibility; $N=2607$ randomised). Duplicate surveys were mailed to non-responders. Telephone calls were made to some of the non-responders, focusing on those in the intervention group. 
Scholes 1996 (Continued)

\section{Inclusion criteria:}

- Women in the target age group with no spouse registered who had a certain risk score based on criteria related to: age, race, gravidity, vaginal douching in the preceding 12 months, and number of sexual partners in the preceding 12 months

\section{Exclusion criteria:}

- Pregnant, sexually inexperienced, hysterectomised or married women

- Women with regular use of antibiotics

\section{Interventions Intervention group: screening:1009 women enrolled}

Invitation to be tested for $C$. trachomatis by use of 2 cervical samples that were analysed by ELISA and culture, respectively. All women with a positive test result were treated for chlamydia infection by their primary care provider.

\section{Control group: usual care:1598 women enrolled}

No intervention; women in the usual care group saw their health care providers as needed.

Primary outcomes
Outcomes
Incidence of pelvic inflammatory disease in women. The diagnoses were retrieved after 12 months but
records for the preceding 12 months were evaluated. Several sources were used to identify women
who could have had a PID: questionnaire answered by included women, assignment to or discharge
from the hospital with a diagnostic code indicating PID or cervicitis, positive test for C. trachomatis
or with 10-day courses of doxycycline. Medical records from these women were reviewed to identify
PID cases.

\section{Secondary outcomes:none reported}

\begin{tabular}{|c|c|}
\hline Notes & $\begin{array}{l}\text { All study procedures were reviewed and approved by the institutional review unit at the HMO. It is not } \\
\text { clear to what extent this includes ethical approval. Supported in part by a grant (A1-24756) from the } \\
\text { National Institute of Allergy and Infectious Diseases and by a grant from Bristol-Myers Squibb. }\end{array}$ \\
\hline
\end{tabular}

\section{Risk of bias}

\begin{tabular}{lll}
\hline Bias & Authors' judgement & Support for judgement \\
\hline $\begin{array}{l}\text { Random sequence genera- } \\
\text { tion (selection bias) }\end{array}$ & Unclear risk & $\begin{array}{l}\text { Comment: method not stated. Quote: "The women were randomly assigned } \\
\text { to either the screening group or the usual-care group at the time the original } \\
\text { sample was selected in October 1990." }\end{array}$ \\
\end{tabular}

\begin{tabular}{|c|c|c|}
\hline $\begin{array}{l}\text { Allocation concealment } \\
\text { (selection bias) }\end{array}$ & High risk & $\begin{array}{l}\text { Comment: Investigators made special efforts in the intervention group to in- } \\
\text { crease participation rate. As a result, the intention was a } 1: 2 \text { randomisation } \\
\text { but the study ended up with 1:1.5. }\end{array}$ \\
\hline
\end{tabular}

Blinding of participants High risk and personnel (performance bias)

All outcomes
Comment: no blinding. The lack of participant blinding and the outcome evaluation partly based on questionnaire data may have influenced the results, making women in intervention group more aware of PID symptoms and therefore causing an under- or overestimation of the intervention effect. No information about if the $76 \%$ completing the questionnaire were from intervention or control group.

\begin{tabular}{lll}
\hline $\begin{array}{l}\text { Blinding of outcome as- } \\
\text { sessment (detection bias) } \\
\text { All outcomes }\end{array}$ & Unclear risk & $\begin{array}{l}\text { Quote: "The abstracters were unaware of the study group assignments" (p. } \\
1363) .\end{array}$ \\
\hline $\begin{array}{l}\text { Incomplete outcome data } \\
\text { (attrition bias) }\end{array}$ & Unclear risk & $\begin{array}{l}\text { Comment: Several databases were searched (blinded) for outcome data, and } \\
\text { these data represent a low risk of bias as missingness will probably be evenly }\end{array}$ \\
\hline
\end{tabular}


Scholes 1996 (Continued)

All outcomes distributed between groups. However, questionnaires were also used and participants between groups may have answered unequally because they were not blinded.

\begin{tabular}{|c|c|c|}
\hline $\begin{array}{l}\text { Selective reporting (re- } \\
\text { porting bias) }\end{array}$ & Unclear risk & $\begin{array}{l}\text { Comment: no protocol available, so the risk of reporting bias is unclear. The } \\
\text { outcomes specified in the methods were all reported in the results. }\end{array}$ \\
\hline
\end{tabular}

Other bias Unclear risk Received funding of diagnostic tests from manufacturer.

van den Broek 2012

Study design: controlled trial with randomised stepped wedge implementation in 3 blocks
Setting: population-based screening in 3 regions of the Netherlands - the urban areas of Amsterdam
and Rotterdam and a defined suburban area of South Limburg (Parkstad)

Study duration: March 2008 to February 2011

Young adults (women and men aged $16-29$ years old, $\mathrm{N}=317,304)$
Inclusion criteria:
- Women and men aged $16-29$ years old
- Listed on the municipal population register from March 2008 to February 2011
- People living in Amsterdam and Rotterdam and reporting that they ever had sex
- 'High risk' people living in South Limburg, where chlamydia prevalence was expected to be lower than
in the cities. A risk score of $\geq 6$ according to a previously developed form was compatible with a posi-
tivity of $4-5 \%$ and excluded 20 -30\% of potential participants.
- Participants providing informed consent online

\section{Exclusion criteria:}

- Aged $<16$ or $>29$ years old

- Moved out of area before invite sent

- Not sexually active (Amsterdam and Rotterdam)

- Low risk (South Limburg)

Interventions

Enrolment: Personalised yearly invitations to be screened for $C$. trachomatis infection sent to the target population through the Chlamydia Screening Implementation Programme. The letter included the address of the programme website (www.chlamydiatest.nl) and a secure login code through which eligible participants could request a kit for self sampling (urine for men, vaginal swab or urine for women). Chlamydia-positive participants automatically received a test package 6 months after the first test.

\section{Intervention group 1: invited for screening 3 times (block A, N = 55,776, 39 clusters)}

Yearly chlamydia screening test offered by post 3 times. People were invited to use an internet site to request a kit for self collected samples to be sent to laboratory for testing. Treatment and partner notification were done via GP or STI clinic. A single reminder letter was sent to anyone who did not access the website within 4 weeks, and email reminders were sent to individuals who requested a kit but did not return a specimen within 2 weeks. Test results, with a referral letter for those with positive results, were provided online, with an email or text message reminder after 14 and 28 days and a letter by post after 6 weeks for those who did not access it.

\section{Intervention group 2: invited for screening 2 times (block $B, N=\mathbf{2 1 3 , 4 9 7 , 1 1 4}$ clusters)}

Yearly chlamydia screening test offered by post 2 times. See intervention group 1 for details.

Control group: usual care (block $\mathrm{C}, \mathrm{N}=48,031,39$ clusters) 
van den Broek 2012 (Continued)

One sixth of the population were invited a single time for $\mathrm{CT}$ testing after the second invitation was sent to blocks $A$ and $B$.

Testing for chlamydia is available from general practitioners and at sexually transmitted infections clinics. There was no specific promotion of chlamydia testing during the trial period.

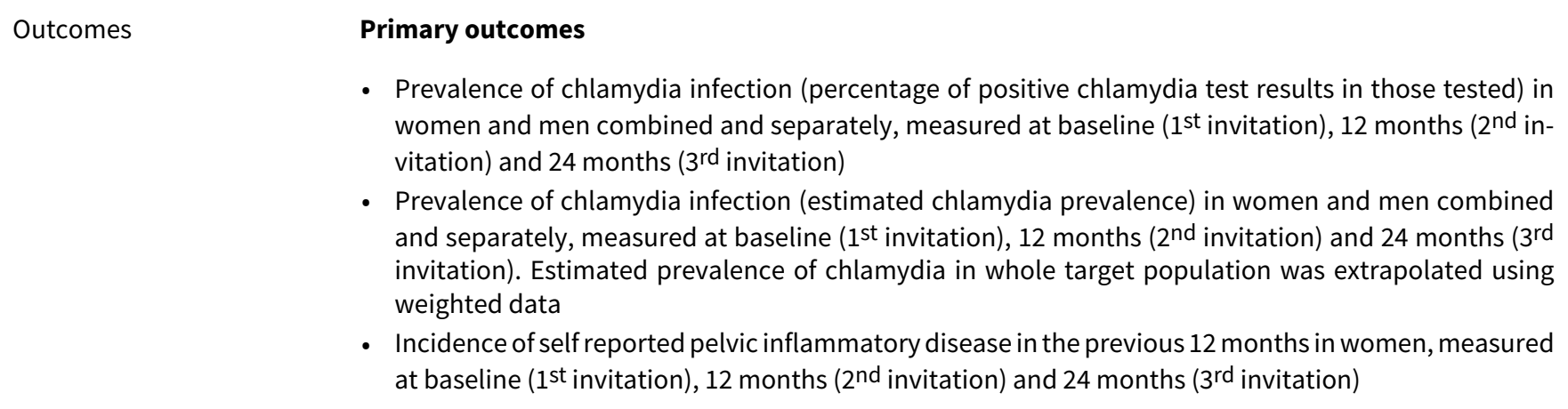

\section{Secondary outcomes}

- Proportion of participants receiving the intervention (= uptake of screening) in women and men combined and separately, measured at baseline (1st invitation), 12 months ( $2^{\text {nd }}$ invitation) and 24 months (3rd invitation). Percentage participating (the proportion of invitees who send a sample to the laboratory)

Notes

The study was approved by the Medical Ethics Committee Free University Amsterdam (Identification number 2007/239). The Dutch organisation for Health Research and Development (ZonMW, project number 12.400.001) funded the project. No protocol available but details of study design are in related paper van den Broek 2010

\section{Risk of bias}

\section{Bias \\ Authors' judgement Support for judgement}

Random sequence genera- High risk tion (selection bias)

Allocation concealment Unclear risk (selection bias)
Quote: "The order of invitation of clusters was randomised by assigning computer generated random numbers to clusters and then sorting clusters within one block using these numbers (using Microsoft Excel 2002)" (p. 3).

Comment: The investigators were blinded to the identity of clusters (allocated to block = comparison groups A, B, C) and did not know whether the intervention effect might differ by risk level or cluster size. The subsequent randomisation of the order of implementation within blocks and addition of a third round of screening in block $B$ would also reduce the risk of bias in the results.

Quotes: "Although we stratified the clusters according to community risk level, the intervention and control block were not completely comparable in all 3 regions" (p. 5).

"The participation rate in the control block $\mathrm{C}$ was not completely comparable to that achieved after the first invitation in the intervention blocks A and B" ( $p$. 5).

Blinding of participants Low risk Comment: no blinding

and personnel (perfor-

mance bias)

All outcomes 
van den Broek 2012 (Continued)

\begin{tabular}{|c|c|c|}
\hline $\begin{array}{l}\text { Blinding of outcome as- } \\
\text { sessment (detection bias) } \\
\text { All outcomes }\end{array}$ & Low risk & $\begin{array}{l}\text { Comment: no blinding of outcome assessment, but the review authors judge } \\
\text { that the outcome measurement is not likely to be influenced by lack of blind- } \\
\text { ing }\end{array}$ \\
\hline
\end{tabular}

Incomplete outcome data High risk
(attrition bias)

(attrition bias)

Comment: primary outcomes only: incomplete data (for positivity and thus prevalence) associated with intervention uptake. For PID, very low reporting All outcomes ( $1^{\text {st }}$ invitation, assumed to be baseline with no screening in the previous 12 months, $1072 / 29,831 ; 2^{\text {nd }}$ invitation, presumed to be 12 months after screen-

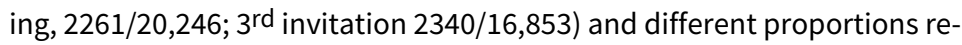
sponding to questionnaire at each round.

Reason for missing outcome data likely to be related to true outcome

\begin{tabular}{lll}
\hline $\begin{array}{l}\text { Selective reporting (re- } \\
\text { porting bias) }\end{array}$ & Low risk & All outcomes in study design paper reported in main paper \\
\hline Other bias & Unclear risk & $\begin{array}{l}\text { Contamination; quote: "cluster allocation could have reduced, but not elim- } \\
\text { inated, transmission of chlamydia within clusters. Sexual networks do not } \\
\text { strictly follow geographical boundaries and the blocks for implementation } \\
\text { were not contiguous" ( } \mathrm{p} \text {. 5). Not enough information to assess whether conta- } \\
\text { mination occurred. Low uptake of the intervention could reduce the size of any } \\
\text { difference between intervention and control groups. }\end{array}$ \\
\end{tabular}

CT: Chlamydia trachomatis; FSW: female sex workers; GP: general practitioner; PID: pelvic inflammatory disease; STI: sexually transmitted infection.

\section{Characteristics of excluded studies [ordered by study ID]}

\begin{tabular}{|c|c|}
\hline Study & Reason for exclusion \\
\hline ACTRN12608000499381 & $\begin{array}{l}\text { RCT. CLASP trial. No eligible primary outcome: report uptake of testing and CT prevalence at } 6 \\
\text { months only }\end{array}$ \\
\hline Andrews 2006 & $\begin{array}{l}\text { Not an RCT. Observational study nested within RCT of pregnant women randomised to antibiotic or } \\
\text { no treatment for Trichomonas vaginalis or bacterial vaginosis }\end{array}$ \\
\hline Bailey 2013 & RCT; no eligible primary outcome; chlamydia testing at 3 months only \\
\hline Banhidy 2011 & $\begin{array}{l}\text { RCT in pregnant women; no real difference between groups; both groups screened, report pre-term } \\
\text { birth for treated vs untreated and for infection with any sexually transmitted infection vs no infec- } \\
\text { tion }\end{array}$ \\
\hline Bowden 2008 & RCT; no eligible primary outcome; main outcome was chlamydia testing uptake \\
\hline Brown 2010 & $\begin{array}{l}\text { RCT; no eligible primary outcome; routine chlamydia testing only. Outcomes were patient satisfac- } \\
\text { tion, doctor/nurse screening vs self taken sample, number of cases detected, time taken in clinic }\end{array}$ \\
\hline Cabeza 2015 & Feasibility study of chlamydia screening in pregnant women; no control group \\
\hline Chandeying 1998 & $\begin{array}{l}\text { RCT; no eligible primary outcome; routine chlamydia screening only. Immediate results only; no } \\
\text { long term outcomes }\end{array}$ \\
\hline Cohen 1999 & $\begin{array}{l}\text { Register-based screening cluster-CCT, repeat testing in schools } 5 \text { screening rounds vs usual care. } \\
\text { Wrong intervention, cluster-CCT 'control' schools not enrolled concurrently with intervention }\end{array}$ \\
\hline
\end{tabular}




\begin{tabular}{|c|c|}
\hline Study & Reason for exclusion \\
\hline Cook 2007 & $\begin{array}{l}\text { RCT; participants not eligible. Didn't measure prevalence, but screened women with recent sexual- } \\
\text { ly transmitted infection }\end{array}$ \\
\hline De Barbeyrac 2013 & $\begin{array}{l}\text { RCT; no eligible primary outcome; main outcome was screening rate after internet offer of home } \\
\text { screening vs usual care }\end{array}$ \\
\hline Downing 2013 & RCT; no eligible primary outcome; chlamydia retesting at 3 months only \\
\hline Gotz 2013 & $\begin{array}{l}\text { RCT; no eligible primary outcome; chlamydia retesting at 4-5 months only after home vs clin- } \\
\text { ic-based recall }\end{array}$ \\
\hline Graseck 2010 & $\begin{array}{l}\text { RCT; no eligible primary outcome; chlamydia retesting at } 12 \text { months was cross-sectional, not per- } \\
\text { formed as a follow-up }\end{array}$ \\
\hline Guy 2013 & RCT; no eligible primary outcome; CT retesting at 3 months only \\
\hline Hodgins 2002 & $\begin{array}{l}\text { RCT; no eligible primary outcome; 'prevalence' at } 12 \text { months measured differently in intervention } \\
\text { and control after cluster-randomised mass screening }\end{array}$ \\
\hline ISRCTN16261241 & RCT; no eligible primary outcome; reports uptake of testing and uptake of Papanicolau smears \\
\hline ISRCTN38526137 & $\mathrm{RCT}$; no primary outcome; reports uptake of testing only \\
\hline Jones 2007 & RCT; no eligible primary outcome; main outcome uptake of screening at 6 weeks \\
\hline Kekki 2001 & $\begin{array}{l}\text { RCT in pregnant women; intervention not eligible. All women screened for chlamydia, and only } \\
\text { those with bacterial vaginosis randomised to treatment or no treatment for bacterial vaginosis }\end{array}$ \\
\hline Kersaudy-Rahib 2013 & RCT; no eligible primary outcome; main outcome was uptake of screening \\
\hline Kiss 2004 & $\begin{array}{l}\text { RCT in pregnant women; no eligible primary outcome; screening for bacterial vaginosis, Tri- } \\
\text { chomonas vaginalis and candida only, but not chlamydia }\end{array}$ \\
\hline Klovstad 2013 & RCT; no eligible primary outcome; study period 3 months only \\
\hline Lawton 2010 & RCT; pilot study only. No eligible primary outcome; main outcome was uptake of testing \\
\hline Martin 1997 & RCT in pregnant women; intervention not eligible \\
\hline McGregor 1990 & $\begin{array}{l}\text { RCT in pregnant women; intervention not eligible. Treatment with erythromycin vs no treatment } \\
\text { was not equivalent to screen vs no screening }\end{array}$ \\
\hline McGregor 1995 & CCT in pregnant women; comparison not eligible: no comparison of screened vs unscreened \\
\hline McKee 2011 & RCT; no eligible primary outcome; main outcome uptake of chlamydia testing \\
\hline Meyer 1991 & RCT; no eligible primary outcome: main outcome was incidence of discharge \\
\hline NCT00829517 & RCT; no eligible primary outcome; report chlamydia positivity at 3 months only \\
\hline NCT01654991 & RCT; no eligible primary outcome; report uptake of chlamydia screening in men \\
\hline Niza 2014 & RCT; no eligible primary outcome; main outcome was return of screening kits \\
\hline Scholes 2006 & RCT; no eligible primary outcome; only reports uptake of chlamydia testing \\
\hline
\end{tabular}




\begin{tabular}{|c|c|}
\hline Study & Reason for exclusion \\
\hline Scholes 2007 & RCT; no eligible primary outcome; chlamydia retesting at 4 months only \\
\hline Senok 2005 & $\begin{array}{l}\text { RCT; no eligible primary outcome; only reports uptake of testing and chlamydia positivity up to } 4 \\
\text { months }\end{array}$ \\
\hline Shafer 2002 & RCT; no eligible primary outcome; do not report positivity at 12 months \\
\hline Smith 2014 & RCT; no eligible primary outcome; chlamydia retesting at 1-4 months only \\
\hline Stevens-Simon 2002 & $\begin{array}{l}\text { Study in pregnant teenagers; no eligible primary outcome; only measured chlamydia positivity } \\
\text { once in a random subset of pregnancy test urine samples; no pregnancy outcomes }\end{array}$ \\
\hline Tebb 2005 & RCT; no eligible primary outcome; report chlamydia screening rate in boys \\
\hline Tebb 2009 & RCT; no eligible primary outcome; report chlamydia screening rate in girls \\
\hline Walker 2010 & RCT; no eligible primary outcome; report uptake of chlamydia testing \\
\hline Xu 2011 & RCT; no eligible primary outcome; chlamydia retesting at 3 months of treated women \\
\hline
\end{tabular}

$\mathbf{C T}$ : Chlamydia trachomatis; $\mathbf{C C T}$ : controlled clinical trial; $\mathbf{R C T}$ : randomised controlled trial.

Characteristics of ongoing studies [ordered by study ID]

\section{Hocking 2010}

Trial name or title

\begin{tabular}{ll}
\hline Methods & Cluster-randomised controlled trial \\
\hline Participants & $\begin{array}{l}\text { General practice clinics within postcode areas with a population of between } 5000 \text { to } 30,000 . \text { A to- } \\
\text { tal of } 54 \text { postcodes (towns) will be randomised, and all general practice clinics within the postcode } \\
\text { will be invited to participated. All clinics will be eligible for participation. }\end{array}$
\end{tabular}

Interventions

Intervention group: annual testing. GPs will be asked to screen sexually active men and women aged 16 to 29 years for chlamydia. The multifaceted intervention to maximise testing includes: a computer alert prompting GPs to test; incentive payments for GPs and payments for employing practice nurses; a recall system to encourage annual testing; partner notification, and information/support with regular feedback on testing performance.

Control group: usual care. Clinics in the control group are encouraged to continue their usual practice.

Primary outcome: change in chlamydia prevalence among a consecutive sample of 80-100 pa-
tients attending participating clinics in each postcode

Secondary outcomes: incidence of pelvic inflammatory disease; chlamydia testing rates

\begin{tabular}{ll}
\hline Starting date & 1 May 2010 \\
\hline Contact information & Dr Jane Hocking, jhocking@unimelb.edu.au \\
\hline Notes & Trial registration number: ACTRN12610000297022
\end{tabular}



health care - a randomised community trial to reduce STIs in remote Aboriginal and Torres Strait Islander communities, comparing clinical care enhanced with a Sexual Health Quality Improvement Program with standard clinical care

\begin{tabular}{ll}
\hline Methods & Stepped wedge community cluster-randomisation \\
\hline Participants & $\begin{array}{l}\text { Sexually active 14-34 year olds living in remote communities in Australia with a resident population } \\
\text { of Aboriginal or Torres Strait Islander people aged } 16-34 \text { years. A total of } 68 \text { communities were ran- } \\
\text { domised. }\end{array}$
\end{tabular}

Inclusion criteria: communities considered remote by the Australian Bureau of Statistics (ABS); with a resident population of at least 100 people of Aboriginal people, Torres Strait Islanders or both, aged 16-34 years; with community and health services willing and able to provide access to de-identified clinical data; with health services able to sustain data collection, consistent with the trial protocol

Exclusion criteria: communities where there is a diverse range of health services within the same area that are accessed by Aboriginal people, Torres Strait Islanders or both.

Randomisation will occur over a period of 3 years. At the start of each year, 7 of the trial clusters will be randomised to the intervention, the following year a further 7 will be randomised, and in the third year, the final 7 will be randomised such that by the end of the trial, all clusters will have received the intervention. For clusters that are randomised in year 1 , the intervention will continue for 3 years. For clusters randomised in year 2 , the intervention will continue for 2 years. For clusters randomised in year 3 , the intervention will continue for 1 year.

Intervention group: The intervention, called the Sexual Health Quality Improvement Program will involve the following components:

1. Development of an action plan including goals and strategies to improve clinical service delivery for diagnosis and management of bacterial STIs to reach best practice targets. STRIVE Coordinators will meet with participating primary health services annually for a day to undertake a site assessment, develop an Action Plan tailored to the individual service and discuss goals and strategies for the Action Plan.

2. 6-monthly collaborative feedback meetings to discuss progress on the Action Plan. STRIVE Coordinators will meet with health service management to discuss the Action Plan and progress towards the goals and strategies developed.

3. Quantitative data reports will be provided to health services every 6 months showing progress towards best practice targets.

4. Training - STRIVE coordinators will provide staff with training in quality improvement and basic research skills and encourage further training in sexual health. Training requirements will be discussed at the collaborative feedback meetings.

5. Incentives payments based on progress towards the best practice targets. Opportunities exist for each health service to receive a total incentive payment of between $\$ 10,000$ and $\$ 30,000$ per year. Incentives will be calculated from the quantitative reports and will be paid every 6 months.

Control group: standard clinical care according to clinical guidelines which include screening, assessment, treatment, management, prevention and reporting recommendations. Clinicians are recommended to follow these guidelines on a case-by-case basis. 
Kaldor 2010 (Continued)

Secondary outcome: Proportion of participants receiving the intervention (= uptake of screening), measured annually and at the end of the trial

\begin{tabular}{ll}
\hline Starting date & 1 September 2010 \\
\hline Contact information & J Kaldor, jkaldor@kirby.unsw.edu.au \\
\hline Notes & Ethical approval obtained from Western Australian Aboriginal Health Information Ethics Commit- \\
& tee; Cairns Base Hospital Ethics Committee; Central Australian Human Research Ethics Commit- \\
& tee; Human Research Ethics Committee of Northern Territory Department of Health and Families \\
& and Menzies School of Health Research; Western Australian Country Health Service Board Research \\
& Ethics Committee; University of New South Wales Human Research Ethics Committee (B)
\end{tabular}

Lehtinen 2015

\begin{tabular}{ll}
\hline Trial name or title & Characteristics of a randomised Chlamydia screening trial \\
\hline Methods & Community cluster-randomised trial \\
\hline Participants & Women born in 1992-1995 living in 44 communities in Finland (33 screened, 11 unscreened) \\
& $\begin{array}{l}15,000 \text { women invited for screening per year. The invitation contains information on C. tra- } \\
\text { chomatis and its treatment and about an FVU-sampling kit, which is available through a website } \\
\text { (www.rokotiitus.net). A consent form is included to be mailed/donated together with the FVU-sam- } \\
\text { ple. }\end{array}$
\end{tabular}

Interventions Communities will be divided into 4 groups for biannual, quadrennial or a single screening round at the end of the study. Target number of women born 1992-1995, $\mathrm{N}=60,000$, approximately 15,000 per arm.

Intervention group 1: biannual screening at the ages of 18.5, 20 and 22

Intervention group 2: biannual screening at the ages of 18.5, 20 and 22

Intervention group 3: quadrennial screening at the ages of 18.5 and 22

Control group: 11 unscreened communities (no offer of screening until age 22)

Outcomes Primary outcome: prevalence of chlamydia infection in women at age 22 (3.5 years after start of study); ITT analysis of groups $1+2 \mathrm{vs}$ control (screened 3 times vs screened $1 \mathrm{x}$ only at end of study); prevalence of chlamydia infection in women at age 22 (3.5 years after start of study) groups $1+2$ vs groups $3+$ control, ITT analysis (screened 3 times vs screened $2 x$ or $1 x$ only at end of study)

Secondary outcome: proportion of participants receiving the intervention (= uptake of screening) at baseline (other time points not reported)

\begin{tabular}{ll}
\hline Starting date & Autumn 2010 \\
\hline Contact information & M Lehtinen, University of Tampere, Finland \\
\hline Notes & $\begin{array}{l}\text { Permission for the trial was obtained from the ethical review board of the North Ostrobotnia Hospi- } \\
\text { tal District, Oulu, Finland. } \\
\\
\text { Performed as part of an HPV vaccination trial. }\end{array}$ \\
\hline
\end{tabular}


NCT01195220

\begin{tabular}{|c|c|}
\hline Trial name or title & Project AWARE: using the ED to prevent STIs in youth \\
\hline Methods & Randomised controlled trial \\
\hline \multirow[t]{2}{*}{ Participants } & Sexually experienced adolescents aged 14 to 21 in a large, inner-city ED in the Bronx (NY) \\
\hline & Estimated enrolment: 690 \\
\hline \multirow[t]{3}{*}{ Interventions } & $\begin{array}{l}\text { Intervention group 1: combined HIV/STI screening. Current standard of care with video to obtain } \\
\text { informed consent for rapid on-site HIV testing, with additional information in video about other } \\
\text { STIs and added gonorrhoea and chlamydia screening of a urine sample }\end{array}$ \\
\hline & $\begin{array}{l}\text { Intervention group 2: combined HIV/STI screening with theory-based risk reduction video coun- } \\
\text { selling. As intervention } 1 \text { with additional behavioural video to encourage safer sex }\end{array}$ \\
\hline & $\begin{array}{l}\text { Control group: HIV testing. Current standard of care with video to obtain informed consent for } \\
\text { rapid on-site HIV testing }\end{array}$ \\
\hline \multirow[t]{2}{*}{ Outcomes } & Primary outcomes: test positivity for chlamydia or gonorrhoea 4 months postintervention \\
\hline & $\begin{array}{l}\text { Secondary outcomes: test positivity for chlamydia or gonorrhoea } 8 \text { months and } 12 \text { months postin- } \\
\text { tervention; intentions for condom use immediately after as well as } 4,8 \text { and } 12 \text { months postinter- } \\
\text { vention }\end{array}$ \\
\hline Starting date & December 2011 \\
\hline Contact information & $\begin{array}{l}\text { Dr Yvette Calderon, Jacobi Medical Center, North Bronx Healthcare Network, New York, United } \\
\text { States, } 10461\end{array}$ \\
\hline Notes & Trial registration number: NCT01195220 \\
\hline
\end{tabular}

ED: emergency department; FVU: first void urine; ITT: intention-to-treat; STI: sexually transmitted infection.

\section{DATA AND ANALYSES}

\section{Comparison 1. Offer of chlamydia screening vs usual care (inactive control)}

\begin{tabular}{|c|c|c|c|c|}
\hline Outcome or subgroup title & No. of studies & $\begin{array}{l}\text { No. of partici- } \\
\text { pants }\end{array}$ & Statistical method & Effect size \\
\hline $\begin{array}{l}1 \text { Prevalence of chlamydia infection } \\
\text { (positivity) measured in the whole } \\
\text { study population at least } 12 \text { months } \\
\text { after start of screening }\end{array}$ & 2 & & $\begin{array}{l}\text { Risk Ratio (M-H, Fixed, 95\% } \\
\mathrm{Cl} \text { ) }\end{array}$ & $\begin{array}{l}\text { Totals not select- } \\
\text { ed }\end{array}$ \\
\hline $1.13^{\text {rd }}$ invitation vs control & 1 & & $\begin{array}{l}\text { Risk Ratio (M-H, Fixed, 95\% } \\
\mathrm{Cl})\end{array}$ & $0.0[0.0,0.0]$ \\
\hline $1.22^{\text {nd }}$ invitation vs control & 1 & & $\begin{array}{l}\text { Risk Ratio (M-H, Fixed, 95\% } \\
\mathrm{Cl})\end{array}$ & $0.0[0.0,0.0]$ \\
\hline $1.31^{\text {st }}$ invitation vs control & 1 & & $\begin{array}{l}\text { Risk Ratio (M-H, Fixed, 95\% } \\
\mathrm{Cl})\end{array}$ & $0.0[0.0,0.0]$ \\
\hline
\end{tabular}




\begin{tabular}{|c|c|c|c|c|}
\hline Outcome or subgroup title & No. of studies & $\begin{array}{l}\text { No. of partici- } \\
\text { pants }\end{array}$ & Statistical method & Effect size \\
\hline $\begin{array}{l}\text { 1.4 Screening offer in high school stu- } \\
\text { dents }\end{array}$ & 1 & & $\begin{array}{l}\text { Risk Ratio (M-H, Fixed, 95\% } \\
\mathrm{Cl})\end{array}$ & $0.0[0.0,0.0]$ \\
\hline $\begin{array}{l}2 \text { Incidence of PID at } 12 \text { months (in- } \\
\text { tention-to-treat) }\end{array}$ & 4 & 21080 & $\begin{array}{l}\text { Risk Ratio (M-H, Fixed, 95\% } \\
\mathrm{CI})\end{array}$ & $0.68[0.49,0.94]$ \\
\hline 2.1 Low risk of detection bias & 2 & 18022 & $\begin{array}{l}\text { Risk Ratio (M-H, Fixed, 95\% } \\
\mathrm{Cl} \text { ) }\end{array}$ & $0.80[0.55,1.17]$ \\
\hline 2.2 High risk of detection bias & 2 & 3058 & $\begin{array}{l}\text { Risk Ratio (M-H, Fixed, 95\% } \\
\mathrm{CI})\end{array}$ & $0.42[0.22,0.83]$ \\
\hline $\begin{array}{l}3 \text { Incidence of PID at } 12 \text { months (per } \\
\text { protocol analysis) }\end{array}$ & 2 & 2749 & $\begin{array}{l}\text { Risk Ratio (M-H, Fixed, 95\% } \\
\mathrm{Cl})\end{array}$ & $0.62[0.35,1.10]$ \\
\hline 3.1 Low risk of detection bias & 1 & 2377 & $\begin{array}{l}\text { Risk Ratio (M-H, Fixed, 95\% } \\
\mathrm{Cl})\end{array}$ & $0.65[0.34,1.24]$ \\
\hline 3.2 High risk of detection bias & 1 & 372 & $\begin{array}{l}\text { Risk Ratio (M-H, Fixed, 95\% } \\
\mathrm{Cl})\end{array}$ & $0.55[0.17,1.80]$ \\
\hline $\begin{array}{l}4 \text { Incidence of epididymitis in men at } \\
12 \text { months (intention to screen) }\end{array}$ & 1 & 14980 & $\begin{array}{l}\text { Risk Ratio (M-H, Fixed, 95\% } \\
\mathrm{Cl})\end{array}$ & $0.80[0.45,1.42]$ \\
\hline $\begin{array}{l}5 \text { Secondary outcomes for reproduc- } \\
\text { tive tract morbidity }\end{array}$ & 1 & & $\begin{array}{l}\text { Risk Difference (M-H, Fixed, } \\
95 \% \mathrm{Cl})\end{array}$ & $\begin{array}{l}\text { Totals not select- } \\
\text { ed }\end{array}$ \\
\hline 5.1 Female infertility & 1 & & $\begin{array}{l}\text { Risk Difference (M-H, Fixed, } \\
95 \% \mathrm{Cl})\end{array}$ & $0.0[0.0,0.0]$ \\
\hline 5.2 Ectopic pregnancy & 1 & & $\begin{array}{l}\text { Risk Difference (M-H, Fixed, } \\
95 \% \mathrm{Cl})\end{array}$ & $0.0[0.0,0.0]$ \\
\hline
\end{tabular}

Analysis 1.1. Comparison 1 Offer of chlamydia screening vs usual care (inactive control), Outcome 1 Prevalence of chlamydia infection (positivity) measured in the whole study population at least 12 months after start of screening.

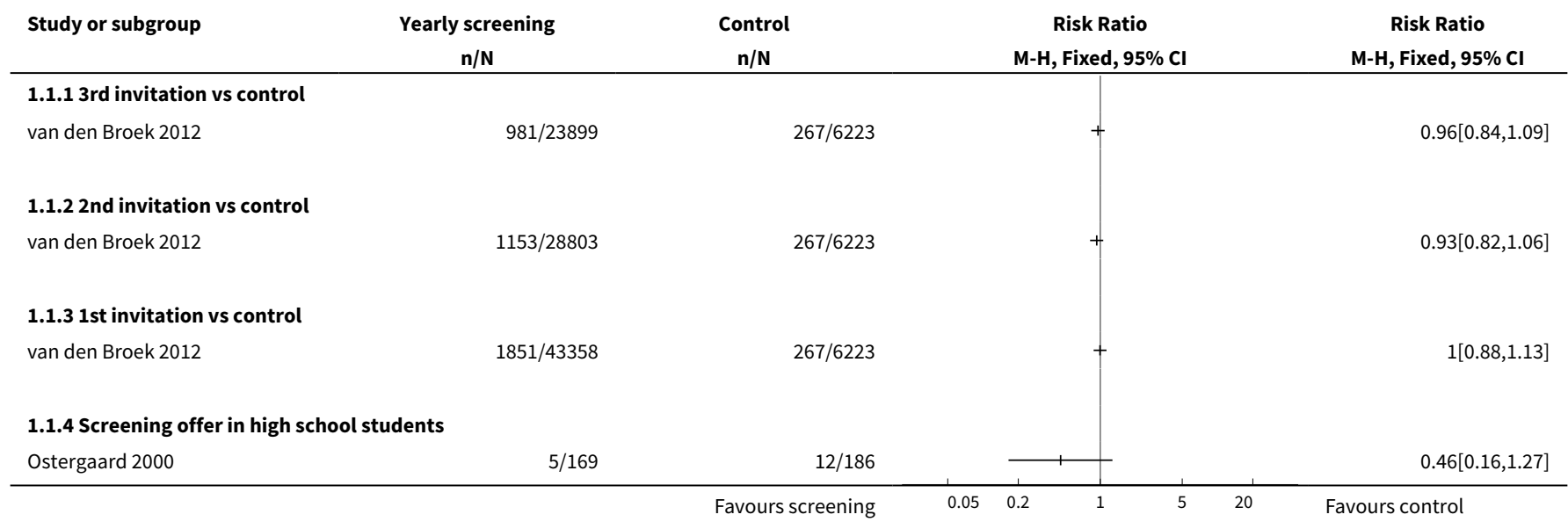


Analysis 1.2. Comparison 10 Offer of chlamydia screening vs usual care (inactive control), Outcome 2 Incidence of PID at 12 months (intention-to-treat).

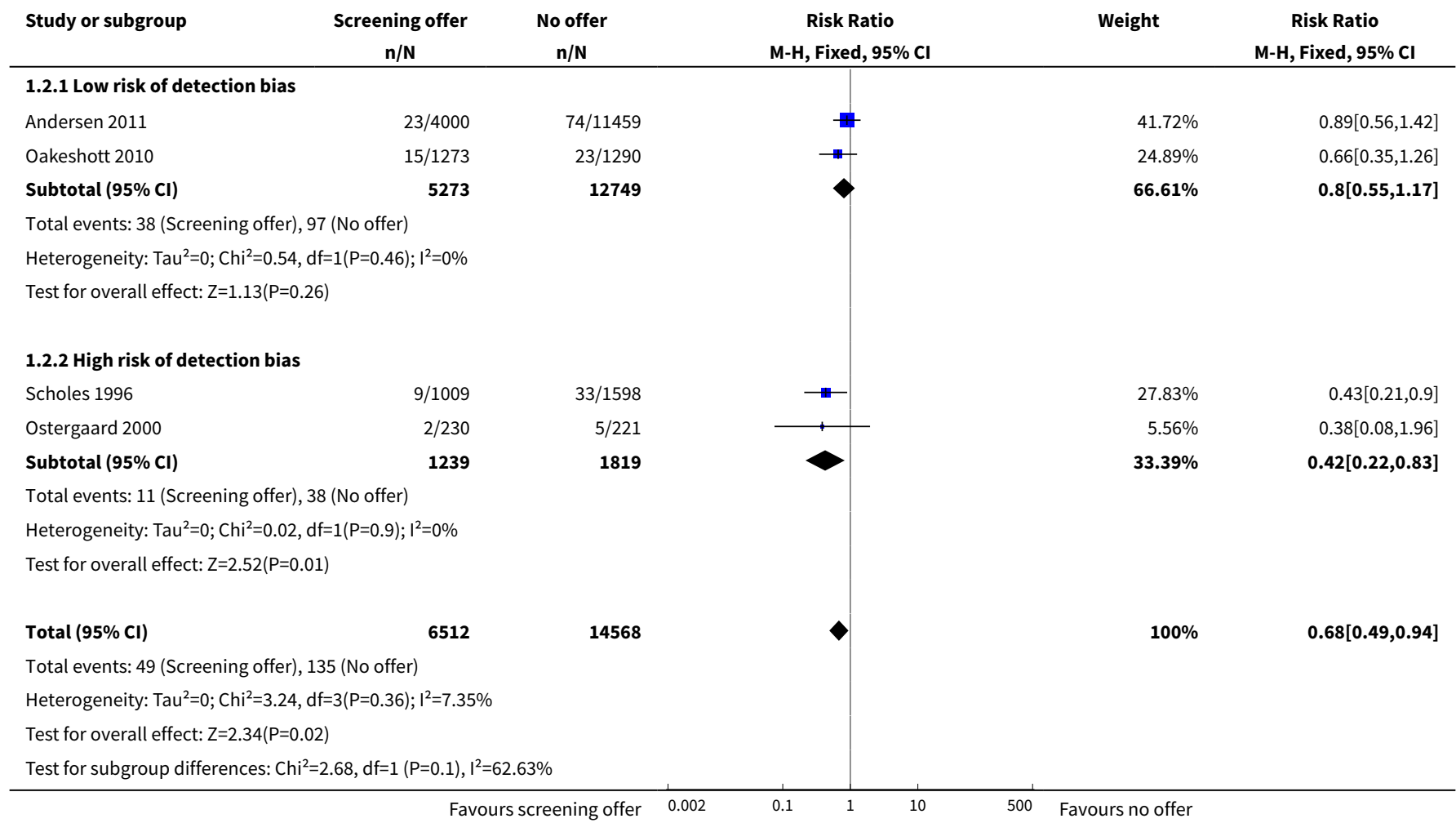

\section{Analysis 1.3. Comparison 1 Offer of chlamydia screening vs usual care (inactive control), Outcome 3 Incidence of PID at 12 months (per protocol analysis).}

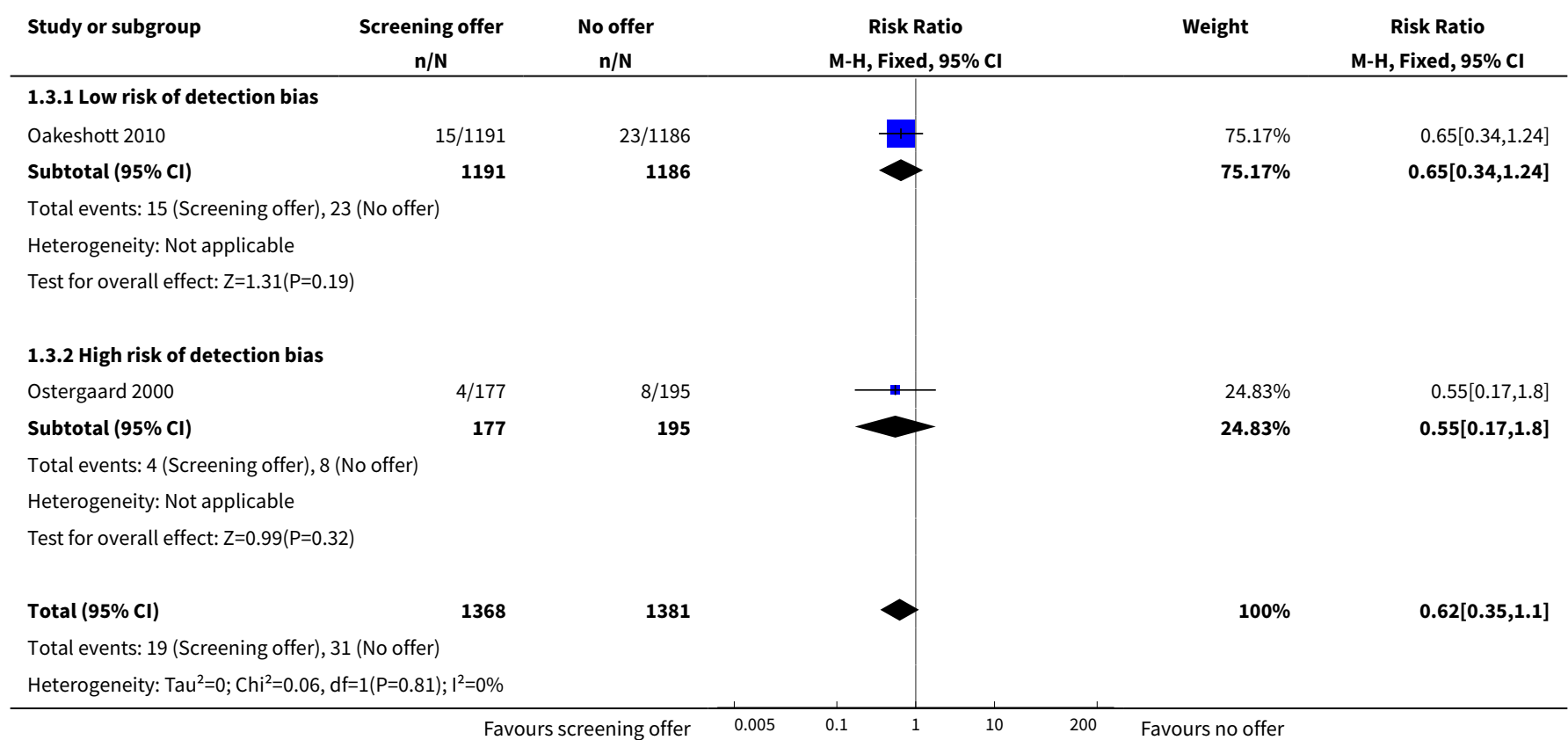




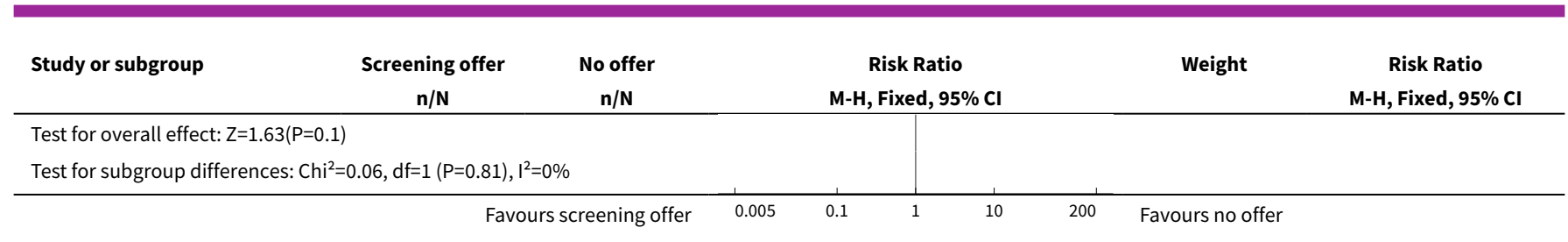

Analysis 1.4. Comparison 1 Offer of chlamydia screening vs usual care (inactive control), Outcome 4 Incidence of epididymitis in men at 12 months (intention to screen).

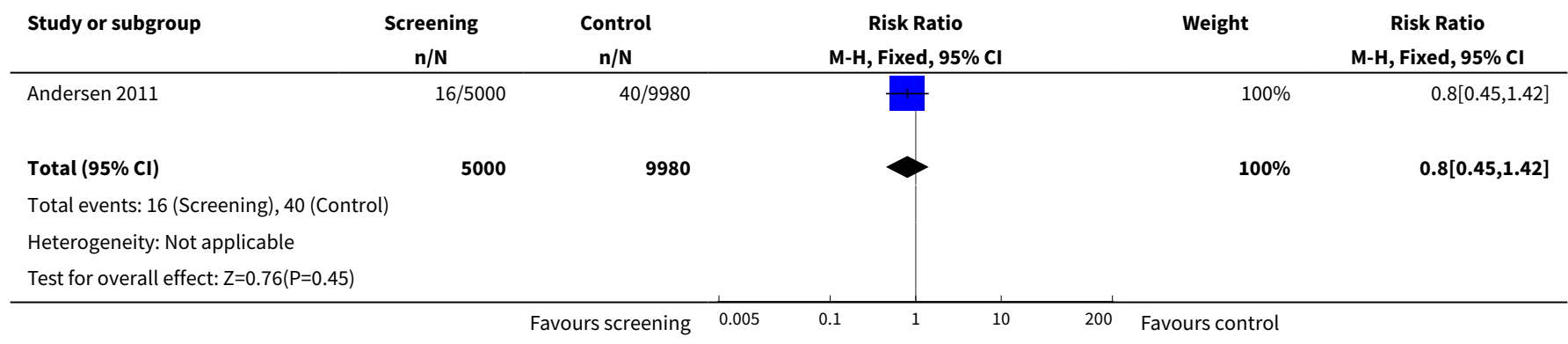

Analysis 1.5. Comparison 1 Offer of chlamydia screening vs usual care (inactive control), Outcome 5 Secondary outcomes for reproductive tract morbidity.

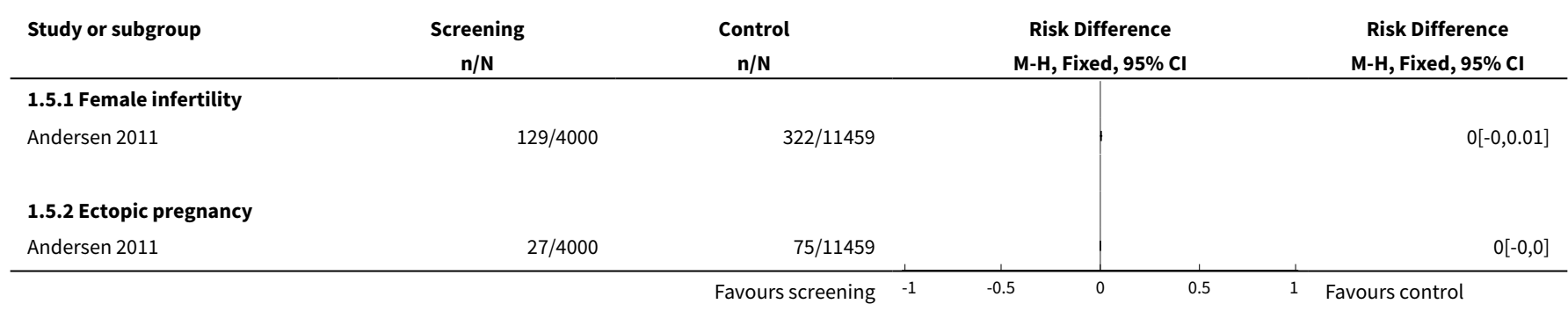


ADDITIONAL TABLES

Table 1. Effect of chlamydia screening interventions on chlamydia prevalence

\begin{tabular}{|c|c|c|c|c|c|c|c|c|c|}
\hline \multirow[t]{2}{*}{ Trial } & \multirow[t]{2}{*}{ Study population } & \multicolumn{2}{|l|}{ Baseline } & \multicolumn{2}{|c|}{ Follow-up, 12 months } & \multirow{2}{*}{$\begin{array}{l}\text { Reported effect } \\
(95 \% \mathrm{Cl})\end{array}$} & \multicolumn{2}{|c|}{ Follow-up, subsequent } & \multirow{2}{*}{$\begin{array}{l}\text { Reported effect } \\
(95 \% \mathrm{Cl})\end{array}$} \\
\hline & & $\begin{array}{l}\text { Interven- } \\
\text { tion }\end{array}$ & Control & $\begin{array}{l}\text { Interven- } \\
\text { tion }\end{array}$ & Control & & $\begin{array}{l}\text { Interven- } \\
\text { tion }\end{array}$ & Control & \\
\hline $\begin{array}{l}\text { Ostergaard } \\
2000\end{array}$ & $\begin{array}{l}\text { High school students, Den- } \\
\text { mark }\end{array}$ & $43 / 867^{a}$ & $\begin{array}{l}\text { Not mea- } \\
\text { sured }\end{array}$ & $13 / 443^{a}$ & $32 / 487$ & $\begin{array}{l}\mathrm{RD}-5.5 \%(-10 \text { to } \\
0.95 \%)^{a}\end{array}$ & - & - & - \\
\hline $\begin{array}{l}\text { van den } \\
\text { Broek } 2012\end{array}$ & $\begin{array}{l}\text { General population, Nether- } \\
\text { lands }\end{array}$ & $1851 / 43358$ & $267 / 6223$ & $1153 / 28803$ & $\begin{array}{l}\text { Not mea- } \\
\text { sured }\end{array}$ & $\begin{array}{l}\text { OR } 0.93(0.81 \text { to } \\
1.07)^{\mathrm{b}}\end{array}$ & $981 / 23899$ & $\begin{array}{l}\text { Not mea- } \\
\text { sured }\end{array}$ & $\begin{array}{l}\text { OR } 0.96 \text { ( } 0.83 \text { to } \\
1.10)^{b}\end{array}$ \\
\hline Garcia 2012 & Female sex workers, Peru & $13.8 \%$ & $15.5 \%$ & - & - & - & $9.9 \%$ & $14.5 \%$ & $\begin{array}{l}\text { RR } 0.66 \text { ( } 0.47 \text { to } \\
0.94)^{c}\end{array}$ \\
\hline
\end{tabular}

$\mathrm{Cl}$ : confidence interval; OR: odds ratio; RD: risk difference; RR: risk ratio.

a Numbers of infections and people are the numbers reported by the authors. Risk difference, as reported by authors (difference in mean incidence proportions across clusters) Confidence intervals for the difference did not take into account clustering.

bComparison is between intervention group at follow-up and control group at baseline. Confidence intervals do not take into account intraclass correlation because, in a

hierarchical multivariable model, clustering did not affect the results.

'Total participants at baseline in 2002, 4130; total participants at follow-up in 2006, 4156; RR adjusted for 2002 prevalence but not for pairing of cities. 
Table 2. Uptake of chlamydia screening

\begin{tabular}{|c|c|c|c|c|c|}
\hline Trial & $\begin{array}{l}\text { Eligibility (ratio in- } \\
\text { tervention: control) }\end{array}$ & Group & $\begin{array}{l}\text { Uptake in interven- } \\
\text { tion }\end{array}$ & $\begin{array}{l}\text { Uptake in con- } \\
\text { trol }\end{array}$ & Comment \\
\hline \multirow[t]{4}{*}{$\begin{array}{l}\text { Andersen } \\
2011\end{array}$} & \multirow{3}{*}{$\begin{array}{l}\text { Selected at random } \\
\text { from register (1:4) } \\
\text { Intervention: invit- } \\
\text { ed for home-sam- } \\
\text { pling. Assessed after } \\
3 \text { months }\end{array}$} & Women & 4000 invited; & $\begin{array}{l}11,459 \text { not invit- } \\
\text { ed; }\end{array}$ & \multirow{4}{*}{$\begin{array}{l}\text { Control group not aware } \\
\text { of trial. Assume routine } \\
\text { health-seeking behaviour } \\
\text { over } 3 \text { months. If control } \\
\text { group testing behaviour } \\
\text { continued at the same lev- } \\
\text { el over } 12 \text { months, the pro- } \\
\text { portion tested by the time } \\
\text { the outcome PID was mea- } \\
\text { sured could have been } \\
\text { higher. }\end{array}$} \\
\hline & & & home-sample & $\begin{array}{l}1076(9.4 \%) \text { op- } \\
\text { portunistic tests }\end{array}$ & \\
\hline & & \multirow[t]{2}{*}{ Men } & 5000 invited; & 9980 not invited; & \\
\hline & $\begin{array}{l}\text { Control: not contact- } \\
\text { ed. Tests at GP and } \\
\text { STI clinics assessed } \\
\text { after } 3 \text { months }\end{array}$ & & $\begin{array}{l}1033(20.7 \%) \text { sent } \\
\text { home-sample }\end{array}$ & $\begin{array}{l}140(1.4 \%) \text { op- } \\
\text { portunistic tests }\end{array}$ & \\
\hline Garcia 2012 & $\begin{array}{l}\text { Sex work venues } \\
\text { identified and visited } \\
\text { by mobile teams }\end{array}$ & Women & $\begin{array}{l}\text { Could not be calculat- } \\
\text { ed }\end{array}$ & $\begin{array}{l}\text { Could not be cal- } \\
\text { culated }\end{array}$ & $\begin{array}{l}\text { Not designed to measure } \\
\text { uptake; no denominator }\end{array}$ \\
\hline \multirow[t]{2}{*}{$\begin{array}{l}\text { Oakeshott } \\
2010\end{array}$} & $\begin{array}{l}\text { Approached in col- } \\
\text { leges; }\end{array}$ & \multirow[t]{2}{*}{ Women } & $\begin{array}{l}1259(100 \%) \text { immedi- } \\
\text { ate screening; }\end{array}$ & $\begin{array}{l}1270(100 \%) \text { de- } \\
\text { ferred screening; }\end{array}$ & \multirow[t]{2}{*}{$\begin{array}{l}\text { Not designed to measure } \\
\text { uptake }\end{array}$} \\
\hline & $\begin{array}{l}\text { all women enrolled } \\
\text { were tested, ran- } \\
\text { domised }(1: 1)\end{array}$ & & $\begin{array}{l}269(21 \%) \text { opportunis- } \\
\text { tic tests }\end{array}$ & $\begin{array}{l}258(20 \%) \text { oppor- } \\
\text { tunistic tests }\end{array}$ & \\
\hline \multirow[t]{8}{*}{$\begin{array}{l}\text { Ostergaard } \\
2000\end{array}$} & \multirow{8}{*}{$\begin{array}{l}\text { Schools randomised } \\
(1: 1) \\
\text { Intervention: allocat- } \\
\text { ed to home-sampling } \\
\text { Control: allocated to } \\
\text { offer of GP testing } \\
\text { Sexually active re- } \\
\text { spondents eligible. } \\
\text { Assessed after } 4 \\
\text { months }\end{array}$} & \multirow[t]{5}{*}{ Women } & & & \multirow{5}{*}{$\begin{array}{l}\text { All students in school were } \\
\text { allocated to intervention } \\
\text { or control groups and } \\
\text { asked if they would take } \\
\text { part. Of the responders, } \\
\text { only those who had ever } \\
\text { had sex were eligible. The } \\
\text { denominator of of all who } \\
\text { had ever had sex was not } \\
\text { known. } \\
\text { Intervention group given } \\
\text { home-sampling kits }\end{array}$} \\
\hline & & & $\begin{array}{l}928 \text { eligible respon- } \\
\text { ders; }\end{array}$ & $\begin{array}{l}833 \text { eligible re- } \\
\text { sponders; } 63\end{array}$ & \\
\hline & & & $\begin{array}{l}867(93.4 \%) \text { sent } \\
\text { home-sample }\end{array}$ & tunistic tests & \\
\hline & & & & & \\
\hline & & & & & \\
\hline & & \multirow[t]{3}{*}{ Men } & 1733 allocated; & 1689 allocated; & \multirow[t]{3}{*}{-} \\
\hline & & & $\begin{array}{l}442 \text { eligible respon- } \\
\text { ders; }\end{array}$ & $\begin{array}{l}246 \text { eligible re- } \\
\text { sponders; }\end{array}$ & \\
\hline & & & $\begin{array}{l}430(97.3 \%) \text { sent home } \\
\text { sample }\end{array}$ & $\begin{array}{l}4(1.6 \%) \\
\text { opportunistic } \\
\text { tests }\end{array}$ & \\
\hline \multirow[t]{3}{*}{ Scholes 1996} & $\begin{array}{l}\text { Individuals ran- } \\
\text { domised (1:2) }\end{array}$ & \multirow[t]{3}{*}{ Women } & \multicolumn{2}{|c|}{$\begin{array}{l}36,457 \text { randomised; } 20,836 \text { responded; } \\
3111 \text { at high risk }\end{array}$} & \multirow{3}{*}{$\begin{array}{l}\text { Numbers allocated to in- } \\
\text { tervention and control } \\
\text { not reported. Intervention } \\
\text { group actively contacted }\end{array}$} \\
\hline & $\begin{array}{l}\text { Respondents fulfill- } \\
\text { ing criteria for high }\end{array}$ & & 1009 invited & 1598 not invited; & \\
\hline & $\begin{array}{l}\text { risk of chlamydia eli- } \\
\text { gible }\end{array}$ & & $645(64 \%)$ tested & $\begin{array}{l}\% \text { tested not } \\
\text { known }\end{array}$ & \\
\hline
\end{tabular}


Table 2. Uptake of chlamydia screening (Continued)

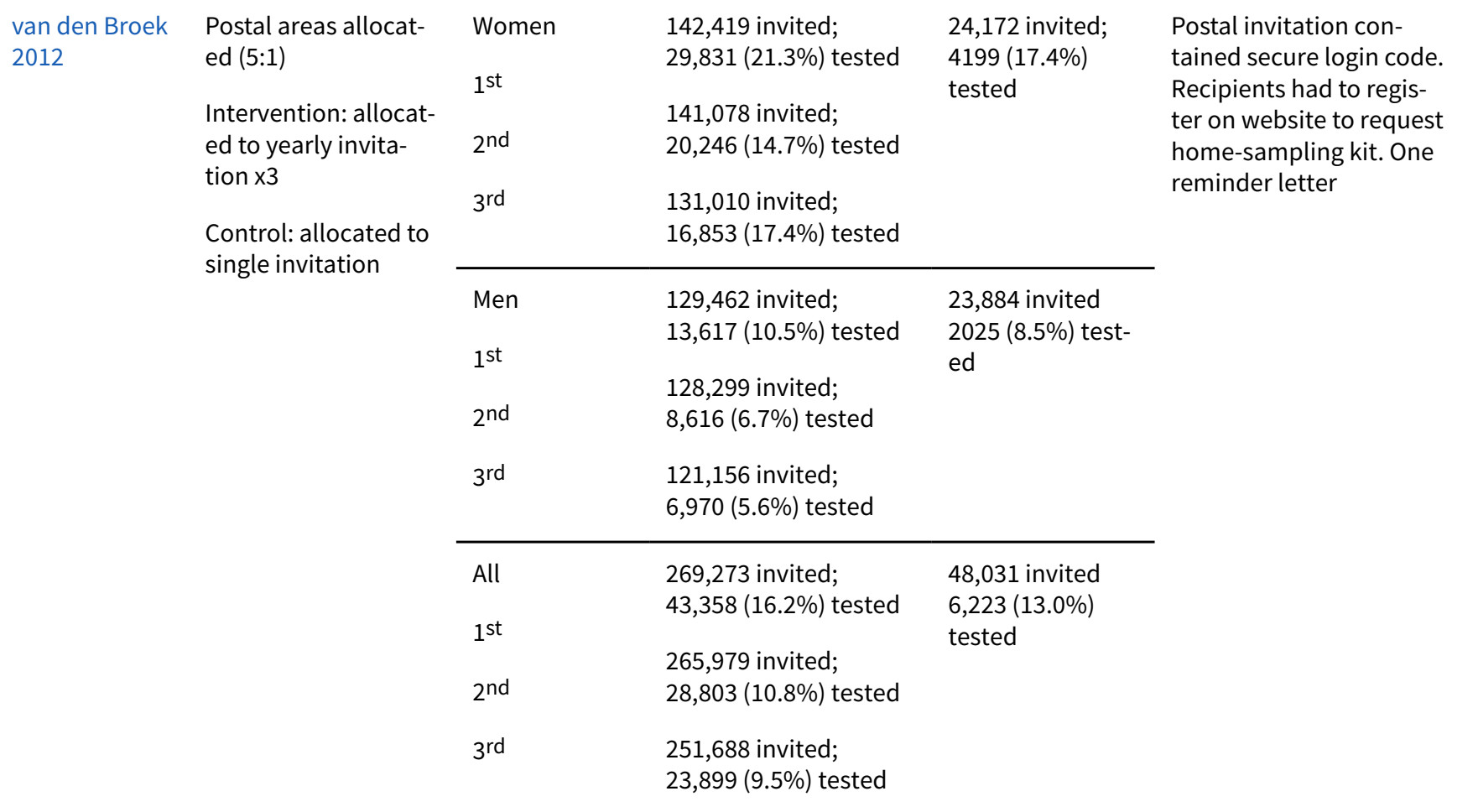

GP: general practitioner; PID: pelvic inflammatory disease; STI: sexually transmitted infection.

\section{APPENDICES}

\section{Appendix 1. Electronic search strategies \\ MEDLINE and CENTRAL (Ovid platform)}

1 exp Mass Screening/

2 screening\$.tw.

3 tested.tw.

4 testing.tw.

5 or/1-4

6 exp Chlamydia/

7 chlam?di\$.tw.

8 exp Chlamydia trachomatis/

9 exp Chlamydia Infections/

10 or/6-9

11 randomized controlled trial.pt.

12 controlled clinical trial.pt.

13 randomized.ab.

14 placebo.ab.

15 clinical trials as topic.sh.

16 randomly.ab.

17 trial.ti.

18 or/11-17

19 exp animals/ not humans.sh.

2018 not 19

215 and 10 and 20

Note: the CENTRAL search strategy does not include the terms \#11 to \#20. 


\section{EMBASE}

\#1 'mass screening'/exp

\#2 screening*:ti,ab

\#3 'screening'/exp

\#4 tested:ti,ab

\#5 testing:ti,ab

\#6 \#1 OR \#2 OR \#3 OR \#4 OR \#5

\#7 'Chlamydia'/exp

\#8 chlamydi*:ti,ab

\#9 chlamidi*:ti,ab

\#10 'Chlamydia trachomatis'/exp

\#11 'chlamydiasis'/exp

\#12 \#7 OR \#8 OR \#9 OR \#10 OR \#11

$\# 13$ 'randomized controlled trial'/exp

\#14 'single blind procedure'/exp

\#15 'double blind procedure'/exp

\#16 'crossover procedure'/exp

\#17 \#13 OR \#14 OR \#15 OR \#16

\#18 random*:ab,ti

\#19 placebo*:ab,ti

\#20 allocat*:ab,ti

\#21 crossover*:ab,ti

\#22 'cross over':ab,ti

\#23 trial:ti

\#24 (doubl* NEXT/1 blind*):ab,ti

\#25 \#18 OR \#19 OR \#20 OR \#21 OR \#22 OR \#23 OR \#24

\#26 \#17 OR \#25

\#27 'animal'/de

\#28 'animal experiment'/de

\#29 'nonhuman'/de

\#30 \#27 OR \#28 OR \#29

\#31 'human'/de

\#32 \#30 AND \#31

\#33 \#30 NOT \#32

\#34 \#26 NOT \#33

\#35 \#6 AND \#12 AND \#34 AND [embase]/lim

\section{LILACS (iAHx interface)}

(mh:(tamizaje masivo)) OR (ti:(tamizaje)) OR (ab:(tamizaje)) OR (ti:(tamización)) OR (ab:(tamización)) OR (mh:(cribado)) OR (ti:(cribado)) OR (ab:(cribado)) AND (mh:(chlamydia)) OR (ti:(chlamydi $)$ ) OR (ab:(chlamydi $\left.\left.{ }^{\star}\right)\right)$ OR (ti:(chlamidi $)$ ) OR (ab:(chlamidi $\left.\left.{ }^{\star}\right)\right)$ OR (ti:(clamidia*)) OR (ab:(clamidia*)) OR (mh:(chlamydia trachomatis)) OR (mh:(infecciones por chlamydia)) AND db:("LILACS") AND type_of_study: ("clinical_trials")

\section{Other resources}

"Screening" and "Chlamydia" in title, abstract and keywords.

\section{CONTRIBUTIONS OF AUTHORS}

Nicola Low selected studies, extracted data, conducted statistical analyses and drafted and revised the review.

Shelagh Redmond conducted electronic databases searches, selected studies, entered data and conducted statistical analyses.

Berit Andersen, Hannelore Götz, Anneli Uusküla, Jan van Bergen and Helen Ward extracted data, commented on and revised the review.

\section{DECLARATIONS OF INTEREST}

Berit Andersen is coauthor of two completed trials that are included in the review.

Jan van Bergen, Hannelore Götz and Nicola Low are coauthors on a completed trial that is included in the review . 
Authors of included studies will not be involved in assessing and extracting data of their own studies.

\section{SOURCES OF SUPPORT}

\section{Internal sources}

- No sources of support supplied

\section{External sources}

- European Centre for Disease Prevention and Control, Sweden.

Financial support for staff to conduct review as part of a project Chlamydia Control in Europe (ECDC/2011/027).

\section{DIFFERENCES BETWEEN PROTOCOL AND REVIEW}

Types of outcome measures: there is an error in a part of the text of the protocol, but the outcomes stated under the headings 'Primary outcomes' and 'Secondary outcomes' in the protocol are correct and are the same as those reported in the review. The statement following the list of secondary outcomes, "The following outcome will not be included: uptake of chlamydia screening ..." should read, "The following outcome will not be included as a primary outcome: uptake of chlamydia screening."

We did not calculate the number needed to treat for an additional beneficial outcome (NNTB) or the number needed to treat for an additional harmful outcome (NNTH). 